\title{
Crevice Corrosion \& Pitting of High-Level Waste Containers: A First Step Towards the Integration of Deterministic \& Probabilistic Models
}

\author{
Joseph C. Farmer
}

July 1997

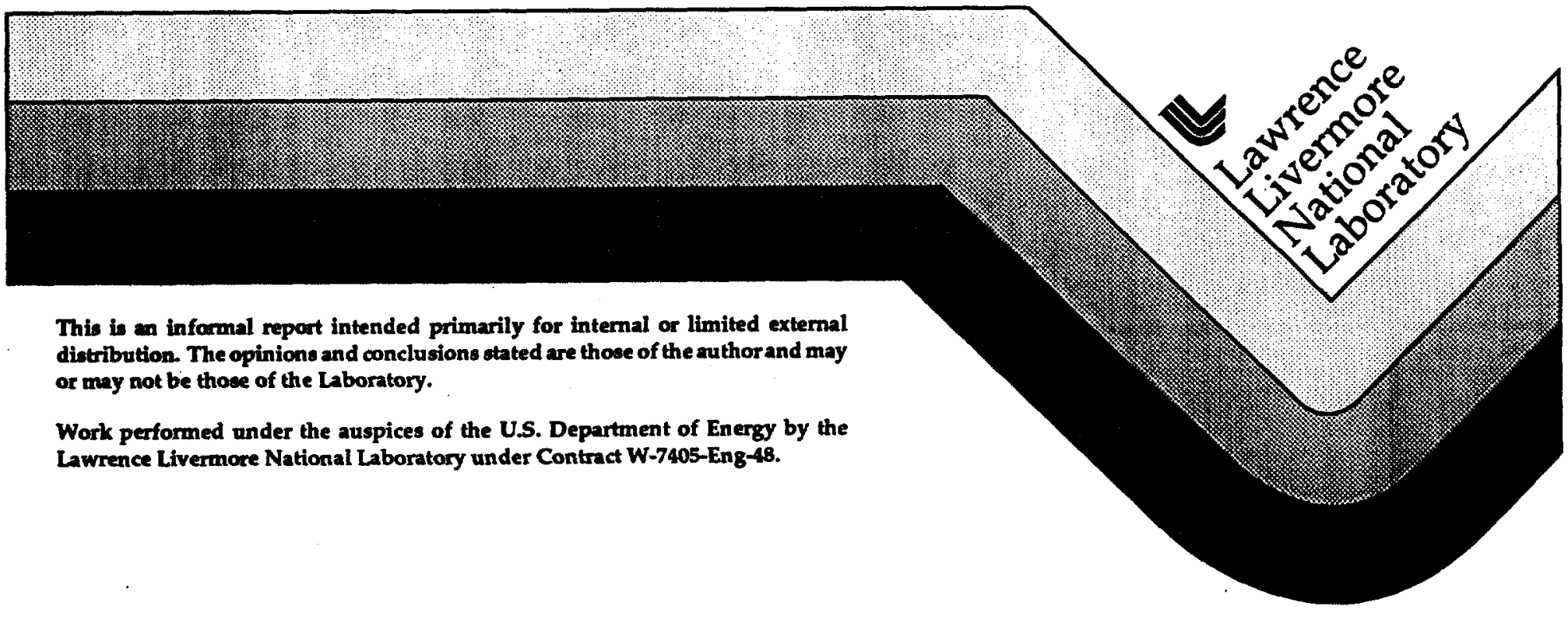




\section{DISCLAIMER}

This document was prepared as an account of work sponsored by an agency of the United States Government. Neither the United States Government nor the University of California nor any of their emplojees, makes any warranty, express or implied, or assumes any legal liability or responsibility for the accuracy, completeness, or usefulness of any information, apparatus, product, or process disclosed, or represents that its use would not infringe privately owmed rights. Reference herein to any specific commercial products, process, or service by trade name, trademark, manufacturer, or otherwise, does not necessarily constitute or imply its endorsement, recommendation, or favoring by the United States Government or the University of Callfornin. The views and opinions of authors expressed herein do not necessarily state or reflect those of the United States Government or the University of Calffornin, and shall not be used for advertising or product endorsement purposes.

This report has been reproduced directly from the beat available copy.

Available to DOE and DOE contractors from the

Orfice of Scientific and Technical Information

P.O. Box 62, Oak Ridge, TN 37831

Prices available from (615) 576-8401, FTS 626-8401

Available to the public from the

National Technical Information Service

US. Department of Commerce

5285 Port Royal Rd.

Springrield, VA 22161 
Lawrence Livermore National Laboratory, University of California

Yucca Mountain Project - EBS Inner Barrier Corrosion Modeling - Farmer - July 1997

\title{
CREVICE CORROSION \& PITTING OF HIGH-LEVEL WASTE CONTAINERS: A FIRST STEP TOWARDS THE INTEGRATION OF DETERMINISTIC \& PROBABILISTIC MODELS
}

\author{
Joseph C. Farmer \\ University of California \\ Lawrence Livermore National Laboratory \\ Livermore, California 94550
}

\begin{abstract}
An integrated predictive model is being developed to account for the effects of localized environmental conditions in crevices on pit initiation and propagation. A deterministic calculation is used to estimate the accumulation of hydrogen ions ( $\mathrm{pH}$ suppression) in the crevice solution due to equilibrium hydrolysis reactions of dissolved metal. Pit initiation and growth within the crevice is dealt with by either a stochastic probability model, or an equivalent deterministic model. While the strategy presented here is very promising, the integrated model is not yet ready for accurate quantitative predictions. Empirical expressions for the rate of penetration based upon experimental crevice corrosion data should be used in the interim period, until the integrated model can be refined. Both approaches are discussed.
\end{abstract}

\section{INTRODUCTION}

The Engineered Barrier System (EBS) being designed for containment of spent-fuel and highlevel waste at the proposed geological repository at Yucca Mountain, Nevada is a two-layer canister. In this particular design, the inner barrier is made of a corrosion resistant material (CRM) such as Alloys $825,625, \mathrm{C}-276$ or C-22, while the outer barrier is made of a corrosionallowance material (CAM) such as carbon steel or Monel 400 . Initially, the containers will be hot and dry due to the heat generated by radioactive decay. However, eventually the temperature will drop to levels where both humid air and aqueous phase corrosion will be possible. As the outer barrier is penetrated, the possibility for crevice formation between the CAM and CRM will exist. Integrated predictive models are being developed to account for the effects of localized environment in the crevice on pit initiation and propagation. For example, a deterministic calculation is used to estimate the accumulation of hydrogen ions ( $\mathrm{pH}$ suppression) in the crevice due to equilibrium hydrolysis reactions of dissolved iron, nickel and chromium. Sufficient chloride must be transported into the crevice by diffusion and electromigration to satisfy conditions of electroneutrality. Pit initiation and growth within the crevice is dealt with by either a stochastic probability model, or an equivalent deterministic model that is based upon simultaneous integration of the rate expressions for pit embryo formation, the rate of stable pit formation form embryos, and the time-dependent rate of pit propagation.

\section{INNER BARRIER CORROSION}

The overall objective of this work is to derive predictive tools that will enable performance assessment of candidate materials during extended periods of time while exposed to Yucca 
Mountain conditions. Most recently, attention has been directed towards the development a corrosion model to predict the rate of penetration of the inner barrier, which is comprised of corrosion resistant material (CRM), as a function of the near field environment (NFE). Note that the NFE is characterized by: temperature; humidity; in-drift water dripping; and the chemistry of the contacting water. There are several modes of generalized and localized corrosion that may play an important role in the ultimate failure of engineered barriers used for the geological disposal of high-level radioactive wastes. Penetration of the CRM will be assumed to be due to localized corrosion: pitting and active crevice corrosion. In the case of Alloys 825, 625, C-276, and $\mathrm{C}-22$, all candidates for the CRM,-it is evident that a crevice will have to form before significant penetration of the CRM can occur. This model will account for the interaction between the outer barrier, which is comprised of a corrosion allowance material (CAM), and the inner barrier (CRM). Interactions will include: $\mathrm{pH}$ suppression in the crevice due to the hydrolysis of products from CAM corrosion; establishment of a mixed potential at the CRM surface; and eventual crevice corrosion of the CRM beneath accumulated corrosion product. Several of these effects will be accounted for with a NFE correction (calculation of $\mathrm{pH}$ and mixed potential) applied at the interface between the CAM and CRM, prior to application of the stochastic pitting, or prior to the application of a general corrosion model.

A recent workshop focused on the formulation of model abstractions suitable for application in performance assessment codes. During this workshop, the following hypotheses were formulated: (1) penetration of the outer barrier comprised of CAM will be by either humid air corrosion or aqueous corrosion; (2) the inner barrier comprised of CRM will be exposed in patches as the outer barrier corrodes; (3) the crevice region surrounding each exposed patch can be subdivided into three generic zones. These zones are defined as follows. Zone I: the CRM will be directly exposed to the NFE, via humid air or a thin layer of oxygenated and acidified water. Zone 2: the CRM will be exposed to a thin layer of acidified water, with a gradient in oxygen concentration. Zone 3: the CRM will be exposed to a thin layer of acidified and deoxygenated water. The corrosion phenomena in these zone may progress through two distinct phases. Furthermore, corrosion within the crevice progresses through two phases. Phase 1: active corrosion of the CAM crevice wall. Phase 2i classical crevice corrosion of the CRM, with passive-active transition. These zones are illustrated in Figure i.

During Phase 1, the CAM wall will undergo active anodic dissolution while the CRM wall will be maintained below the damage threshold. The crevice between the CAM and CRM will be filled with water as the temperature of the container drops below $100^{\circ} \mathrm{C}$. This wall will begin to corrode at a rate limited by the availability of cathodic reactants necessary for depolarization of the anodic dissolution reaction. These reactants will probably be dissolved $\mathrm{O}_{2}$ entering the crevice through the mouth, or $\mathrm{H}^{+}$from the electrolyte. The $\mathrm{pH}$ of this crevice solution (electrolyte) will be suppressed by various hydrolysis reactions involving dissolved iron. The corrosion potential of the CAM at the point of penetration will be located between the redox potentials for cathodic oxygen reduction (or hydrogen evolution) and anodic iron dissolution. This value can be calculated from mixed potential theory and is expected to be below the damage threshold of the CRM, and is believed to galvanically protect the CRM, though the extent of protection is under debate. Passivation of the crevice wall formed by the CAM will be not be 


\section{Lawrence Livermare National Laboratory, University of California \\ Yucca Mountain Project - EBS Inner Barrier Corrosion Modeling - Farmer - July 1997}

possible at the $\mathrm{pH}$ and potential maintained at the mouth of the crevice. The rate of formation of precipitated products from corrosion of the CAM wall will be greatest near the mouth of the crevice. These hydroxides and oxyhydroxides will accumulate near the crevice mouth, eventually filling the space. During Phase 2, a second crevice will form between the precipitated, tightly packed corrosion products and the CRM. Initially, the two walls of this new crevice will be formed by the precipitated solids, which will be relatively dielectric in nature, and the passive surface of the CRM.

\section{APPROACH}

A first-order approach to CAM-CRM interaction will be to account for the effects of CAM corrosion on the localized environment that exists in the crevice separating the outer and inner barriers: suppression of $\mathrm{pH}$ due to hydrolysis of corrosion products; initial establishment mixed potential below damage threshold of CRM; and classical crevice corrosion of CRM beneath precipitated corrosion products. These interfacial effects will "set the stage" for localized attack (pitting; active crevice corrosion; etc.) of the CRM, and will be accounted for with an "interfacial NFE correction." This relatively simple correction will facilitate application of other corrosion models at this boundary, including the stochastic pitting model developed by Shibata $[1,2]$, Henshall [3-5], and others.

The interfacial correction of the NFE, which will determine the extent of localized corrosion within the crevice, will be fully developed. The $\mathrm{pH}$ in this electrolyte will be suppressed by an accumulation of hydrogen ions from various hydrolysis reactions involving dissolved iron, nickel, chromium, molybdenum and other elements. Here, we begin by accounting for iron, nickel, and chromium. Molybdenum is not yet included. The $\mathrm{pH}$ can be calculated by finding values of $\left[\mathrm{H}^{+}\right]$that satisfy a nonlinear mass balance equation. This is equivalent to finding the roots of a polynomial in $[\mathrm{H}+]$. The terms in this equation are defined by: (i) equilibrium constants for hydrolysis and other reactions; (ii) the solubility products for precipitated corrosion products; (iii) the dissociation constant for. water; and (iv) total quantity of dissolved metal. Since electroneutrality must be maintained, sufficient $\mathrm{Cl}^{-}$must be transported into the crevice to balance the charge of accumulated hydrogen ions. The corrosion potential of the CAM at the point of penetration will probably be located between the redox potentials for cathodic oxygen reduction and anodic iron dissolution, which can be calculated from mixed potential theory. Furthermore, the CAM corrosion potential (mixed potential) is expected to be below the damage threshold of the CRM, and should galvanically protect the CRM close to the penetration. Passivation of the crevice wall formed by the CAM is not expected at the $\mathrm{pH}$ and potential maintained at the mouth of the crevice. The rate of formation of precipitated products from corrosion of the CAM wall will be greatest near the mouth of the crevice. Hydroxides and oxyhydroxides will accumulate near the crevice mouth, eventually filling the space and closing the crevice. These simple concepts will govern the localized environment in Zones 1,2 and 3, which will set the stage for application of either stochastic or probabilistic models. Necessary data such as equilibrium constants for hydrolysis, oxygen solubility, diffusion coefficients, and electrokinetic rate constants can be gleaned from the literature, and from corrosion experiments now underway at Lawrence Livermore National Laboratory (LLNL). 


\section{Lawrence Livermore National Laboratory, University of California . \\ Yucca Mountain Project - EBS Inner Barrier Corrosion Modeling - Farmer - July 1997}

It is planned to use Shibata's stochastic probability theory [1-2] to predict the nucleation and growth of pits on the CRM during Phase 2 . Henshall has recently developed a code, based upon Shibata's probabilistic model, and applied it to candidate barrier materials for the repository [35]. It is necessary to enhance these pitting models to account for effects recognized by other investigators. New codes have been used to produce the results shown here. A deterministic crevice model is being developed to define localized conditions with the crevice that lies between the CAM and the CRM. Ultimately, this model will account for: (a) $\mathrm{pH}$ suppression due to the hydrolysis of dissolved iron, nickel, and chromium; (b) differential oxygenation in the crevice due to mass transport limitations; (c) the temporal and spatial dependence of general and localized corrosion within the crevice. The $\mathrm{pH}$ in Zones 1,2 and 3 will be determined with equilibrium chemistry models. Thus far, only $\mathrm{pH}$ suppression has been dealt with.

\section{PITTING MODELS}

Several models have been published for individual modes of corrosion [6]. For example, models for pit initiation include: the halide nuclei theory by Okada [7,8]; the point defect model by Chao, Lin and McDonald [9]; the electrostriction model by Sato [10]; and the stochastic probability model by Shibata [1,2]. Here, a deterministic pitting model that has many of the attributes of Shibata's model will also be introduced for consideration. Models for pit propagation include: the Pickering-Frankenthal model [11], which assumes passive walls and and active base; the Galvele modification of the Pickering-Frankenthal model [12], which accounts for the effects of metal ion hydrolysis on pH suppression; and the Beck-Alkire model, which deals with a hemispherical pit covered by a thin, electrically-resistive halide film [13].

\section{Stochastic Pitting Model}

The stochastic model developed by this author for pitting of the CRM divides the container surface into a two-dimensional (2D) array of hypothetical cells, where probabilities for the transition from one pitting state to another can be assigned. Nucleation or death of a pit embryo is determined by comparing random numbers, generated by a power residue method, to an environment-dependent birth or death probability, respectively. After a pit embryo reaches a critical age, it is assumed to become a stable pit. This approach has already been explored for modeling pit initiation and growth on high-level waste containers by Henshall [3-5]. However, the Henshall model required additional work to enable it to deal with important environmental parameters, such as $\mathrm{pH}$. This model assumed that the birth and death probabilities were functions of potential, chloride concentration, and temperature alone. More specifically, the effect of $\mathrm{pH}$ was not accounted for. Furthermore, it was necessary to assume that the birth probability decayed exponentially with time in order to obtain reasonably shaped pit distributions, number of pits verses depth. Ideally, the birth rate (or birth probability) should be time invariant in such a mechanistic model. Finally, the functions used for calculating the birth and death probabilities could have values much greater than unity $(\gg>1)$, though the code ilimited the values to one $(\leq 1)$. It is better to use probability expressions where all calculated values lie between zero and one, as done by Shibata [2]. This feature has now been incorporated into the stochastic pitting model described here. 
Based upon empirical observations regarding the roles of $\mathrm{Cl}^{-}$and E-E $\mathrm{E}_{\text {crit }}$ on pit initiation (birth), as well as empirical observations regarding the roles of $\mathrm{OH}$ and $\mathrm{E}-\mathrm{E}_{\text {pass }}$ on repassivation (death), the following equations are assumed for the rates of embryo birth and death:

$$
\begin{aligned}
& \lambda_{1}=\lambda_{0}\left[C l^{-}\right] \exp \left(\frac{\alpha_{\lambda} F}{R T}\left(E-E_{c r i l}\right)\right) \\
& \mu_{1}=\mu_{0}\left[O H^{-}\right] \exp \left(-\frac{\alpha_{\mu} F}{R T}\left(E-E_{\text {pass }}\right)\right)
\end{aligned}
$$

where $[\mathrm{Cl}]$ is the concentration of the chloride anion; $[\mathrm{OH}]$ is the concentration of the hydroxyl anion; $F$ is Faraday's constant; $R$ is the universal gas constant; $T$ is the absolute temperature; $E$ is the electrochemical potential applied to the surface; Ecrit is the critical pitting potential; Epass is the repassivation potential; $\alpha_{\lambda}$ and $\alpha_{\mu}$ are constants; and $\lambda_{0}$ and $\mu_{0}$ are intrinsic rate constants for the birth and death of embryos, respectively. The rate of converting an embryo into a stable pit is referred to as the transition rate, $\gamma_{1}$. This conversion process is assumed to be thermally activated and governed by the Ahrenius rate law.

$\gamma_{1}=\gamma_{0} \exp \left(-\frac{A_{\gamma}}{R T}\right)$

where $A_{y}$ is the apparant activation energy and $\gamma_{0}$ is the intrinsic rate constant. The induction time, $\tau_{1}$, is the age that an embryo must reach before it can become a stable pit. This quantity is also assumed to obey an Ahrenius-like expression.

$\tau_{1}=\tau_{0} \exp \left(-\frac{A_{\mathrm{r}}}{R T}\right)$

where $\dot{A}_{\tau}$ is the apparant activation energy and $\tau_{0}$ is the intrinsic induction time. As described by . Shibata [Eqns. 63 \& 64, Ref. 2], the birth probability in a single cell $(0<\lambda<1)$ is then calculated from the rate as follows.

$\lambda=1-e^{-\lambda_{1} \&}$

The death and transition probabilities are calculated in a similar manner.

$\mu=1-e^{-\mu \phi_{1}^{\delta}}$

$\gamma=1-e^{-\gamma / \alpha}$

At a given time step, an embryo will be born in a vacant cell if the following criteria are met: 
$R N D \leq \lambda$

where RND is a random number. Similarly, an existing embryo will die if:

$R N D \leq \mu$

An embryo will become a stable pit if both of the following criteria are met:

$R N D \leq \gamma$

$\tau_{\text {age }} \geq \tau_{1}$

where $\tau_{\text {age }}$ is the age of the embryo under consideration.

\section{Deterministic Pitting Model}

A deterministic model has been formulated by the author, and can also be used to predict the tranients in vacancy, embryo, and stable pit denisty. This model gives results comparable to the stochastic pitting model proposed by Shibata, and was motivated by the similarity between adsorption kinetics and the transition probabilities for birth and death presented by Shibata. For example, first consider the kinetic expression for the classic Langmuir adsorption isotherm. The fractional coverage of the surface by the adsorbate, $\theta_{\mathrm{ads}}$, and the fractional coverage of the surface by vacancies, $\theta_{\text {vac }}$, must sum to one.

$\theta_{\text {act }}+\theta_{\text {rac }}=1$

The rate at which sites are covered by adsorbates is:

$\frac{d \theta_{\text {at }}}{d t}=-k_{b} \theta_{a d s}+k_{f} C\left(1-\theta_{a d t}\right)$

where $k_{f}$ is the forward (adsorption) rate constant, $k_{b}$ is the reverse (desorption) rate constant, and $\mathrm{C}$ is the liquid or gas phase concentration of the adsorbate. Now consider the equations presented by Shibata [Eqns. $38 \& 39$, Ref. 2]. The probabilites for existing in either of two states are $P_{0}$ and $P_{1}$ and must sum to one.

$P_{0}+P_{1}=1$

The rate at which one transitions from one state to the other is:

$$
\frac{d P_{0}}{d t}=-\lambda_{0} P_{0}+\mu_{1}\left(1-P_{0}\right)
$$


where $\mu_{1}$ is a forward rate constant and $\lambda_{0}$ is a reverse rate constant. If the probability of finding an embryo is $P_{0}$ and the probability of finding a vacancy is $P_{1}\left(1-P_{0}\right), \lambda_{0}$ corresponds to the birth probability and $\mu_{1}$ corresponds to the death probability. In this instance, it should be noted that $\lambda_{0}$ should not be interpreted as the intrinsic rate constant for embryo birth. Now consider the more general case, where cells are filled with vacancies, embryos, or stable pits. The corresponding fractional surface coverages must sum to one.

$$
\theta_{E}+\theta_{V}+\theta_{P}=1
$$

where $\theta_{E}$ is the fraction of the surface covered by embryos, $\theta_{V}$ is the fraction of the surface that remains vacant, and $\theta_{\mathrm{p}}$ is the fraction of the surface covered by stable pits. The accumulation rate of pit embryos on the surface is determined by the difference in birth and death rates.

$$
\frac{d \theta_{E}}{d t}=k_{\text {birth }}\left[C l^{-}\right]^{a}\left(1-\theta_{E}-\theta_{P}\right)-k_{\text {death }}\left[O H^{-}\right]^{b} \theta_{E}-k_{p t} \theta_{E}
$$

where $k_{\text {birth }}$ is analagous to $\lambda_{1}, k_{\text {death }}$ is analagous to $\mu_{1}$, and $k_{\text {pit }}$ is analagous to $\gamma_{1}$. Consistent with experience, $\mathrm{Cl}^{-}$is assumed to promote formation of pit embryos, while $\mathrm{OH}^{-}$is assumed to promote repassivation and embryo death. It is clear that the proposed model involves competitive adsorption of $\mathrm{Cl}^{-}$and $\mathrm{OH}$. There is no induction time per se. The accumulation rate of stable pits on the suface is then proportional to the fractional coverage of the surface by embryos.

$$
\frac{d \theta_{P}}{d t}=k_{p i x} \theta_{E}
$$

This rate expression assumes that a stable pit evolves from a single embryo. In reality, several embryos may coalesce to form a pit. Thus, the dependence of the pit generation rate on $\theta_{\mathrm{E}}$ may not be first order. Coalescence of " $n$ " embryos would give rise to an " $n$-th order". rate expression. These two first order ordinary differential equations can be solved simultaneously by numeric integration with a fourth-order Runge-Kutta algorithm. In some cases, assumptions regarding the relative size of terms in the rate expressions lead to formulation of a useful quasi steady state assumption. For example, assume that the following criteria are met:

$$
\begin{aligned}
& k_{p i t} \theta_{E} \ll k_{b i n h}\left[\mathrm{Cl}^{-}\right]^{a}\left(1-\theta_{E}\right) \\
& k_{p i t} \theta_{E} \ll k_{\text {deanh }}\left[O H^{-}\right]^{b} \theta_{E}
\end{aligned}
$$

Then, the fractional surface coverages by embryos and stable pits can be written as:

$$
\theta_{E}=\left(1-\theta_{P}\right)\left[\frac{G}{1+G}\right]
$$


$\theta_{P}=1-\exp \left[-k_{p w} t \frac{G}{1+G}\right]$

where $\mathrm{G}$ is defined in terms of chloride and hydrogen ion concentrations, the dissociation constant for water, and the ratio of birth and death rate constants.

$G=\frac{k_{\text {binth }}\left[\mathrm{Cl}^{-}\right]^{a}\left[\mathrm{H}^{+}\right]^{b}}{k_{\text {death }} K_{w}^{b}}$

Based upon assumed functional forms, which are consistent with empirical observations, the ratio of birth and death rate constants is:

$\frac{k_{\text {birhh }}}{k_{\text {dearh }}}=\frac{k_{\text {binh }}^{o}}{k_{\text {birnh }}^{o}} e^{\frac{n F\left(E-E_{\text {ont }}\right)}{R T}}$

The growth rate of a stable pit is assumed to be diffusion controlled; it obeys the following relationship.

$d \approx A \sqrt{t}$

The author will elaborate on this simple penetration rate law in subsequent publications.

\section{CREVICE CORROSION MODELS}

Attention is now directed to corrosion in the crevice separating the CAM and CRM. One of the best known theoretical treatments of crevice corrosion is that published several years ago by France $[14,15]$ He categorizes crevice corrosion mechanisms based upon the type of concentration cell formed between the mouth and base of the crevice. Specific catagories of concentration cells include: metal ion; differential aeration; active-passive; hydrogen ion; neutral salt; and inhibitor. Expressions are presented that enable calculation of the critical depth for crevice corrosion. Similar equations have been published by Gartland [16]. A more mathematically rigorous, numerical model has been developed and published by Oldfield and Sutton [17]. Their model accounts for: depletion of oxygen in the crevice; increased acidity of the crevice solution due to the accumulation of hydrogen ions from hydrolysis reactions involving dissolved metal ions; increased chloride concentration in the crevice, driven by the need to maintain electroneutrality; permanent breakdown of the passive film and active corrosion; and the propagation of crevice corrosion. Unfortunately, the possibility of pit initiation and propagation in the acidified crevice region is not accounted for. Pickering et al. have developed analytical models based upon solution of the one-dimensional Nernst-Planck equation [18-19]. Fluxes of ions are estimated with the Nernst-Planck equation, which governs electromigration, diffusion, and convective transport [20]: 
$\bar{N}_{i}=-z_{i} u_{i} F c_{i} \bar{\nabla} \Phi-D_{i} \bar{\nabla} c_{i}+\bar{v} c_{i}$

where $N_{i}$ is the flux, $z_{i}$ is the charge, $u_{i}$ is the mobility, $c_{i}$ is the concentration and $D_{i}$ is the diffusivity of the i-th ion; $\Phi$ is the potential; and $v$ is the convective velocity of the electrolyte. The current density is then defined in terms of the flux:

$\bar{i}=-F^{2} \bar{\nabla} \Phi \sum_{i} z_{i}^{2} u_{i} c_{i}-F \sum_{i} z_{i} D_{i} \bar{\nabla} c_{i}$

Though Pickering et al. assume quasi steady state, it should be noted that transients in concentration can be dealt with through application of the following equation:

$\frac{\partial c_{i}}{\partial t}=-\bar{\nabla} \cdot \bar{N}_{i}+R_{i}$

where $R_{i}$ a homogeneous rate. By assuming one-dimensional (1D) transport, Pickering et al. were able to make the following simplifications:

$$
\begin{aligned}
& N_{i, x}=-z_{i} u_{i} F c_{i} \frac{d \Phi}{d x}-D_{i} \frac{d c_{i}}{d x} \\
& i_{x}=-\kappa_{x} \frac{d \Phi}{d x}-F \sum_{i} z_{i} D_{i} \frac{d c_{i}}{d x}
\end{aligned}
$$

They also include a term (not shown here) for the passive current density along the crevice walls. The conductance of the crevice solution is estimated from a summation of products formed from the valence, mobility, and concentration of each ion.

$\kappa_{x}=-F \sum_{i} z_{i}^{2} u_{i} c_{i}$

The Pickering-Xu model can be used to calculate potential drop in the crevice, which can then be used to establish criteria for depassivation of the crevice wall. This model provides both potential and current distribution along the length of the crevice. It also enables calculation of a critical depth, $d_{c}$, for depassivation. For distances less than the critical depth $\left(x<d_{c}\right)$, the crevice walls are assumed to be passive, whereas for distances greater than the critical depth $\left(x>d_{c}\right)$, the crevice walls are assumed to be active. More recently, Lillard and Scully have employed linear network theory (equivalent circuit models) for the interpretation of crevice corrosion data [21]. In summary, rigorous modeling of the crevice between the CAM and CRM appears to be possible. However, advances have to be made in order to couple individual mechanistic models (crevice corrosion, pit initiation and growth, and stress corrosion cracking). First, the suppression of $\mathrm{pH}$ will be discussed. 


\section{Localized Süpression of pH Due to Hydrolysis Reactions}

The effects of hydrolysis in the crevice will suppress the $\mathrm{pH}$. In order to account for this effect, it is necessary to account for the net accumulation of hydrogen ions due to the hydrolysis of various dissolved metal ions. The net quantity of hydrogen ions accumulated in the crevice solution is:

$$
\left[H^{+}\right]=\left[H^{+}\right]_{F e(I I)}+\left[H^{+}\right]_{\text {re(III) }}+\left[H^{+}\right]_{N(I I)}^{-}+\left[H^{+}\right]_{C r(I I)}+\left[H^{+}\right]_{C r(n)}-\left[H^{+}\right]_{H_{2}}-\left[H^{+}\right]_{O_{2}}
$$

The dissolution of the CAM generates divalent iron ions that hydrolyze, thereby producing hydrogen ions that accumulate in the crevice. The quantity of hydrogen ions due to such hydrolysis reactions is:

$$
\left[\mathrm{H}^{+}\right]_{\mathrm{Fe}(I I)}=2\left[\mathrm{Fe}(\mathrm{OH})_{2}\right](\mathrm{s})+\left[\mathrm{Fe}(\mathrm{OH})^{+}\right]
$$

The dissolved $\mathrm{Fe}^{2+}$ can be converted to $\mathrm{Fe}^{2+}$ by: (I) microbial action; (ii) oxidation by naturally occuring $\mathrm{MnO}_{2}$ or other oxidants; or (ii) anodic oxidation at potentials greater than $+0.770 \mathrm{~V}$ versus NHE. Once formed, it is assumed that $\mathrm{Fe}^{3+}$ can also undergo hydrolysis. The quantity of hydrogen ions produced by suct reations is:

$$
\left[\mathrm{H}^{+}\right]_{\mathrm{Fe}(\mathrm{MI})}=3\left[\mathrm{Fe}(\mathrm{OH})_{3}\right](\mathrm{s})+2\left[\mathrm{Fe}(\mathrm{OH})_{2}^{+}\right]+\left[\mathrm{Fe}(\mathrm{OH})^{2+}\right]
$$

From the discussion in Cotton and Wilkinson [22], it will be assumed that:

$$
\left[\mathrm{Fe}(\mathrm{OH})_{3}\right](s) \approx 0
$$

and that:

$$
\left[\mathrm{Fe}(\mathrm{OH})_{2}^{+}\right] \approx 0
$$

Therefore,

$$
\left[\mathrm{H}^{+}\right]_{\mathrm{Fe}(\mathrm{III})} \approx\left[\mathrm{Fe}(\mathrm{OH})^{2+}\right]
$$

The precipitated iron hydroxide, $\mathrm{Fe}(\mathrm{OH})_{2}$, can be estimated by deducting the amount of iron contained in various dissolved species from the overall iron accumulation rate in the crevice solution:

$$
\left[\mathrm{Fe}(\mathrm{OH})_{2}\right](s)=[\mathrm{Fe}(\mathrm{II})]-\left[\mathrm{Fe}^{2+}\right]-\left[\mathrm{Fe}(\mathrm{OH})^{+}\right]
$$


where $[\mathrm{Fe}(\mathrm{II})]$ is the total quantitiy of dissolved iron in the +2 oxidation state. Ultimately, the CRM will undergo dissolution, thereby producing divalent nickel ions and trivalent chromium ions. The equations for the divalent nickel are analagous to those for the divalent iron:

$\left[\mathrm{H}^{+}\right]_{\mathrm{Ni(I)}}=2\left[\mathrm{Ni}(\mathrm{OH})_{2}\right](s)+\left[\mathrm{Ni}(\mathrm{OH})^{+}\right]$

where the precipitated nickel hydroxide is defined by:

$\left[\mathrm{Ni}(\mathrm{OH})_{2}\right](s)=[\mathrm{Ni}(\mathrm{II})]-\left[\mathrm{Ni}^{2+}\right]-\left[\mathrm{Ni}(\mathrm{OH})^{+}\right]$

The equations for the trivalent chromium are analogous to those for the trivalent iron:

$\left[\mathrm{H}^{+}\right]_{\mathrm{Cr}(\mathrm{III})}=3\left[\mathrm{Cr}(\mathrm{OH})_{3}\right](\mathrm{s})+2\left[\mathrm{Cr}(\mathrm{OH})_{2}^{+}\right]+\left[\mathrm{Cr}(\mathrm{OH})^{2+}\right]$

where the precipitated chromium hydroxide is defined by:

$\left[\mathrm{Cr}(\mathrm{OH})_{3}\right](s)=[\mathrm{Cr}(\mathrm{III})]-\left[\mathrm{Cr}^{3+}\right]-\left[\mathrm{Cr}(\mathrm{OH})^{2+}\right]-\left[\mathrm{Cr}(\mathrm{OH})_{2}^{+}\right]$

The formation of hexavalent chromium from divalent chromium also generates hydrogen ions:

$\left[\mathrm{H}^{+}\right]_{\mathrm{Cr}(v)}=2\left[\mathrm{Cr}_{2} \mathrm{O}_{7}^{2-}\right]$

The hydrogen ions lost due to cathodic reduction reactions is represented by:

$\left[H^{+}\right]_{H_{2}}=2\left[H_{2}\right]$

$\left[H^{+}\right]_{\dot{O}_{2}}=4\left[\dot{O}_{2}\right]$

The concentrations of species containing dissolved metal are expressed in terms of the hydrogen ion concentration, as discussed by Oldfield and Sutton [17]. In the case of divalent iron species:

$$
\begin{aligned}
& {\left[\mathrm{Fe}^{2+}\right]=\frac{K_{3,3}}{\left[\mathrm{OH}^{-}\right]^{2}} ;\left[\mathrm{Fe}^{2+}\right]=\frac{K_{3,3}}{K_{w}^{2}}\left[\mathrm{H}^{+}\right]^{2}} \\
& {\left[\mathrm{Fe}(\mathrm{OH})^{+}\right]=\frac{K_{3,1}\left[\mathrm{Fe}^{2+}\right]}{\left[\mathrm{H}^{+}\right]} ;\left[\mathrm{Fe}(\mathrm{OH})^{+}\right]=\frac{K_{3,1} K_{3,3}}{K_{w}^{2}}\left[\mathrm{H}^{+}\right]}
\end{aligned}
$$

Here, it is assumed that the concentration of ferric ion is defined in terms of ferrous ion: 
$\left[F e^{3+}\right] \approx\left[F e^{2+}\right] e^{f(E-0.770)}$

where

$f=\frac{F}{R T} \approx 38.92 V^{-1}$

and $F$ is Faraday's constant, $R$ is the universal gas constant, and $T$ is the absolute temperature.

The hydrolysis of ferric ion is represented by:

$\left[F e(O H)^{2+}\right]=\frac{K_{4,1}\left[F e^{3+}\right]}{\left[H^{+}\right]} ; \quad\left[F e(O H)^{2+}\right]=\frac{K_{4,1} K_{3,3}}{K_{w}^{2}}\left[H^{+}\right] e^{f(E-0.770)}$

In the case of divalent nickel species:

$$
\begin{aligned}
& {\left[N i^{2+}\right]=\frac{K_{s, 3}}{\left[O H^{-}\right]^{2}} ;\left[N i^{2+}\right]=\frac{K_{5,3}}{K_{w}^{2}}\left[H^{+}\right]^{2}} \\
& {\left[N i(O H)^{+}\right]=\frac{K_{s, 1}\left[N i^{3+}\right]}{\left[H^{+}\right]} ;\left[N i(O H)^{+}\right]=\frac{K_{5,3} K_{5,3}}{K_{w}^{2}}\left[H^{+}\right]}
\end{aligned}
$$

In the case of trivalent chromium species:

$$
\begin{aligned}
& {\left[\mathrm{Cr}^{3+}\right]=\frac{K_{1,3}}{\left[O H^{3}\right]^{3}} ;\left[\mathrm{Cr}^{3+}\right]=\frac{K_{1,3}}{K_{w}^{3}}\left[H^{+}\right]^{3}} \\
& {\left[\mathrm{Cr}(\mathrm{OH})^{2+}\right]=\frac{K_{1,1}\left[\mathrm{Cr}^{3+}\right]}{\left[\mathrm{H}^{+}\right]} ;\left[\mathrm{Cr}(\mathrm{OH})^{2+}\right]=\frac{K_{1,1} K_{1,3}}{K_{w}^{3}}\left[\mathrm{H}^{+}\right]^{2}} \\
& {\left[\mathrm{Cr}(\mathrm{OH})_{2}^{+}\right]=\frac{K_{1,2}\left[\mathrm{Cr}(\mathrm{OH})^{2+}\right]}{\left[\mathrm{H}^{+}\right]} ;\left[\mathrm{Cr}(\mathrm{OH})_{2}^{+}\right]=\frac{K_{1,1} K_{1,2} K_{1,3}}{K_{w}^{3}}\left[\mathrm{H}^{+}\right]}
\end{aligned}
$$

In the case of hexavalent chromium species, but only if $\mathrm{MnO}_{2}$ is present:

$$
\left[\mathrm{Cr}_{2} \mathrm{O}_{7}^{2-}\right]=\frac{K_{2,1}\left[\mathrm{Cr}^{3+}\right]^{2}}{\left[\mathrm{Mn}^{2+}\right]^{3}\left[\mathrm{H}^{+}\right]^{2}} ;\left[\mathrm{Cr}_{2} \mathrm{O}_{7}^{2-}\right]=\frac{K_{2,1} K_{1,3}^{2}\left[\mathrm{H}^{+}\right]^{4}}{K_{w}^{6}\left[\mathrm{Mn}^{2+}\right]^{3}}
$$


Each hydrogen generation term can be replaced, which gives:

$$
\begin{gathered}
{\left[\mathrm{H}^{+}\right]=2[\mathrm{Fe}(\mathrm{II})]+2[\mathrm{Ni}(\mathrm{II})]+3[\mathrm{Cr}(\mathrm{III})]-4\left[\mathrm{O}_{2}\right]-2\left[\mathrm{H}_{2}\right]} \\
-2\left[\mathrm{Fe}^{2+}\right]-\left[\mathrm{Fe}(\mathrm{OH})^{+}\right]+\left[\mathrm{Fe}(\mathrm{OH})^{2+}\right]-2\left[\mathrm{Ni}^{2+}\right]-\left[\mathrm{Ni}(\mathrm{OH})^{+}\right] \\
-3\left[\mathrm{Cr}^{2+}\right]-2\left[\mathrm{Cr}(\mathrm{OH})^{2+}\right]-\left[\mathrm{Cr}(\mathrm{OH})_{2}^{+}\right]+2\left[\mathrm{Cr}_{2} \mathrm{O}_{7}^{2-}\right]
\end{gathered}
$$

Since the individual concentrations are functions of hydrogen ion concentration, $[\mathrm{H}+]$, this equation can also be expressed as a polynomial:

$$
a_{n}\left[H^{+}\right]^{n}+a_{n-1}\left[H^{+}\right]^{n-1}+a_{n-2}\left[H^{+}\right]^{n-2}+\ldots . .+a_{3}\left[H^{+}\right]^{3}+a_{2}\left[H^{+}\right]^{2}+a_{1}\left[H^{+}\right]+a_{0}=0
$$

where the coefficients are defined in terms of: (i) corrosion rates; (ii) equilibrium constants for hydrolysis reactions; (iii) solubilities of corrosion products; and (iv) the dissociation constant for water. The roots of either equation, which determine the $\mathrm{pH}$, can be easily determined by application of an iterative bisection technique. In the following section, it will be shown how individual concentrations can be rewritten in terms of $\left[\mathrm{H}^{+}\right]$. It is necessary to have values for the various hydrolysis equilibrium constants in order to determine the roots of the polynomial, and to determine the extent of $\mathrm{pH}$ suppression. Several of these values can be found in the seminal

\begin{tabular}{|c|c|c|c|c|c|c|c|c|}
\hline Species & $\mathrm{i}$ & Ref. & $\mathrm{K}_{\mathrm{i}, 1}$ & $\mathrm{~K}_{\mathrm{i}, 2}$ & $\mathrm{~K}_{\mathrm{i}, 3}$ & $\mathrm{~K}_{\mathrm{i}, 4}$ & $\mathrm{~K}_{\mathrm{i}, 5}$ & $\mathrm{~K}_{\mathrm{i}, 5}$ \\
\hline $\mathrm{Cr}(\mathrm{III})$ & 1 & A6,A7. & $1.58 \times 10^{-4}$ & $6.31 \times 10^{-1}$ & $4.0 \times 10^{-38}$ & $2.00 \times 10^{3}$ & $3.16 \times 10^{4}$ & $3.16 \times 10^{3}$ \\
\hline $\mathrm{Cr}(\mathrm{VI})$ & 2 & A7 & $6.92 \times 10^{-11}$ & - & : : : : : : : & (: & 砮 & \\
\hline $\mathrm{Fe}(\mathrm{II})$ & 3 & A6 & $5.0 \times 10^{-9}$ & , & $7.9 \times 10^{-16}$ & 2. & & \\
\hline $\mathrm{Fe}(\mathrm{III})$ & 4 & Al & $1.84 \times 10^{-3}$ & unknown & unknown & & & \\
\hline $\mathrm{Ni}(\mathrm{II})$ & 5 & A6 & $3.16 \times 10^{-4}$ & & $1.35 \times 10^{-15}$ & & & \\
\hline
\end{tabular}
publication on crevice corrosion by Oldfield and Sutton [17]. These values are summarized in Table 1.

Table 1. $K_{i, j}$ for $i-t h$ Species and $j$-th Reaction at $25^{\circ} \mathrm{C}$

\section{Iron Chemistry}

Electrochemical Reactions. Ferrous ions are formed by the anodic dissolution of either the inner or outer barrier. The dissolution can be assumed to occur via the electrochemical reaction given by Bard and Faulkner [23]:

$$
F e \longrightarrow F e^{2+}+2 e^{-} \quad E^{o}=-0.409 V
$$

Ferric ions can then be formed by the electrochemical or biological oxidation of dissolved ferrous ion: 
$\mathrm{Fe}^{2+} \longrightarrow \mathrm{Fe}^{3+}+e^{-} \quad E^{0}=+0.770 \mathrm{~V}$

Microbes $+\mathrm{O}_{2}+\mathrm{Fe}^{2+} \longrightarrow \mathrm{Fe}^{3+}$

Similar reactions for the overall reaction for the oxidation of ferrous to ferric ion are presented by Cotton and Wilkinson [22]:

$4 \mathrm{Fe}^{2+}+\mathrm{O}_{2}+4 \mathrm{H}^{+} \longrightarrow 4 \mathrm{Fe}^{3+}+2 \mathrm{H}_{2} \mathrm{O}^{-} \mathrm{E}^{\circ}=+0.46 \mathrm{~V}$

The oxidation of $\mathrm{Fe}^{2+}$ to $\mathrm{Fe}^{3+}$ in neutral solution by molecular oxygen may involve a reaction between $\mathrm{FeOH}^{+}$and $\mathrm{O}_{2} \mathrm{H}$, but the details are uncertain. The ferrous ion can also be oxidized by other common oxidants. The action of $\mathrm{NO}_{3}^{-}$or $\mathrm{NO}_{2}^{-}$involves the transient formation of a brown nitrosyl [ $\left.\mathrm{FeNO}\left(\mathrm{H}_{2} \mathrm{O}\right)_{5}\right]^{2+}$ in the overall reaction [24]:

$$
3 \mathrm{Fe}^{2+}+\mathrm{NO}_{3}^{-}+4 \mathrm{H}^{+} \longrightarrow 3 \mathrm{Fe}^{3+}+2 \mathrm{H}_{2} \mathrm{O}
$$

Solution Equilbria. According to Cotton and Wilkinson [22], aqueous solutions of Fe(II) contain the "pale blue-green" divalent hydroxo ion, $\left[\mathrm{Fe}\left(\mathrm{H}_{2} \mathrm{O}\right)_{6}\right]^{2+}$, in the absence of complexing agents. As discussed by Oldfield and Sutton, it can be assumed that $\mathrm{Fe}^{2+}$ undergoes hydrolysis to form $\mathrm{Fe}(\mathrm{OH})^{+}$, and $\mathrm{Fe}\left(\mathrm{OH}_{2}[17]\right.$.

$$
\begin{aligned}
& \mathrm{Fe}^{2+}+\mathrm{H}_{2} \mathrm{O} \underset{\mathrm{K}_{3,1}}{\longleftrightarrow} \mathrm{Fe}(\mathrm{OH})^{+}+\mathrm{H}^{+} \\
& K_{3,1}=\frac{\left.\left[\mathrm{Fe}(\mathrm{OH})^{+}\right] \mathrm{H}^{+}\right]}{\left[\mathrm{Fe}^{2+}\right]} \\
& \mathrm{Fe}(\mathrm{OH})_{2}(\mathrm{~s}) \stackrel{\mathrm{K}_{3.3}}{\longrightarrow} \mathrm{Fe}^{2+}+2 \mathrm{OH} \\
& K_{3,3}=\left[F e^{2+}\left[O H^{-}\right]^{2}\right.
\end{aligned}
$$

In a similar fashion, one might assume that $\mathrm{Fe}^{3+}$ can then undergo hydrolysis to form $\mathrm{Fe}(\mathrm{OH})^{2+}$, $\mathrm{Fe}(\mathrm{OH})_{2}^{+}$and $\mathrm{Fe}(\mathrm{OH})_{3}$.

$$
\begin{aligned}
& \mathrm{Fe}^{3+}+\mathrm{H}_{2} \mathrm{O} \underset{K_{4,1}}{\longleftrightarrow} \mathrm{Fe}(\mathrm{OH})^{2+}+\mathrm{H}^{+} \\
& K_{4,1}=\frac{\left[\mathrm{Fe}(\mathrm{OH})^{2+}\left[\mathrm{H}^{+}\right]\right.}{\left[\mathrm{Fe}^{3+}\right]}
\end{aligned}
$$




$$
\begin{aligned}
& \mathrm{Fe}(\mathrm{OH})^{2+}+\mathrm{H}_{2} \mathrm{O} \underset{\mathrm{K}_{4,2}}{\longrightarrow} \mathrm{Fe}(\mathrm{OH})_{2}^{+}+\mathrm{H}^{+} \\
& \mathrm{K}_{4,2}=\frac{\left[\mathrm{Fe}(\mathrm{OH})_{2}^{+}\right]\left[\mathrm{H}^{+}\right]}{\left[\mathrm{Fe}(\mathrm{OH})^{2+}\right]} \\
& \mathrm{Fe}(\mathrm{OH})_{3}(\mathrm{~s}) \stackrel{\mathrm{K}_{4,3}}{\longrightarrow} \mathrm{Fe}^{3+}+3 \mathrm{OH}^{-} \\
& \mathrm{K}_{4,3}=\left[\mathrm{Fe}^{3+}\left[\mathrm{OH}^{-}\right]^{3}\right.
\end{aligned}
$$

According to Cotton and Wilkinson [22], aqueous solutions of $\mathrm{Fe}(\mathrm{III})$ contain the "pale purple" trivalent hydroxo ion, $\left[\mathrm{Fe}\left(\mathrm{H}_{2} \mathrm{O}\right)_{6}\right]^{3+}$. At $\mathrm{pH}<1$, the sole species present in solution is the aqua ion, $\mathrm{Fe}^{3+}$. However, stepwise hydrolysis occurs at $\mathrm{pH}>1$. At low concentrations, the main equilibria is believed to be [22]:

$\left[\mathrm{Fe}\left(\mathrm{H}_{2} \mathrm{O}\right)_{6}\right]^{3+} \stackrel{K_{1,4}}{\longleftrightarrow}\left[\mathrm{Fe}(\mathrm{OH})\left(\mathrm{H}_{2} \mathrm{O}\right)_{5}\right]^{2+}+H^{+} \quad K_{4,1}=1.84 \times 10^{-3}$

For the purpose of this work, $\left[\mathrm{Fe}(\mathrm{OH})\left(\mathrm{H}_{2} \mathrm{O}\right)_{5}\right]^{2+}$ and $[\mathrm{Fe}(\mathrm{OH})]^{2+}$ are assumed to be equivalent. A small amount of $\left[\mathrm{Fe}(\mathrm{OH})_{2}\right]^{2+}$ may be formed, but the second main species is a diamagnetic $\mu$-oxo dimer:

$$
2\left[\mathrm{Fe}(\mathrm{OH})\left(\mathrm{H}_{2} \mathrm{O}\right)_{5}\right]^{2+} \longleftrightarrow\left[\left(\mathrm{H}_{2} \mathrm{O}\right)_{5} \mathrm{FeOFe}\left(\mathrm{H}_{2} \mathrm{O}\right)_{5}\right]^{4+}+\mathrm{H}_{2} \mathrm{O}
$$

More condensed species and colloidal gels are formed at $\mathrm{pH}>2$, which leads to the precipitation of a red-brown gelatinous hydrous oxide. In the presence of complexing ions such ad $\mathrm{Cl}^{-}$, the hydrolysis of $\mathrm{Fe}^{3+}$, or of $\mathrm{FeCl}_{3}$, is more complicated, giving chloro, aqua; and hydroxy species, as well as $\left[\mathrm{FeCl}_{4}\right]^{2}$ at high $\mathrm{Cl}^{2}$ concentrations $[25,26]$.

\section{Nickel Chemistry}

Electrochemical Reactions. In alkaline solutions, the anodic dissolution of nickel is believed to occur by the reaction presented by Bard and Faulkner [23]:

$$
\mathrm{Ni}+2 \mathrm{OH}^{-} \longrightarrow \mathrm{Ni}(\mathrm{OH})_{2}+2 e^{-} \quad E^{\circ}=-0.660 \mathrm{~V}
$$

This may actually be equivalent to the dissolution of nickel as $\mathrm{Ni}^{2+}$, followed by hydrolysis. In acidic solutions, the dissolution is believed to occur via the electrode reaction presented by Cotton and Wilkinson [22], as well as by Bard and Faulkner [23]:

$$
\begin{aligned}
& \mathrm{Ni} \longrightarrow \mathrm{Ni}^{2+}+2 e^{-} \quad E^{0}=-0.24 \mathrm{~V} \quad \text { (Cotton \& Wilkinson) } \\
& \mathrm{Ni} \longrightarrow \mathrm{Ni}^{2+}+2 e^{-} \quad E^{\circ}=-0.230 \mathrm{~V} \quad \text { (Bard \& Faulkner) }
\end{aligned}
$$


Solution Equilibria. Nickelous ions are formed by the anodic dissolution of the inner barrier. As discussed by Oldfield and Sutton, the $\mathrm{Ni}^{2+}$ then undergoes hydrolysis to form other $\mathrm{Ni}$ (II) species, including $\mathrm{Ni}(\mathrm{OH})^{+}$, and $\mathrm{Ni}(\mathrm{OH})_{2}[17]$.

$$
\begin{aligned}
& \mathrm{Ni}^{2+}+\mathrm{H}_{2} \mathrm{O} \underset{\mathrm{K}_{5,1}}{\longrightarrow} \mathrm{Ni}(\mathrm{OH})^{+}+\mathrm{H}^{+} \\
& \mathrm{K}_{5,1}=\frac{\left.\left[\mathrm{Ni}(\mathrm{OH})^{+}\right] \mathrm{H}^{+}\right]}{\left[\mathrm{Ni}^{2+}\right]} \\
& \mathrm{Ni}(\mathrm{OH})_{2}(s) \stackrel{\mathrm{K}_{\mathrm{S}, 3}}{\longrightarrow} \mathrm{Ni}^{2+}+2 \mathrm{OH}^{-} \\
& \mathrm{K}_{\mathrm{s,3}}=\left[\mathrm{Ni}^{2+}\left[\mathrm{OH}^{-}\right]^{2}\right.
\end{aligned}
$$

The hydroxide, $\mathrm{Ni}(\mathrm{OH})_{2}$, precipitates from basic aqueous solutions of $\mathrm{Ni}(\mathrm{II})$, forming a voluminous green gel that crystallizes with the crystal structure of $\mathrm{Mg}(\mathrm{OH})_{2}$.

\section{Chromium Chemistry}

Electrochemical Reactions. Chromium is a white, hard, lustrous, and brittle metal (melting point of $1903 \pm 10^{\circ} \mathrm{C}$ ) [22]. It is extremely resistant to ordinary corrosive agents, which accounts for its extensive use as an electroplated protective coating. The metal dissolves fairly readily in nonoxidizing mineral acids, such as $\mathrm{HCl}$ and $\mathrm{H}_{2} \mathrm{SO}_{4}$. However, it does not dissolve in concentrated or dilute $\mathrm{HNO}_{3}$, or aqua regia. The last two reagents, aqua regia and $\mathrm{HNO}_{3}$, passivate the metal in a manner that is not well understood. The electrode potentials of the metal are [22]:

$$
\begin{aligned}
& C r \stackrel{\because}{\longrightarrow} C r^{2+}+2 e^{-} E^{-}=-91 \% \\
& \dot{C} \longrightarrow C^{3+}+3 r^{-} \quad E^{0}=-0.74 V
\end{aligned}
$$

The dissolution could also be assumed to occur via the sequential electrochemical reactions given by Bard and Faulkner [23]:

$$
\begin{aligned}
& \mathrm{Cr} \longrightarrow \mathrm{Cr}^{2+}+2 e^{-} \quad E^{o}=-0.557 \mathrm{~V} \\
& \mathrm{Cr}^{2+} \longrightarrow \mathrm{Cr}^{3+}+e^{-} \quad E^{o}=-0.410 \mathrm{~V}
\end{aligned}
$$

Solutions of $\mathrm{Cr}^{2+}$ are usually produced by reducing $\mathrm{Cr}^{3+}$ with $\mathrm{Zn}$, or by cathodic reduction at $-0.410 \mathrm{~V}$. In acidic solutions, dichromate anion can be reduced to trivalent chromium cation: 


$$
\mathrm{Cr}_{2} \mathrm{O}_{7}^{2-}+14 \mathrm{H}^{+}+6 e^{-} \longrightarrow 2 \mathrm{Cr}^{3+}+7 \mathrm{H}_{2} \mathrm{O} \quad E^{\circ}=+1.33 \mathrm{~V}
$$

In basic solutions, chromate anion can be reduced to form insoluble chromium hydroxide:

$$
\mathrm{CrO}_{4}^{2-}+4 \mathrm{H}_{2} \mathrm{O}+3 e^{-} \longrightarrow \mathrm{Cr}(\mathrm{OH})_{3}+5 \mathrm{OH}^{-} \quad E^{\circ}=-0.13 \mathrm{~V}
$$

Solution Equilibria. Note that the $\mathrm{Cr}^{2+}$ is readily oxidized to $\mathrm{Cr}^{3+}$ in the presence of air. Even in the absence of air, the process can be driven by the reduction of water to liberate hydrogen. In aqueous solution, the aqua ion undergoes hydrolysis [27]:

$$
\mathrm{Cr}^{2+}(a q) \underset{\mathrm{K}}{\longrightarrow} \mathrm{Cr}(\mathrm{OH})^{+}+H^{+} \quad \mathrm{pK}=-5.30
$$

It has been proposed that the oxidation of $\mathrm{Cr}^{2+}$ by $\mathrm{O}_{2}$ first gives $\mathrm{CrO}_{2} \mathrm{Cr}$, which undergoes protonation to $\left[\left(\mathrm{H}_{2} \mathrm{O}\right)_{4} \mathrm{Cr}(\mu-\mathrm{OH})_{2} \mathrm{Cr}\left(\mathrm{H}_{2} \mathrm{O}\right)_{2}\right]^{2+}$; this in turn splits to give the trivalent hydroxo ion, $\left[\mathrm{Cr}\left(\mathrm{H}_{2} \mathrm{O}\right)_{6}\right]^{3+}$. The trivalent hydroxo ion can then undergo dimerazation with loss of a proton:

$$
\begin{aligned}
& {\left[\mathrm{Cr}\left(\mathrm{H}_{2} \mathrm{O}\right)_{6}\right]^{3+} \longleftrightarrow\left[\mathrm{Cr}\left(\mathrm{H}_{2} \mathrm{O}\right)_{5} \mathrm{OH}\right]^{2+}+\mathrm{H}^{+}} \\
& 2\left[\mathrm{Cr}\left(\mathrm{H}_{2} \mathrm{O}\right)_{5} \mathrm{OH}\right]^{2+} \longleftrightarrow\left[\left(\mathrm{H}_{2} \mathrm{O}\right)_{4} \mathrm{Cr}(\mathrm{OH})_{2} \mathrm{Cr}\left(\mathrm{H}_{2} \mathrm{O}\right)_{4}\right]^{4+}+2 \mathrm{H}_{2} \mathrm{O}
\end{aligned}
$$

A precipitate that consists of H-bonded layers, $\left[\mathrm{C}(\mathrm{OH})_{3}\left(\mathrm{H}_{2} \mathrm{O}\right)_{3}\right]$, is formed with the addition of base. Prior to aging, which takes about one minute, this precipitate readily dissolves in acid. However, aging results in an oligomeric or polymeric structure that is much less soluble $[28,29]$.

As discussed by Cotton and Wilkinson [22], Chromium trioxide $\left(\mathrm{CrO}_{3}\right)$ forms a yellow tetrahedral chromate ion $\left(\mathrm{CrO}_{3}{ }^{2}\right)$ at $\mathrm{pH}>6$; chromate $\left(\mathrm{HCrO}^{4}\right)$ ion and red-orange dichromate ion $\left(\mathrm{Cr}_{2} \mathrm{O}_{7}{ }^{2}\right)$ at $2<\mathrm{pH}<6$; and chromic acid $\left(\mathrm{H}_{2} \mathrm{CrO}_{4}\right)$ at $\mathrm{pH}<1$. The equilibria are as follows:

$$
\begin{aligned}
& \mathrm{HCrO}_{4} \longleftrightarrow \mathrm{CrO}_{4}^{2-}+\mathrm{H}^{+} \quad \mathrm{K}=1 \mathrm{O}^{-5.9} \\
& \mathrm{H}_{2} \mathrm{CrO}_{4} \longleftrightarrow \mathrm{HCrO}_{4}^{-}+\mathrm{H}^{+} \quad \mathrm{K}=10^{4 . \mathrm{i}} \\
& \mathrm{Cr}_{2} \mathrm{O}_{7}^{2-}+\mathrm{H}_{2} \mathrm{O} \longleftrightarrow 2 \mathrm{HCrO}_{4}^{-} \quad \mathrm{K}=10^{-2.2}
\end{aligned}
$$

The base hydrolysis equilibria are:

$$
\begin{aligned}
& \mathrm{Cr}_{2} \mathrm{O}_{7}^{2-}+\mathrm{OH}^{-} \longleftrightarrow \mathrm{HCrO}_{4}^{-}+\mathrm{CrO}_{4}^{2-} \\
& \mathrm{HCrO}_{4}^{-}+\mathrm{OH}^{-} \longleftrightarrow \mathrm{CrO}_{4}^{-}+\mathrm{H}_{2} \mathrm{O}
\end{aligned}
$$

Cations $\mathrm{Ba}^{2+}, \mathrm{Pb}^{2+}$, and $\mathrm{Ag}^{+}$react with hexavalent chromium to form insoluble chromates, not dichromates. If any of these cationic species are released from the waste package, the chromate and dichromate will aid in their precipitation. At the present time, barium is being considered as a sintering aid in a ceramic waste form. Furthermore, the species present in solution depend 


\section{Lawrence Livermore National Laboratory, University of California \\ Yucca Mountain Project - EBS Inner Barrier Corrosion Modeling - Farmer - July 1997}

upon the type of mineral acid used as electrolyte. When hydrochloric acid is used, there is essentially quantitative conversion into the chlorchromate ion; with sulfuric acid a sulfato complex results:

$$
\begin{aligned}
& \mathrm{CrO}_{3}(\mathrm{OH})^{-}+\mathrm{H}^{+}+\mathrm{Cl}^{-} \longleftrightarrow \mathrm{CrO}_{3} \mathrm{Cl}^{-}+\mathrm{H}_{2} \mathrm{O} \\
& \mathrm{CrO}_{3}(\mathrm{OH})^{-}+\mathrm{HSO}_{4}^{-} \longleftrightarrow \mathrm{CrO}_{3}\left(\mathrm{OSO}_{3}\right)^{2-}+\mathrm{H}_{2} \mathrm{O}
\end{aligned}
$$

As discussed in Oldfield and Sutton, as well as others, equilibria between $\mathrm{Cr}^{3+}, \mathrm{Cr}(\mathrm{OH})^{2+}$, $\mathrm{Cr}(\mathrm{OH})_{2}^{+}, \mathrm{Cr}(\mathrm{OH})_{3}, \mathrm{Cr}(\mathrm{OH})_{4}^{-}$, and $\mathrm{CrO}_{2}^{-}[17,30]$. This equilibria for the first three species is illustrated by the following equations:

$$
\begin{aligned}
& \mathrm{Cr}^{3+}+\mathrm{H}_{2} \mathrm{O} \underset{\mathrm{K}_{\mathrm{t}, 1}}{\longrightarrow} \mathrm{Cr}(\mathrm{OH})^{2+}+\mathrm{H}^{+} \\
& \mathrm{K}_{1,1}=\frac{\left.\left[\mathrm{Cr}(\mathrm{OH})^{2+}\right] \mathrm{H}^{+}\right]}{\left[\mathrm{Cr}^{3+}\right]} \\
& \mathrm{Cr}(\mathrm{OH})^{2+}+\mathrm{H}_{2} \mathrm{O} \underset{\mathrm{K}_{1,2}}{\longrightarrow} \mathrm{Cr}(\mathrm{OH})_{2}^{+}+H^{+} \\
& \mathrm{K}_{1,2}=\frac{\left.\left[\mathrm{Cr}(\mathrm{OH})_{2}^{+}\right] \mathrm{H}^{+}\right]}{\left[\mathrm{Cr}(\mathrm{OH})^{2+}\right]} \\
& \mathrm{Cr}(\mathrm{OH})_{3}(\mathrm{~s}) \stackrel{\mathrm{K}_{1,3}}{\longrightarrow} \mathrm{Cr}^{3+}+3 O \mathrm{H}^{-} \\
& \left.\mathrm{K}_{1,3}=\left[\mathrm{Cr}^{3+}\right] \mathrm{OH}^{-}\right]^{3}
\end{aligned}
$$

It is noteworthy that these species can polymerize [30]. The dimerization reaction is represented by:

$$
\mathrm{Cr}(\mathrm{OH})^{2+}+\mathrm{Cr}(\mathrm{OH})^{2+} \stackrel{\cdot}{\longleftrightarrow} \mathrm{Cr}_{2}(\mathrm{OH})^{4+}
$$

with the value of $\mathrm{K}_{1,4}$ at $25^{\circ} \mathrm{C}$ given as:

$$
\log \left(K_{1,4}\right)=3.3
$$

Formation of the trimer is represented by:

$$
\mathrm{Cr}(\mathrm{OH})^{2+}+\mathrm{Cr}_{3}(\mathrm{OH})^{3+} \stackrel{\mathrm{K}_{1,5}}{\longrightarrow} \mathrm{Cr}_{3}(\mathrm{OH})_{4}^{5+}
$$


with the value of $\mathrm{K}_{1,5}$ at $25^{\circ} \mathrm{C}$ given as:

$\log \left(K_{1,5}\right)=4.5$

Finally, formation of the tetramer is represented by:

$\mathrm{Cr}(\mathrm{OH})^{2+}+\mathrm{Cr}_{3}(\mathrm{OH})_{5}^{4+} \stackrel{\kappa_{1.6}}{\longrightarrow} \mathrm{Cr}_{4}(\mathrm{OH})_{6}^{6+}$

with the value of $\mathrm{K}_{1,6}$ at $25^{\circ} \mathrm{C}$ given as:

$\log \left(K_{1,6}\right)=35$

These polymerization reactions are assumed to be of secondary importance in pH suppression, and are not accounted for in this analysis.

Because of the carcinogenicity and toxicity of $\mathrm{Cr}(\mathrm{VI})$ species, numerous studies have recently been conducted on $\mathrm{Cr}$ speciation and the kinetics of $\mathrm{Cr}$ (III) oxidation to $\mathrm{Cr}(\mathrm{VI})$. Fortunately, the only natrually occurring, non-biological oxidants of $\mathrm{Cr}(\mathrm{III})$ are manganese oxides [30]. The formation of dichromate, $\mathrm{Cr}_{2} \mathrm{O}_{7}{ }^{2-}$, is shown in the following equation.

$3 \mathrm{MnO}_{2}+\mathrm{H}_{2} \mathrm{O}+2 \mathrm{Cr}^{3+} \underset{\mathrm{K}_{2,1}}{\longrightarrow} 3 \mathrm{Mn}^{2+}+\mathrm{Cr}_{2} \mathrm{O}_{\tau}^{2-}+2 \mathrm{H}^{+}$

$K_{2,1}=\frac{\left[\mathrm{Mn}^{2+}\right]^{3}\left[\mathrm{H}^{+}\right]^{2}\left[\mathrm{Cr}_{2} \mathrm{O}_{7}^{2-}\right]}{\left[\mathrm{Cr}^{3+}\right]^{2}}$

At $25^{\circ} \mathrm{C}$ the value of $\mathrm{K}_{2,1}$ is: .

$\log \left(\dot{K}_{2,1}\right)=-10.16$

In addition to to dichromate anion, chromate and hydrochromate may also exist: $\mathrm{CrO}_{4}{ }^{2-}$ and $\mathrm{HCrO}_{4}^{-}[\mathrm{A} 7]$.

\section{Water and Oxygen Chemistry}

Electrochemical Reactions. The anodic dissolution of chromium, iron, and nickel can be depolarized by the the cathodic reduction of water, which can represented by one of the following two reactions, depending upon $\mathrm{pH}[23]$ :

$$
\mathrm{O}_{2}+4 \mathrm{H}^{+}+4 \mathrm{e}^{-} \longrightarrow 2 \mathrm{H}_{2} \mathrm{O} \quad E^{\circ}=+1.229 \mathrm{~V}
$$


$\mathrm{O}_{2}+2 \mathrm{H}_{2} \mathrm{O}+4 e^{-} \longrightarrow 4 \mathrm{OH}^{-} \cdot E^{\circ}=+0.401 \mathrm{~V}$

Anodic dissolution reactions can also be depolarized by hydrogen evolution, which can represented by one of the following two reactions, depending upon $\mathrm{pH}$ [23]:

$2 \mathrm{H}^{+}+2 \mathrm{e}^{-} \longrightarrow \mathrm{H}_{2} \quad E^{\bullet}=+0.000 \mathrm{~V}$

$2 \mathrm{H}_{2} \mathrm{O}+2 \mathrm{e}^{-} \longrightarrow \mathrm{H}_{2}+2 \mathrm{OH}^{-} \quad E^{\circ}=-0.8277 \mathrm{~V}$

Solution Equilibria. The dissociation of water is also $\mathrm{pH}$ dependent. The concentration of hydroxyl ions can be expressed in terms of the hydrogen ion concentration.

$$
\begin{aligned}
& \mathrm{H}_{2} \mathrm{O} \underset{\mathrm{K}_{w}}{\longrightarrow} \mathrm{H}^{+}+\mathrm{OH}^{-} \\
& \mathrm{K}_{w}=\left[\mathrm{H}^{+}\left[\mathrm{OH}^{-}\right]\right.
\end{aligned}
$$

\section{No Accumulation of Hydrogen Ions and Electroneutrality}

In this case, is assumed that no hydrogen ions accumulate in the crevice solution. These ions are lost during a purge of the acidified crevice solution. This solution is in equilibrium with precipitated corrosion products. The coefficients are determined from the concentrations of ions such as sodium, magnesium, chloride, sulfate, as well as the equilibrium constants for the various hydrolysis reactions, the solubility products of the neutral hydroxides, and $\mathrm{K}_{\mathrm{w}}$. The first step in deriving the polynomial is to write the expression for electroneutrality. The general expression is:

$\sum_{j=1}^{m_{+}} \dot{n}_{j}^{-} z_{j}^{-}=\sum_{j=1}^{m_{c}} n_{j}^{+} z_{j}^{+}$

where $n_{j}{ }^{-}$is the molar concentration of the $j$-th anion, $z_{j}^{-}$is the charge of that anion, $m_{a}$ is the total number of anionic species, $n_{j}{ }^{+}$is the molar concentration of the $j$-th cation, $z_{j}^{+}$is the charge of that cation, and $m_{c}$ is the total number of cationic species. This can be written more specifically in terms of anticipated species:

$$
\begin{gathered}
{\left[\mathrm{OH}^{-}\right]+\left[\mathrm{Cl}^{-}\right]+\left[\mathrm{F}^{-}\right]+\left[\mathrm{NO}_{3}^{-}\right]+\left[\mathrm{HCO}_{3}^{-}\right]+2\left[\mathrm{SO}_{4}^{2-}\right]+2\left[\mathrm{~S}^{2-}\right]+2\left[\mathrm{Cr}_{2} \mathrm{O}_{7}^{2-}\right]=} \\
{\left[\mathrm{H}^{+}\right]+\left[\mathrm{Na}^{+}\right]+\left[\mathrm{K}^{+}\right]+2\left[\mathrm{Mg}^{2+}\right]+2\left[\mathrm{Ca}^{2+}\right]+2\left[\mathrm{Mn}^{2+}\right]+2\left[\mathrm{Ni}^{2+}\right]+\left[\mathrm{Ni}(\mathrm{OH})^{+}\right]+} \\
2\left[\mathrm{Fe}^{2+}\right]+\left[\mathrm{Fe}(\mathrm{OH})^{+}\right]+3\left[\mathrm{Fe}^{3+}\right]+2\left[\mathrm{Fe}(\mathrm{OH})^{2+}\right]+\left[\mathrm{Fe}(\mathrm{OH})_{2}^{+}\right]+ \\
3\left[\mathrm{Cr}^{3+}\right]+2\left[\mathrm{Cr}(\mathrm{OH})^{2+}\right]+\left[\mathrm{Cr}(\mathrm{OH})_{2}^{+}\right]
\end{gathered}
$$


Here too the concentrations of dissolved species are expressed in terms of the hydrogen ion concentration, equilibrium constants for the hydrolysis reactions, solubilities of corrosion products, and the dissociation constant for water. In this case, the solution becomes slightly alkaline.

\section{Mass Balance for Dissolution of Metal in the Crevice}

The total quantities of dissolved metal are determined by integration of the corrosion rates for the CAM and CRM, respectively. The total quantity of dissolved iron is defined in terms of the integral $\mathrm{Fe}_{\mathrm{T}}$ :

$$
\begin{aligned}
& F e_{T}=[F e(I I)]+[F e(I I I)] \\
& F e_{T}=F e_{T, C A M}+F e_{T, C R M} \\
& F e_{T, C A M}=\frac{1}{2 F}\left\{\frac{1}{h_{C A M}} \int_{0}^{\tau_{C M I}} i_{C A M} d t\right\} \\
& F e_{T, C R M}=\frac{1}{2 F}\left\{\frac{\theta_{F e}\left(d_{c} / L\right)}{h_{C R M}} \int_{\tau_{C M I}}^{\tau_{C C M}} i_{C R M} d t\right\}
\end{aligned}
$$

where $F e_{T, C A M}$ is the integral for $\left(0<t<\tau_{C A M}\right)$; and $F e_{T, C R M}$ is the integral for $\left(\tau_{C A M}<t<\tau_{C R M}\right)$; where $h_{C A M}$ is the width of the Phase 1 crevice (separation of the CAM and CRM); $h_{C R M}$ is the width of the Phase 2 crevice (separation of precipitated corrosion product and CAM); $\tau_{\mathrm{CAM}}$ is the time for active-wall corrosion of CAM in Phase 1 crevice; $\tau_{\text {CRM }}$ is the time for active corrosion of CRM in Phase 2 crevice $\left(x \geq d_{c}\right)$; $d_{c}$ is the critical distance from Phase 2 crevice required for depassivation; $\mathcal{L}$ is the total length of the crevice; $\theta_{\mathrm{Fe}}$ is the mole fraction of the $C R M$ that is iron; $\mathrm{i}_{C A M}$ is the corrosion current of the active CAM wall in the in the Phase 1 crevice; and $\mathrm{i}_{C A M}$ is the corrosion current of the depassivated CRM wall. The total quantity of dissolved nickel is defined in terms of the integral $\mathrm{Ni}_{\mathrm{T}}$ :

$$
\begin{aligned}
& N i_{T}=[N i(I I)] \\
& N i_{T}=N i_{T, C A M}+N i_{T, C R M} \\
& N i_{T, C A M}=0 \\
& N i_{T, C R M}=\frac{1}{2 F}\left\{\frac{\theta_{N i}\left(d_{c} / L\right)}{h_{C R M}} \int_{r_{C M I}}^{\tau_{C M M}} i_{C R M} d t\right\}
\end{aligned}
$$

The total quantity of dissolved chromium is defined in terms of the integral $\mathrm{Cr}_{\mathrm{T}}$ : 


$$
\begin{aligned}
& C r_{T}=[C r(I I I)]+[C r(V I)] \\
& C r_{T}=C r_{T, C M M}+C r_{T, C R M} \\
& C r_{T, C A M}=0 \\
& C r_{T, C R M}=\frac{1}{3 F}\left\{\frac{\theta_{C r}\left(d_{c} / L\right)}{h_{C R M}} \int_{\tau_{C M M}{ }^{r_{C M N}}}^{i_{C R M}} d t\right\}
\end{aligned}
$$

Mass Balance for Oxygen Reduction and Hydrogen Evolution Reactions

The $\left[\mathrm{H}^{+}\right]$generation term due to oxygen reduction is defined in terms of the integral $\mathrm{O}_{\mathrm{T}}$ :

$$
\begin{aligned}
& O_{T}=\left[O_{2}\right] \\
& O_{T}=O_{T, C M M}+O_{T, C R M} \\
& O_{T, C M}=\frac{1}{4 F}\left\{\frac{1}{h_{C M M}} \int_{0}^{T_{C M I}} 4 F J_{O 2, C M M} d t\right\} \\
& O_{T, C R M}=\frac{1}{4 F}\left\{\frac{\left(d_{c} / L\right)^{T_{C O M}}}{h_{C R M}} \int_{T_{C M M}}^{T_{C M}} 4 F J_{O 2, C R M} d t\right\}
\end{aligned}
$$

where $\mathrm{J}_{\mathrm{O}, \mathrm{CAM}}$ is the mass transport-limited oxygen flux into the mouth of a Phase 1 crevice, and $\mathrm{J}_{\mathrm{O} 2, \mathrm{CRM}}$ is the mass-transport limited oxygen flux into the mouth of a Phase 2 crevice. The loss tèrm due to hydrogen evolution is defined in terms of $\mathrm{H}_{\mathrm{T}}$.

$$
\begin{aligned}
& H_{T}=\left[H_{2}\right] \\
& H_{T}=H_{T, C M}+H_{T, C R M} \\
& H_{T, C A M}=\frac{1}{2 F}\left\{\frac{1}{h_{C A M}} \int_{0}^{\tau_{C M T}} i_{H_{2}}^{\infty} \frac{\left[H^{+}\right]_{1<, \bullet}}{\left[H^{+}\right]_{r d}} e^{-\frac{E F}{R T}} d t\right\} \\
& H_{T, C R M}=\frac{1}{2 F}\left\{\frac{\left(d_{c} / L\right)}{h_{C R M}} \int_{\tau_{C M I}}^{T_{C M I}} i_{H_{2}}^{o} \frac{\left[H^{+}\right]_{\ell<t^{*}}}{\left[H^{+}\right]_{\text {ref }}} e^{-\frac{E F}{R T}} d t\right\}
\end{aligned}
$$


Since the hydrogen ion concentration at $\left(\mathrm{t}<\mathrm{t}^{*}\right)$, and the electrode potential are functions of time, the integral will have to be evaluated numerically. The value of the integral will be used to define the coefficient $a_{0}$, which will be used to calculate the hydrogen ion concentration at $(t=$ $\left.t^{*}\right)$. It should be noted that the assumption of electroneutrality is implicit in these equations. Therefore, additional anions such as chloride will have to diffuse into the crevice to balance the charge of the hydrogen ions.

It is important to know the relative quantities of $\mathrm{Fe}(\mathrm{II})$ and $\mathrm{Fe}(\mathrm{III})$, and that those quantities be defined in terms of the integral, $\mathrm{Fe}_{\mathrm{T}}$.

$$
\begin{aligned}
& {[\mathrm{Fe}(I I)]=\chi F e_{T}} \\
& {[\mathrm{Fe}(I I)]=(1-\chi) \mathrm{Fe}_{T}}
\end{aligned}
$$

It is also important to know the relative quantities of $\mathrm{Cr}(\mathrm{III})$ and $\mathrm{Cr}(\mathrm{VI})$, and that those quantities be defined in terms of the integral, $\mathrm{Cr}_{\mathbf{T}}$.

$$
\begin{aligned}
& {[C r(I I I)]=\zeta C r_{T}} \\
& {[C r(V I)]=(1-\zeta) C r_{T}}
\end{aligned}
$$

The following proportionalities are assumed for polyvalent iron and chromium:

$$
\begin{aligned}
& \frac{[\mathrm{Fe}(I I)]}{[\mathrm{Fe}(I I I)]}=\frac{\chi}{1-\chi} \\
& \frac{[\mathrm{Fe}(I I)]}{[\mathrm{Fe}(I I I)]} \approx \frac{\left[\mathrm{Fe}^{2+}\right]}{\left[\mathrm{Fe}^{3+}\right]} \\
& \frac{[\mathrm{Cr}(I I I)]}{[\mathrm{Cr}(\mathrm{VI})]}=\frac{\zeta}{1-\zeta} \\
& \frac{[\mathrm{Cr}(I I I)]}{[\mathrm{Cr}(\mathrm{VI})]} \approx \frac{\left[\mathrm{Cr}^{3+}\right]}{\left[\mathrm{Cr}_{2} \mathrm{O}_{7}^{2-}\right]}
\end{aligned}
$$

From these ratios, as well as the equations relating soluble iron and chromium species to $\left[\mathrm{H}^{+}\right]$, the parameters $\chi$ and $\zeta$ are found to be:

$$
\chi=\frac{1}{1+e^{f(E-0.770)}}
$$




$$
\zeta=\frac{\dot{K}_{w}\left[M n^{2+}\right]}{K_{w}\left[\mathrm{Mn}^{2+}\right]+K_{2,1} K_{1,3}\left[H^{+}\right]}
$$

Dissolved iron, nickel, and chromium from the inner barrier are assumed to have the same ratios as in the alloy. The following relationships are assumed:

$$
N i_{T, C R M}=\frac{\theta_{N I}}{\theta_{F e}} F e_{T, C R M} \text { and } C r_{T, C R M}=\frac{\theta_{C F}}{\theta_{F e}} F e_{T, C R M}
$$

The anodic current associated with the dissolution of the CAM and CRM will be balanced by the cathodic currents associated with reduction of oxygen and hydrogen ion. For a corrosion limited by the availability of depolarizers and $\left(\tau_{\mathrm{CAM}}<\mathrm{t}<\tau_{\mathrm{CRM}}\right)$, the following relationship should be obeyed:

$$
2 \theta_{F e} F e_{T, C R M}+2 \theta_{N i} N i_{T, C R M}+3 \theta_{C r} C r_{T, C R M}=4 O_{T, C R M}+2 H_{T, C R M}
$$

This can be rewritten as:

$$
\left(2+2 \frac{\theta_{N i}}{\theta_{F e}}+3 \frac{\theta_{C r}}{\theta_{F e}}\right) F e_{T, C R M}=4 O_{T, C R M}+2 H_{T, C R M}
$$

Therefore:

$$
F e_{T, C R M}=\frac{4 O_{T, C R M}+2 H_{T, C R M}}{2+2 \frac{\theta_{N i}}{\theta_{\text {Fe }}}+3 \frac{\theta_{C r}}{\theta_{F e}}}
$$

For $\left(0<t<\tau_{\text {CAM }}\right)$, the terms for nickel and chromium can be eliminated.

$$
F e_{T, C M M}=2 O_{T, C M M}+H_{T, C M}
$$

\section{RESULTS}

\section{Stochastic Pitting Model}

Figure 2 shows the calculated pit density (number per $100 \mathrm{~cm}^{2}$ ) as a function of time, based upon the stochastic model. These calculations were performed with arbitrary parametric values to illustrate the general feature of the stochastic pitting model. The source code and parametric values are given in Appendix 1. As expected, the number of vacancies (unpitted area) decreases with time, while the number of stable pits increases. Initially, the number of pit embryos increases rapidly with time. However, the embryo density reaches a maximum and begins to fall 


\section{Lawrence Livermore National Laboratory, University of California \\ Yucca Mountain Project - EBS Inner Barrier Corrosion Modeling - Farmer - July 1997}

at the point where the rate of embryo conversion to stable pits exceeds the rate of embryo births. The overall pit generation rate is proportional to the embryo density, and also passes through a maximum. Figure 3 shows the corresponding pit distribution, which is typical of those obtained with the stochastic pitting model with time invariant probabilities. Distinguishing characteristics include: peak near the maximum pit depth; and long tail.

Figure 4 shows the calculated pit density (number per $100 \mathrm{~cm}^{2}$ ) as a function of time, based upon the deterministic kinetic model. These calculations were performed with arbitrary parametric values to illustrate the general feature of this approach. The source code and parametric values are given in Appendix 2. Like the-stochastic model, this model also predicts that the number of vacancies (unpitted area) decreases with time, while the number of stable pits increases. Initially, the number of pit embryos increases rapidly with time. However, the embryo density reaches a maximum and begins to fall at the point where the rate of embryo conversion to stable pits exceeds the rate of embryo births. The overall pit generation rate is proportional to the embryo density, and also passes through a maximum. Figure 5 shows the corresponding pit distribution, which is typical of those obtained with the deterministic kinetic pitting model with time invariant probabilities: Like the stochastic model, distinguishing characteristics include: peak near the maximum pit depth; and long tail.

Figure 6 is a prediction of the fractional coverage of the surface by pit embryos as a function of electrode potential, for three arbitrary chloride concentrations (1X, 2X, and 10X). This prediction is based upon the quasi-steady state solution of the governing equations used to formulate the deterministic kinetic pitting model. If one assumes that the cumulative probability of pit initiation is proportional to the fractional coverage of the surface by pit embryos, it is evident that this simple model is capable of predicting the critical pitting potential. For example, one might assume that $E_{\text {crit }}$ is the point where $\theta_{E}$ has a value of 0.5 (cumulative probability of $50 \%$ ). As the potential is increased to levels above $E_{\text {crit }}$, pitting is assured. If the potential is dropped to values below this value, pitting ceases.

\section{Crevice Corrosion Model}

The equations for hydrolysis equilibria and the mass balance for hydrogen ions accumulated in the crevice were combined, as discussed in the previous section outlining the crevice corrosion model. Then, a bisection method was used to determine the concentration hydrogen ions that satisfies the combined equations, as a function of dissolved metal accumulated in the crevice. As previously discussed, exact values of hydrolysis equilibrium constants are given in Table 1. In the illustrative example shown in Figure 7, the composition of the metal being dissolved in the crevice is assumed to be Alloy 825, an early CRM candidate material. The accumulation of metal in the crevice was assumed to increase linearly with time (constant crevice corrosion current), and the crevice solution is assumed to be well mixed. The assumption regarding mixing of the solution is not rigorously true, but is used as an approximation to enable, the overall effects of $\mathrm{pH}$ suppression in the crevice to be accounted for in a tractable manner. As expected, the simple model predicts a rapid drop in $\mathrm{pH}$ of the crevice solution as the amount of dissolved metal in the crevice increases. As shown in Figure 8, the concentrations of iron species dissolved in 
the crevice solution, which include $\left[\mathrm{Fe}^{2+}\right],\left[\mathrm{Fe}^{3+}\right],\left[\mathrm{Fe}(\mathrm{OH})^{2+}\right]$ and $\left[\mathrm{Fe}(\mathrm{OH})^{+}\right]$, approach asymptotic values. The amount of precipitated ferrous hydroxide per unit volume crevice solution, $\left[\mathrm{Fe}(\mathrm{OH})_{2}\right]$, is also shown. In the cases shown, $\left[\mathrm{Fe}(\mathrm{OH})_{2}\right]$ is insignificant compared to the concentrations of other species. Figures 9 and 10 show comparable calculations for the concentrations of nickel and chromium species dissolved in the crevice solution, respectively. In the case of nickel, $\left[\mathrm{Ni}^{2+}\right]$ and $\left[\mathrm{Ni}(\mathrm{OH})^{+}\right]$are significant, while $\left[\mathrm{Ni}(\mathrm{OH})_{2}\right]$ is insignificant. The concentrations of dissolved chromium species, which include $\left.\left[\mathrm{Cr}^{3+}\right], \mathrm{Cr}(\mathrm{OH})^{2+}\right]$ and $\left[\mathrm{Cr}(\mathrm{OH})^{2+}\right]$ are much lower that the concentrations of dissolved iron and nickel species, which is to be expected. Most of the chromium in equilibrium with the solution will exist as precipitated $\left[\mathrm{Cr}(\mathrm{OH})_{3}\right]$, which helps account for the exceptional passivating properties of the chromium alloying element. In summary, it is important to note that all species dissolved in the crevice solution approach asymptotic values as the amount of dissolved metal increases. Consequently, the $\mathrm{pH}$ also approaches an asymptotic value ( $\mathrm{pH} 11)$. This leads one to a very useful conclusion regarding "model abstractions." When treating localized corrosion within the crevice, one can estimate the asyptotic value of $\mathrm{pH}$ and use that value as an input to other corrosion models for predicting rates of localized attack (pitting) of the CRM in the crevice. Clearly, such a simplification would provide great computational advantages for Total System Performance Assessment (TSPA). These calculations were done with the source code shown in Appendix 3.

It is now important to look at the predictions shown in Figures 7 through 10 and determine whether or not those predictions are reasonable. Jones and Wilde have prepared solutions of $\mathrm{CrCl}_{3}, \mathrm{FeCl}_{2}$, and $\mathrm{NiCl}_{2}$ and measured the $\mathrm{pH}$ [31]. Their measurements are summarized in Table 2, as well as in Figure 11. These authors used these valuable data to directly verify the effects of dissolved $\mathrm{FeCl}_{2}, \mathrm{NiCl}_{2}$, and $\mathrm{CrCl}_{3}$ on $\mathrm{pH}$ suppression. The suppression is due to the accumulation of the hydrolysis reactions discussed in previous sections. Clearly, a pH value of approximately 1 is reasonable, as it falls between the values for saturated solutions of $\mathrm{FeCl}_{2}$ and $\mathrm{NiCl}_{2}$. In the case of saturated $\mathrm{CrCl} 3$ solutions, even lower $\mathrm{pH}$ values can be reached. This type of $\mathrm{pH}$ suppression can exacerbate corrosion of the CRM in the crevice, and lead to enhanced rates of pit initiation and propagation.

Table 2. The pH of Aqueous Solutions of Metal Chloride Salts at Room Temperature

\begin{tabular}{|c|c|c|c|}
\hline Salt & $1 \mathrm{~N}$ & $1 \mathrm{~N}$ & Saturated \\
\hline $\mathrm{FeCl}_{2}$ & 2.1 & 0.8 & 0.2 \\
\hline $\mathrm{NiCl}_{2}$ & 3.0 & 2.7 & 2.7 \\
\hline $\mathrm{CrCl}_{3}$ & 1.1 & -0.3 & -1.4 \\
\hline
\end{tabular}

\section{Integration of Pitting and Crevice Corrosion Models}

Figures 12 and 13 illustrate the effect of $\mathrm{pH}$ suppression in a hypothetical crevice on CRM pitting, based upon the stochastic pitting model. Figure 12 shows the calculated pit density (number per $100 \mathrm{~cm}^{2}$ ) as a function of time for two cases, direct exposure to the near field environment (NFE) and exposure to the low-pH crevice solution. These calculations were performed with arbitrary parametric values to illustrate the general feature of the stochastic 
pitting model. The source code and parametric values are given in Appendix 4. As expected, the number of vacancies (unpitted area) decreases with time in both cases, while the number of stable pits increases. Initially, the number of pit embryos increases rapidly with time. However, the embryo density rapidly increases to a maximum and then begins to fall at the point where the rate of embryo conversion to stable pits exceeds the rate of embryo births. The overall pit generation rate is proportional to the embryo density, and also passes through a maximum. Clearly, suppressed $\mathrm{pH}$ increases the rate of pit generation, which is consistent with experience. Figure 13 shows the corresponding pit distribution, which is typical of those obtained with the stochastic pitting model with time invariant probabilities. As previously discussed, distinguishing characteristics include: peak near the maximum pit depth; and long tail. Suppressed $\mathrm{pH}$ pushes the distribution to greater pit depths, as one would anticipate.

Figures 14 and 15 illustrate the effect of $\mathrm{pH}$ suppression in a hypothetical crevice on CRM pitting, based upon the deterministic (kinetic) pitting model. Figure 14 shows the calculated fractional coverage of the surface by pits as a function of time for two cases, direct exposure to the near field environment ( $\mathrm{pH}=6$ and $[\mathrm{Cl}]=0.005$ arbitrary units) and exposure to the low-pH crevice solution( $\mathrm{pH}=5$ and $[\mathrm{Cl}]=0.01$ arbitrary units). These calculations were performed with arbitrary parametric values, given in Table 6, to illustrate the general feature of the deterministic pitting model. As expected, the fractional coverage of the surface by vacancies (unpitted area) decreases with time in both cases, while the fractional coverage of the surface by stable pits increases. Initially, the fractional coverage of the surface by pit embryos increases rapidly with time. However, the coverage by embryos rapidly increases to a maximum and then begins to fall at the point where the rate of embryo conversion to stable pits exceeds the rate of embryo births. The overall pit generation rate is proportional to the embryo coverage, and also passes through a maximum. Clearly, suppressed $\mathrm{pH}$ increases the rate of pit generation, which is consistent with experience. Figure 15 shows the corresponding pit distribution, which is similar to those obtained with the stochastic pitting model with time invariant probabilities. As previously discussed, distinguishing characteristics include: peak near the maximum pit depth; and long tail. Suppressed $\mathrm{pH}$ pushes the distribution to greater pit depths, as one would anticipate. These calculations were done with the source code in Appendix 5.

\section{Improvements in Stochastic Pitting Models to Enable Realistic Predictions}

Another prediction of pit density as a function of time is shown in Figure 16. In this case, the birth probability is assumed to be time dependent and forced to pass through a maximum as time is increased. This is similar to the strategy employed by Henshall. These calculations were performed with parametric values which enabled the stochastic pitting model to mimic the pit distribution observed on Alloy 825 after an exposure of 240 hours [Data of A. Roy, Ref. 5]. Here too the number of vacancies (unpitted area) decreases with time, while the number of stable pits increases. Figure 17 shows the corresponding pit distribution, which is is bell shaped, similar to the data of Roy. The source code and parametric values used to generate these predictions is shown in Appendix 6. This distribution and those shown in Figures 13 are compared in Figure 18. Ideally, model parameters such as the birth probability should be time invariant. The rate equations that underlie the stochastic model must be improved so that such empirical fixes do not have to be employed. 


\section{Empirical Approach to Crevice Corrosion}

Clearly, much more work needs to be done on the mechanistic pitting and crevice corrosion models provided by this report before they can be reliably used to make predictions for TSPA. In the interim period, it is recommended to use empirical rate expressions, based upon experimental data and a general knowledge of such transport-controlled processes:

$$
d=d_{0}\left(\frac{t}{t_{0}}\right)^{n}
$$

where $d_{0}$ is the penetration depth at time $t_{0}, d$ is the penetration depth at time $t$, and $n$ is the power of the growth law. The compilation of data by Gdowski [32] has been used as the basis of the predictions shown in Figures 19 through 22. In Figure 19, it is assumed that the penetration rate observed in various crevices, or simulated crevice conditions, is linearly proportional to time (penetration proportional to $t^{1 / 2}$ ). In this case, penetration of an inner barrier made of either Alloy 625 or C-276 is predicted within 10,000 years, assuming that the wall is $2 \mathrm{~cm}$ thick. In this scenario, both materials would fail within the time of interest in the repository. However, if the penetration rate is transport-controlled (penetration proportional to $t^{1 / 2}$ ), Alloy C-276 is not penetrated during the 10,000 year period of interest to the repository. In contrast, Alloy 625 also fails in this case. In cases involving dissolved copper-based alloys such as Monel 400 , tests with the "Green Death" test solution may be more appropriate since $1 \% \mathrm{CuCl}_{2}$ is present. In this case, there is evidence that Alloy 686 can pass at temperatures below $135^{\circ} \mathrm{C}$. Clearly, the exact time dependence of the penetration rate is critical, but unknown. More research is needed to precisely determine the value of the exponent in the empirical rate expression. Based upon this simple empirical model, it appears that Alloys C-276 and C-22 are better choices for fabrication of the EBS inner barrier than Alloys 825 and 625 , which are less resistant to crevice corrosion.

\section{SUMMARY}

Two independent pitting models have been formulated, one stochastic and the other deterministic. Both are capable of giving comparable qualitative results and predict that vacant surface decreases with time as the number of stable pits increases. The number of pit embryos passes through a maximum as the rate of death and conversion to stable pits exceeds the rate of birth. A rational dependence on chloride concentration, $\mathrm{pH}$, potential and temperature have now been built into both models so that the effects of $\mathrm{pH}$ suppression in the crevice can be accounted for. A solid step has now been taken towards integrating a crevice corrosion and pitting model. However, more work is needed.

Ideally, parameters in any kinetic model should be time invariant. In essence, the rate constant for embryos is such a parameter. However, in order to mimic the pit distribution observed on Alloy 825 after an exposure of $\mathbf{2 4 0}$ hours [Data of A. Roy, Ref. 5], it is ncessary to assume that the birth rate (and probability) is time dependent, passing through a maximum as time is increased. This is similar to the strategy employed by Henshall. The rate equations that underlie 
the stochastic model must be improved so that such empirical fixes do not have to be employed. An improved formulation is under investigation at the present time.

In regard to crevice corrosion, all species dissolved in the crevice solution approach asymptotic values as the amount of dissolved metal increases. Consequently, the $\mathrm{pH}$ also approaches an asymptotic value. Clearly, an asymptotic $\mathrm{pH}$ value of approximately 1 is reasonable in the case of Alloy 825 since it falls between the values for saturated solutions of $\mathrm{FeCl}_{2}$ and $\mathrm{NiCl}_{2}$. This leads one to a very useful conclusion regarding "model abstractions." When treating localized corrosion within the crevice, one can estimate the asyptotic value of $\mathrm{pH}$ and use that value as an input to other corrosion models for predicting rates of localized attack (pitting) of the CRM in the crevice. Clearly, such a simplification would provide great computational advantages for Total System Performance Assessment (TSPA).

Clearly, much more work needs to be done on the mechanistic pitting and crevice corrosion models provided by this report before they can be reliably used to make predictions for TSPA. In the interim period, it is recommended to use empirical rate expressions, based upon experimental data and a general knowledge of such transport-controlled processes. From preliminary predictions based upon published data, it is evident that the exact time dependence of the penetration rate is critical, but unknown. More research is needed to precisely determine the value of the exponent in the empirical rate expression.

\section{ACKNOWLEDGEMENTS}

Discussions with D. Stahl, W. Clarke, W. Halsey, D. McCright, G. Henshall, J. Lee, D. Jones, J. Horne, J. Payer and J. Scully were very helpful. This work was done under the auspices of the U.S. Department of Energy (DOE) by Lawrence Livermore National Laboratory (LLNL) under Contract No. W-7405-Eng-48.

\section{REFERENCES}

1. T. Shibata; T. Takeyama, "Stochàstic Theory of Pitting Corrosion," Corrosion, Vol. 33, No. 7, 1977, pp. 243-251.

2. T. Shibata, "Statistical and Stochastic Approaches to Localized Corrosion," Corrosion, Vol. 52 , No. 11 , pp. 813.

3. G. A. Henshall, "Modeling Pitting Corrosion Damage of High-Level Radioactive-Waste Containers Using a Stochastic Approach," Journal of Nuclear Materials, Vol. 195, 1992, pp. 109-125.

4. G. A. Henshall, "Stochastic Modeling of the Influence of Environment on Pitting Corrosion Damage of Radioactive-Waste Containers," Materials Research Society Symposium, Vol. 353, 1995, pp. 679-686. 
5. G. A. Henshall, “Modeling Pitting Degradation of Corrosion Resistant Alloys," Lawrence Livermore National Laboratory, University of California, UCRL-ID-125300, November 1996, 26 p.

6. J. C. Farmer, G. E. Gdowski, R. D. McCright, H. S. Ahluwahlia, "Corrosion Models for Performance Assessment of High-Level Radioactive-Waste Containers," Nuclear Engineering Design, Vol. 129, 1991, pp. 57-88.

7. T. Okada, "Halide Nuclei Theory- of Pit Initiation in Passive Metals, J. Electrochemical Society, Vol. 131, No. 2, 1984, pp. 241-247.

8. T. Okada, "A Theory of Perturbation-Initiated Pitting, Proceedings of the International Symposium Honoring Professor Marcel Pourbaix on his Eightieth Birthday: Equilibrium Diagrams and Localized Corrosion, R. P. Frankenthal, J. Kruger, Eds., Electrochemical Society, Pennington, NJ, Vol. 84-9, 1984, pp. 402-431.

9. C. Y. Chao, L. F. Lin, D. D. McDonald, "A Point Defect Model for Anodic Passive Films, II. Chemical Breakdown and Pit Initiation," J. Electrochemical Society, Vol. 128, No. 6, 1981, pp. 1194-1198.

10. N. Sato, Electrochimica Acta, Vol. 19, 1971, p. 1683.

11. H. W. Pickering, R. P. Frankenthal, "On the Mechanism of Localized Corrosion of Iron and Stainless Steel: I. Electrochemical Studies," J. Electrochemical Society, Vol. 119, No. 10, 1972, pp. 1297-1304.

12. J. R. Galvele, "Transport Processes and the Mechansim of Pitting of Metals," J. Electrochemical Society, Vol. 123, No. 4, 1976, pp. 464-474.

13. T. R: Beck, R. C. Alkire, "Occurrence of Salt Films During Initiation and Growth of Corrosion Pits," J. Electrochemical Society, Vol. 123, No. 4, 1976, pp. 464-474.

14. M. G. Fontana, N. D. Greene, Corrosion Engineering, 2nd Ed., McGraw-Hill, New York, NY, 1978.

15. W. D. France, Jr., "Crevice Corrosion of Metals: Localized Corrosion, Cause of Metal Failure," American Society of Testing and Materials, Special Technical Publication No. 516,1972 , pp. 164-200.

16. P. O. Gartland, "A Simple Model of Crevice Corrosion Propagation for Stainless Steels in Sea Water," Corrosion 97, Paper No. 417, National Association of Corrosion Engineers, Houston, TX, 1997, 17 p.

17. J. W. Oldfield, W. H. Sutton, "Crevice Corrosion of Stainless Steels: I. A Mathematical Model," British Corrosion Journal, Vol. 13, No. 1, 1978, pp. 13-22. 
18. Y. Xu, H. W. Pickering, "The Initial Potential and Current Distributions of the Crevice Corrosion Process," J. Electrochemical Society, Vol. 140, No. 3, 1993, pp. 658-668.

19. E. A. Nystrom, J. B. Lee, A. A. Sagues, H. W. Pickering, "An Approach for Estimating Anodic Current Distributions in Crevice Corrosion from Potential Measurements," J. Electrochemical Society, Vol. 141, No. 2, 1994, pp. 358-361.

20. J. S. Newman, Electrochemical Systems, 2nd Ed., Prentice Hall, Englewood Cliffs, NJ, 1991.

21. R. S. Lillard, J. R. Scully, "Modeling of the Factors Contributing to the Initiation and Propagation of the Crevice Corrosion of Alloy 626," J. Electrochemical Society, Vol. 141, No. 11, 1994, pp. 3006-3015.

22. F. A. Cotton, G. Wilkinson, Advanced Inorganic Chemistry, 5th Ed., John Wiley \& Sons, New York, NY, 1988, pp. 679-755.

23. A. J. Bard, L. R. Faulkner, Electrochemical Methods, Fundamentals and Applications, John Wiley \& Sons, New York, NY, 1980, pp. 699-702.

24. I. R. Epstein et al., Journal of the American Chemical Society, Vol. 102, 1980, p. 3751.

25. R. Schlogel, W. Jones, Journal of the Chemical Society, Dalton Transactions, 1984, p. 1283.

26. M. Magini et al., Inorganic Chemistry, Vol. 22, 1983, p. 1001.

27. I. Nagypal et al., J. Chem. Soc. Dalton Trans., 1983, p. 1335.

28. L. Spiccia et al., Inorganic Chemistry; Vol. 26, 1987, p. 474.

29. D. Rai et al., Inorganic Chemistry, Vol. 26, 1987, p. 345.

30. F. Y. Saleh, G. E. Mbamalu, Q. H. Jaradat, C. E. Brungardt, "Ion Chromatography: Photodiode Array UV-Visible Detection of Cr(III) Hydrolytic Polymerization Products in Pure and Natural Waters, Analytical Chemistry, Vol. 68, No. 5, March 1, 1996, pp. 740-745.

31. D. A. Jones, B. E. Wilde, "Galvanic Reactions During Localized Corrosion on Stainless Steel," Corrosion Science, Vol. 18, 1978, pp. 631-643.

32. G. E. Gdowski, "Survey of Degradation Modes of Four Nickel-Chromium-Molybdenum Alloys," Lawrence Livermore National Laboratory, University of California, UCRL-ID108330, March 1991, $67 \mathrm{p}$. 
Lawrence Livermore National Laboratory, University of California

Yucca Mountain Project - EBS Inner Barrier Corrosion Modeling - Farmer - July 1997

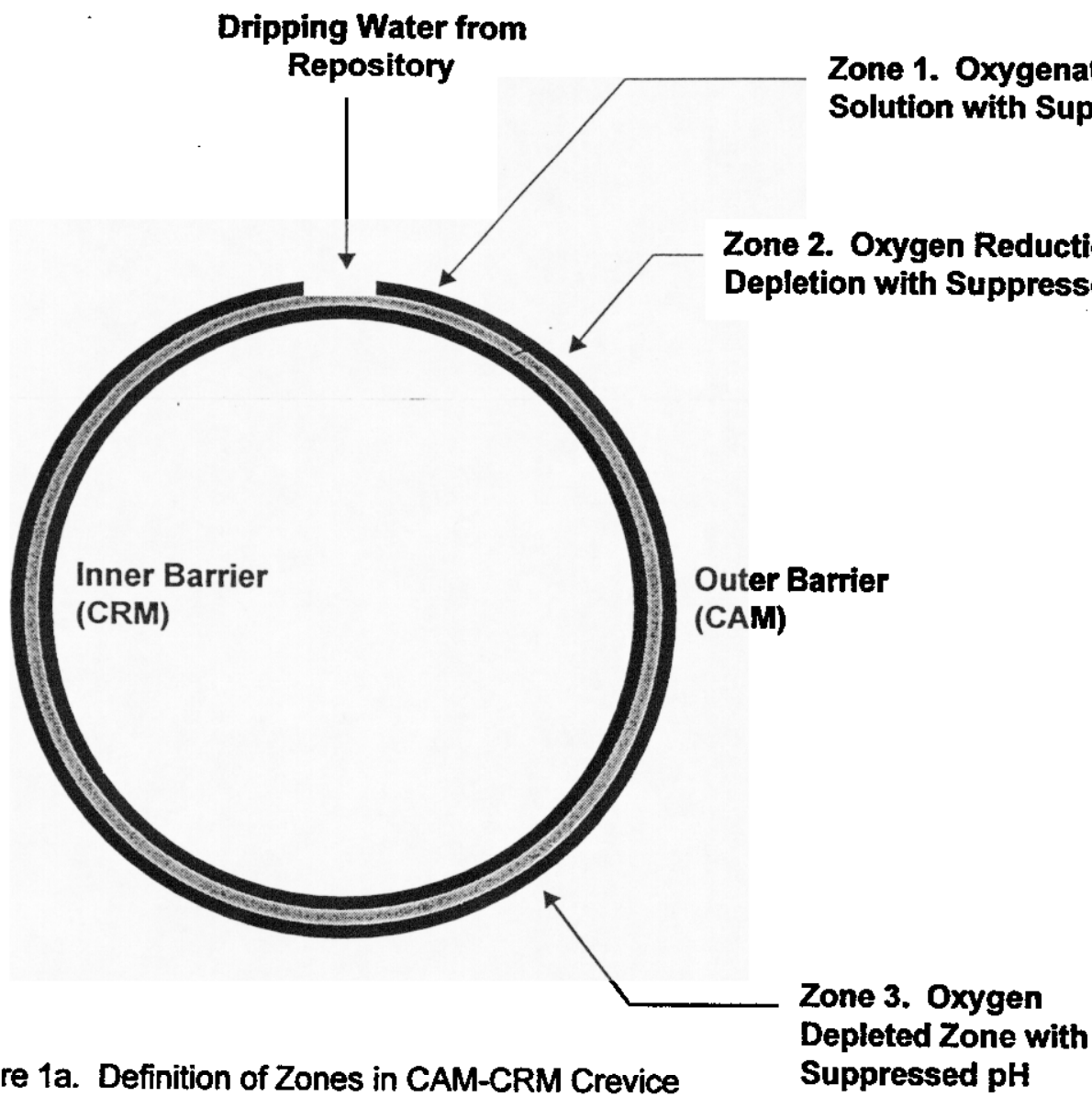

Figure 1a. Definition of Zones in CAM-CRM Crevice

Suppressed pH
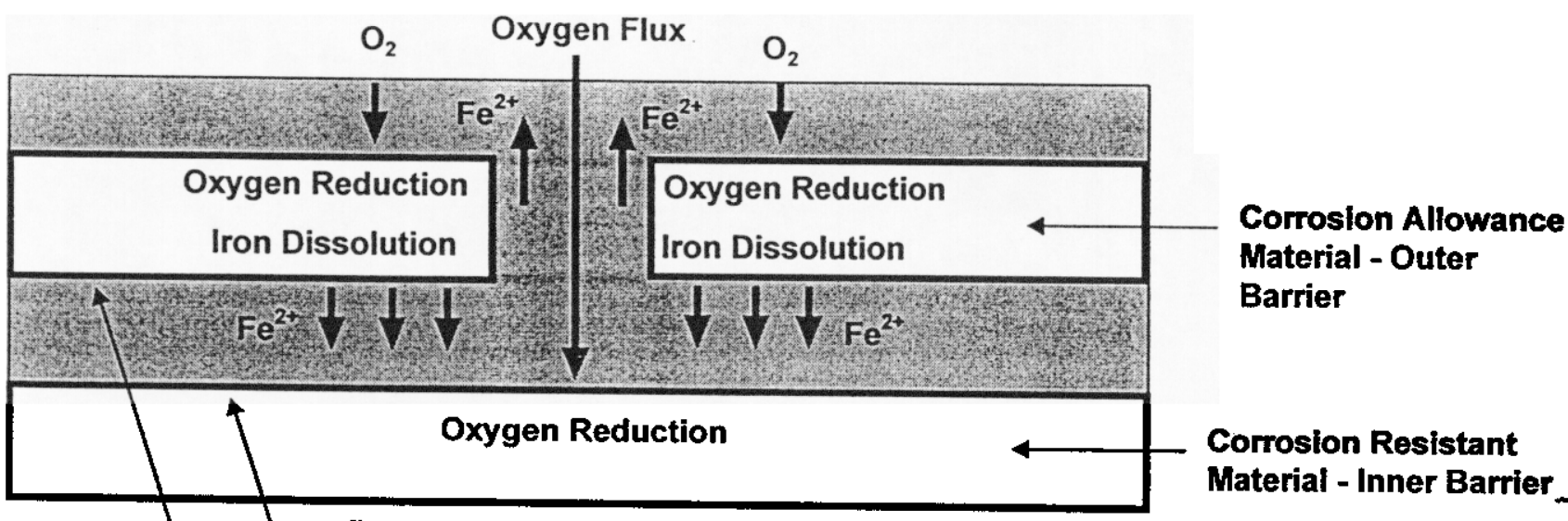

Passive

CRM Wall

Dissolution of Active CAM Wall

Figure 1b. Definition of Phase 1 in Zone 2 


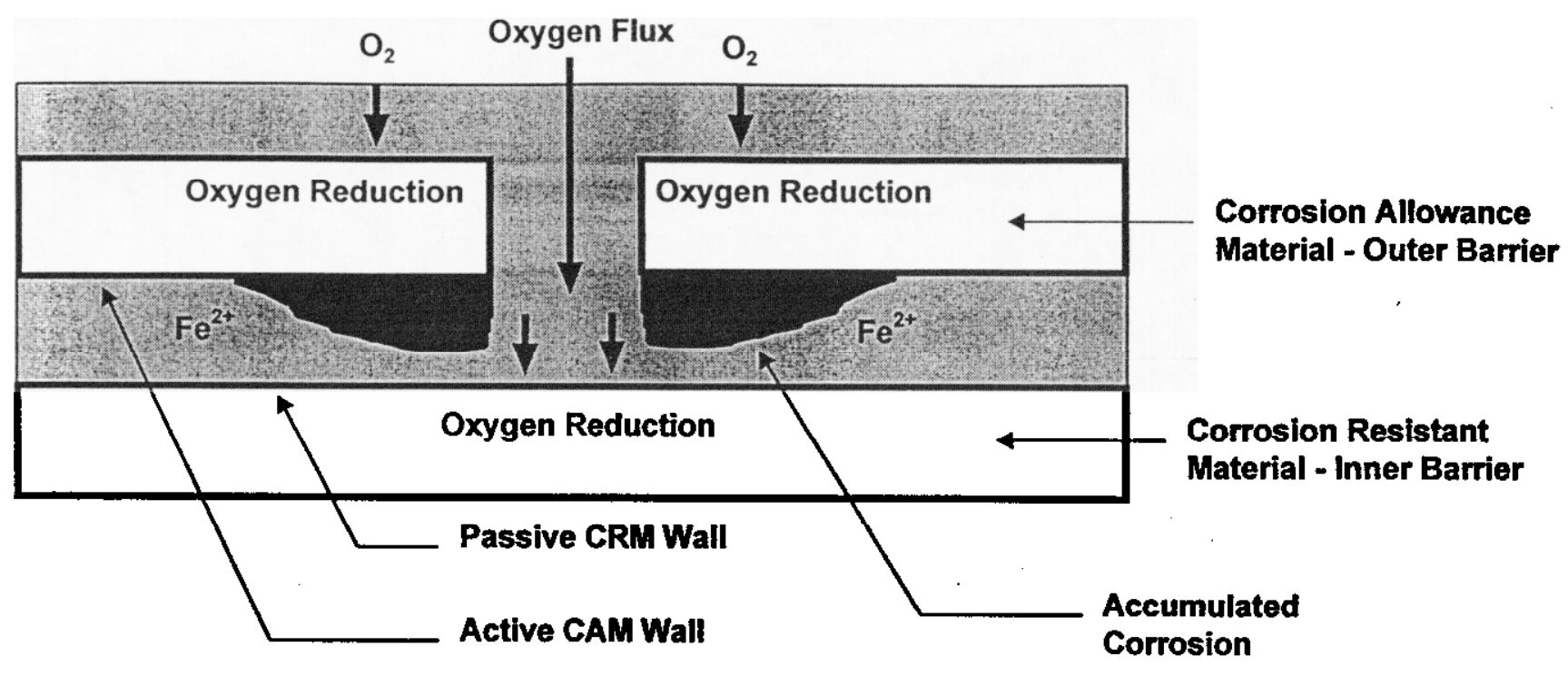

Figure 1c. Definition of Phase 2 in Zone 2

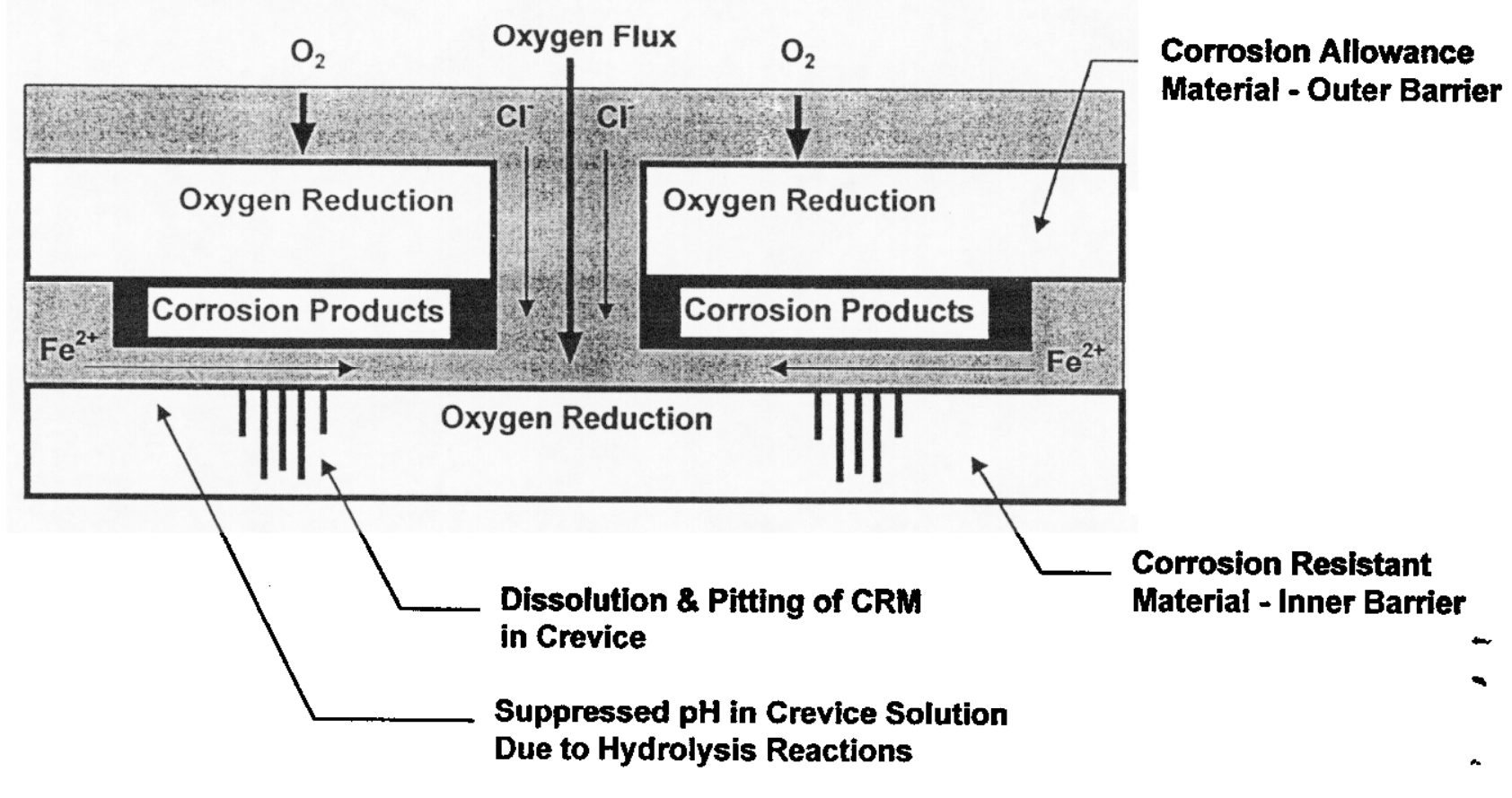

Figure 1d. Definition of Phase 3 in Zone 2 


\section{Probabilistic Pitting Model - Transients}

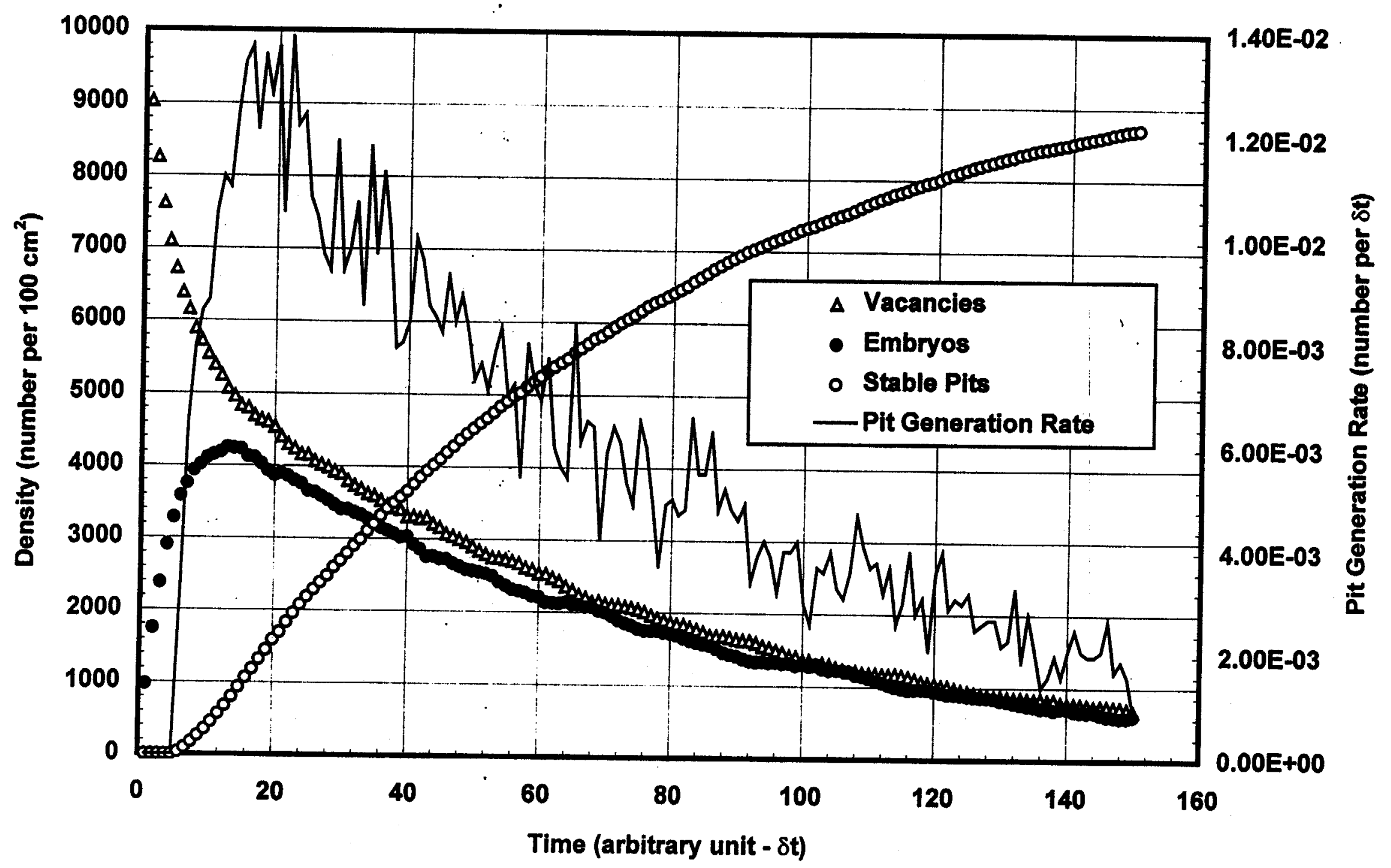

. Figure 2. PIT999I.FOR - Default Values 


\section{Probabilistic Pitting Model - Distribution of Pit Depths}

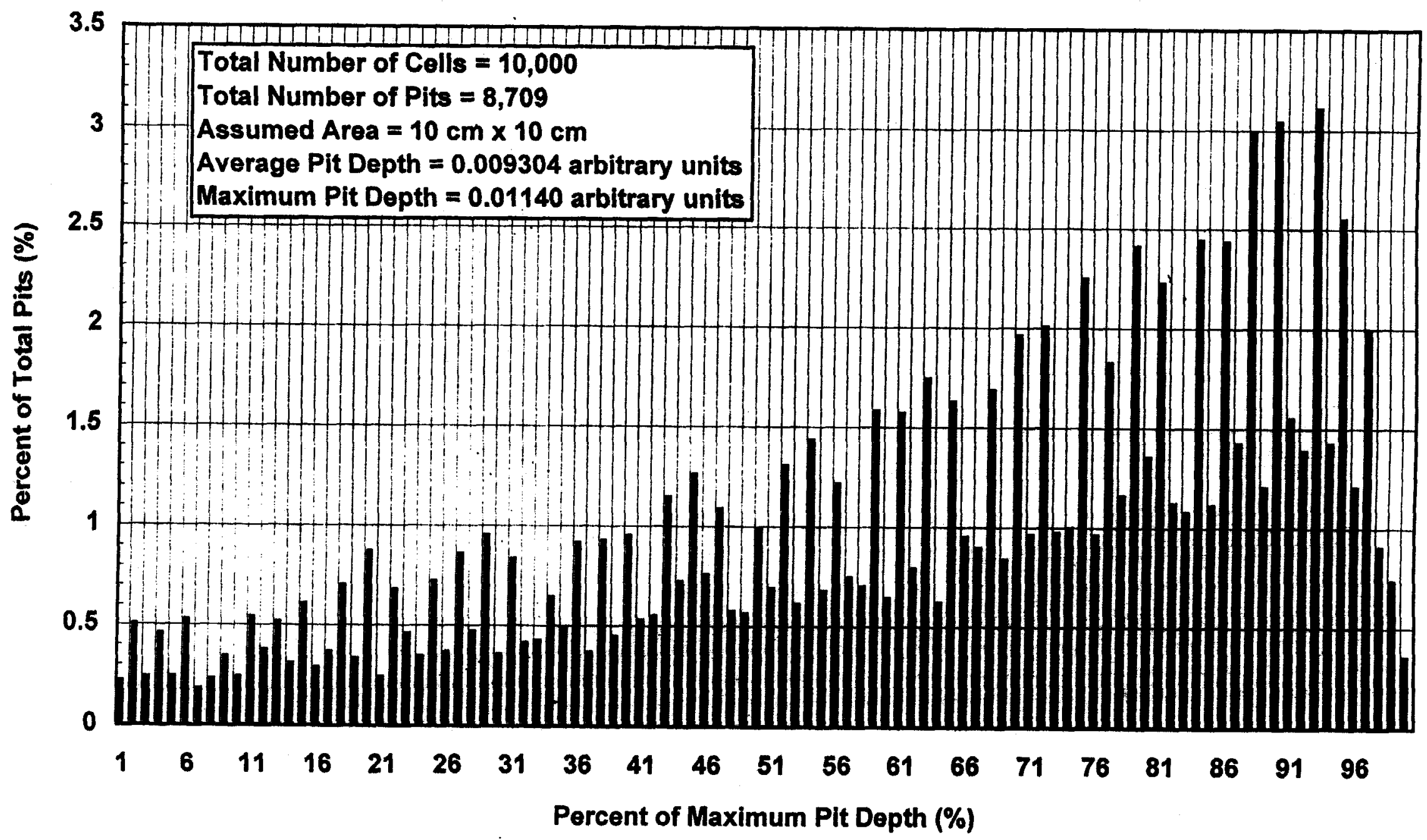

Figure 3. PIT999I.FOR - Default Values 


\section{Deterministic Pitting Model - Transients}

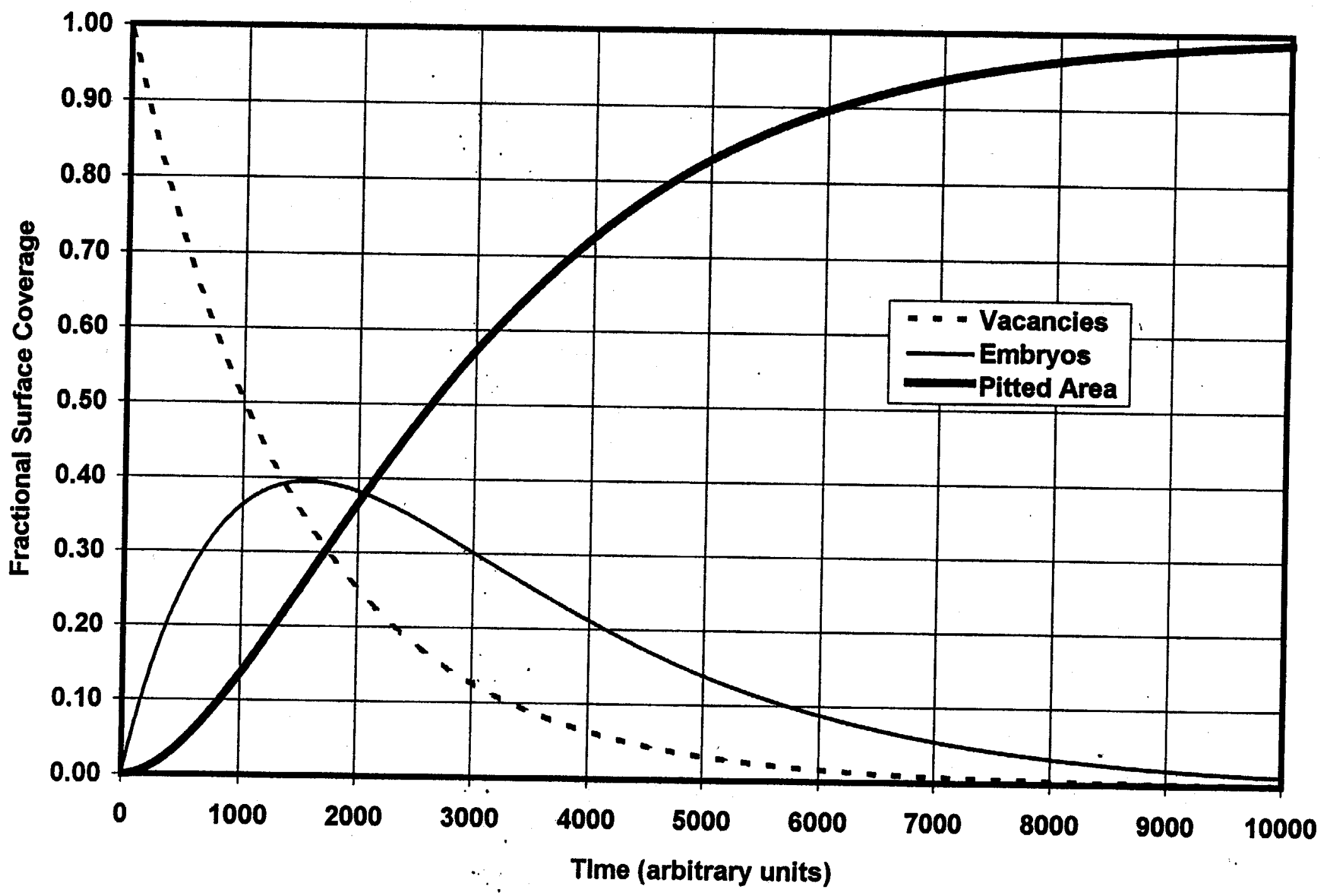

Figure 4. RK-PIT-B.FOR - Alternative Approaches 


\section{Deterministic Pitting Model - Distribution of Pit Depths}

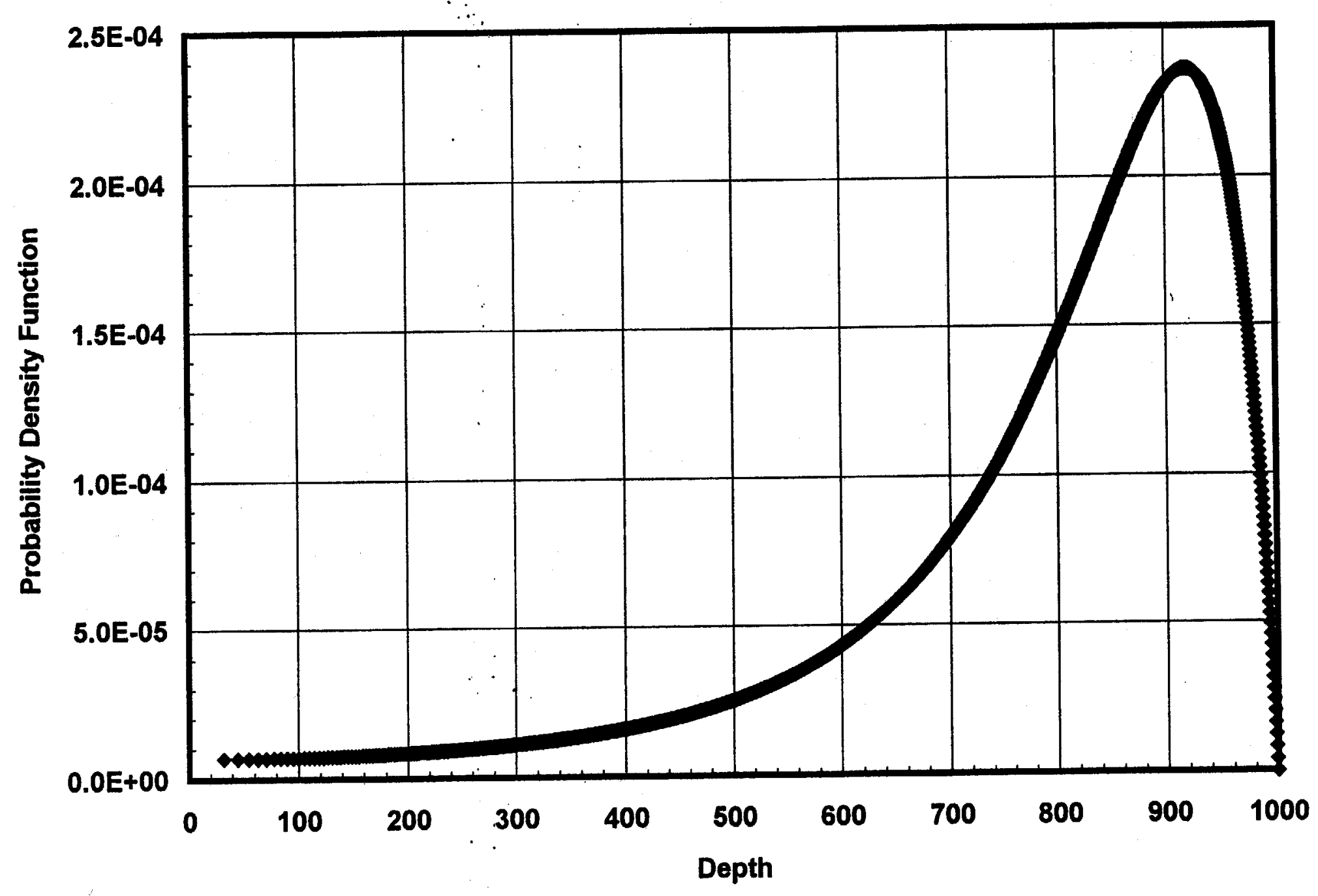

Figure 5. RK-PIT-B.FOR - Alternative Approaches 


\section{Deterministic Pitting Model - Quasi Steady State Solution}

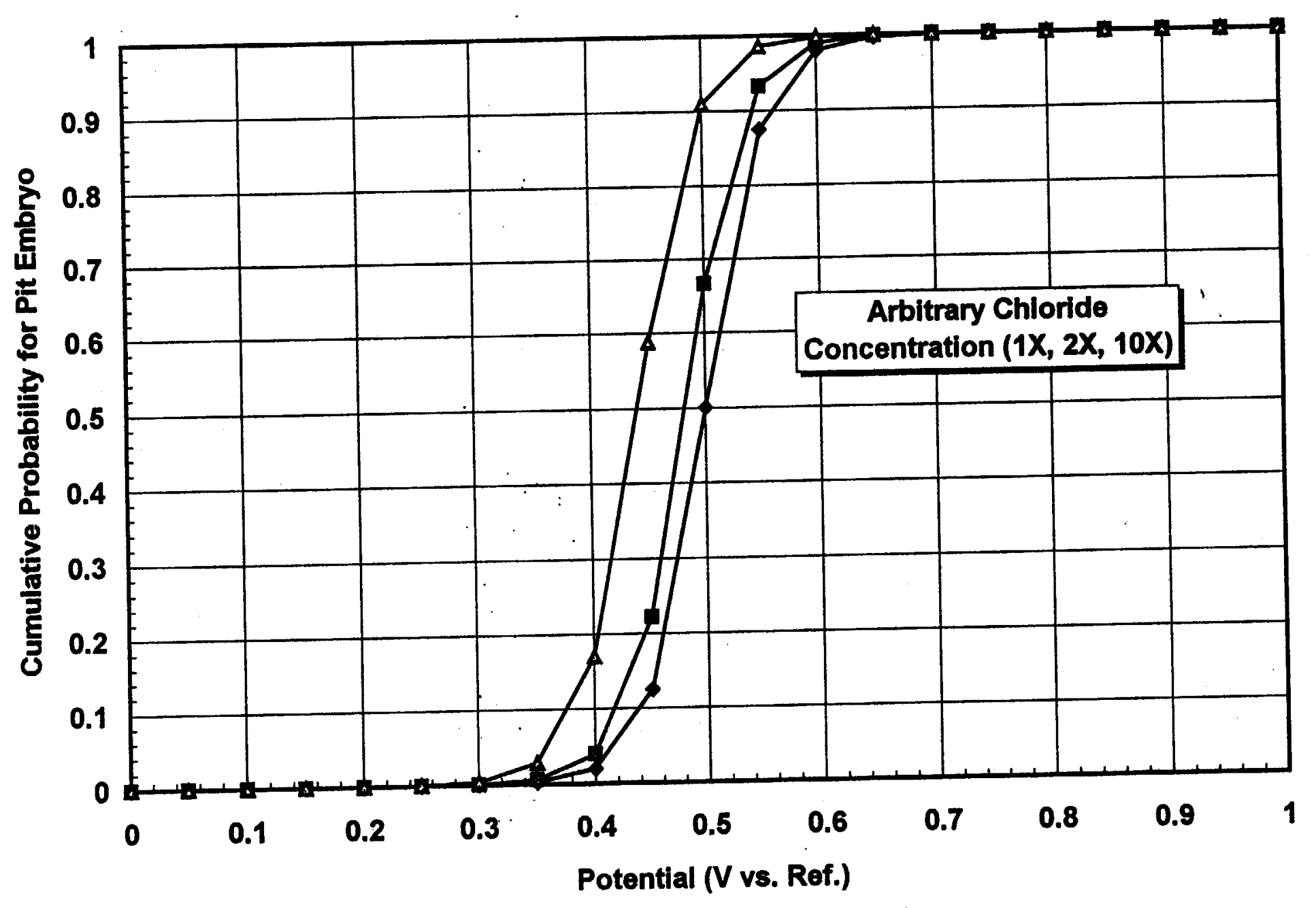




\section{Effect of Hydrolysis on Crevice Solution Chemistry}

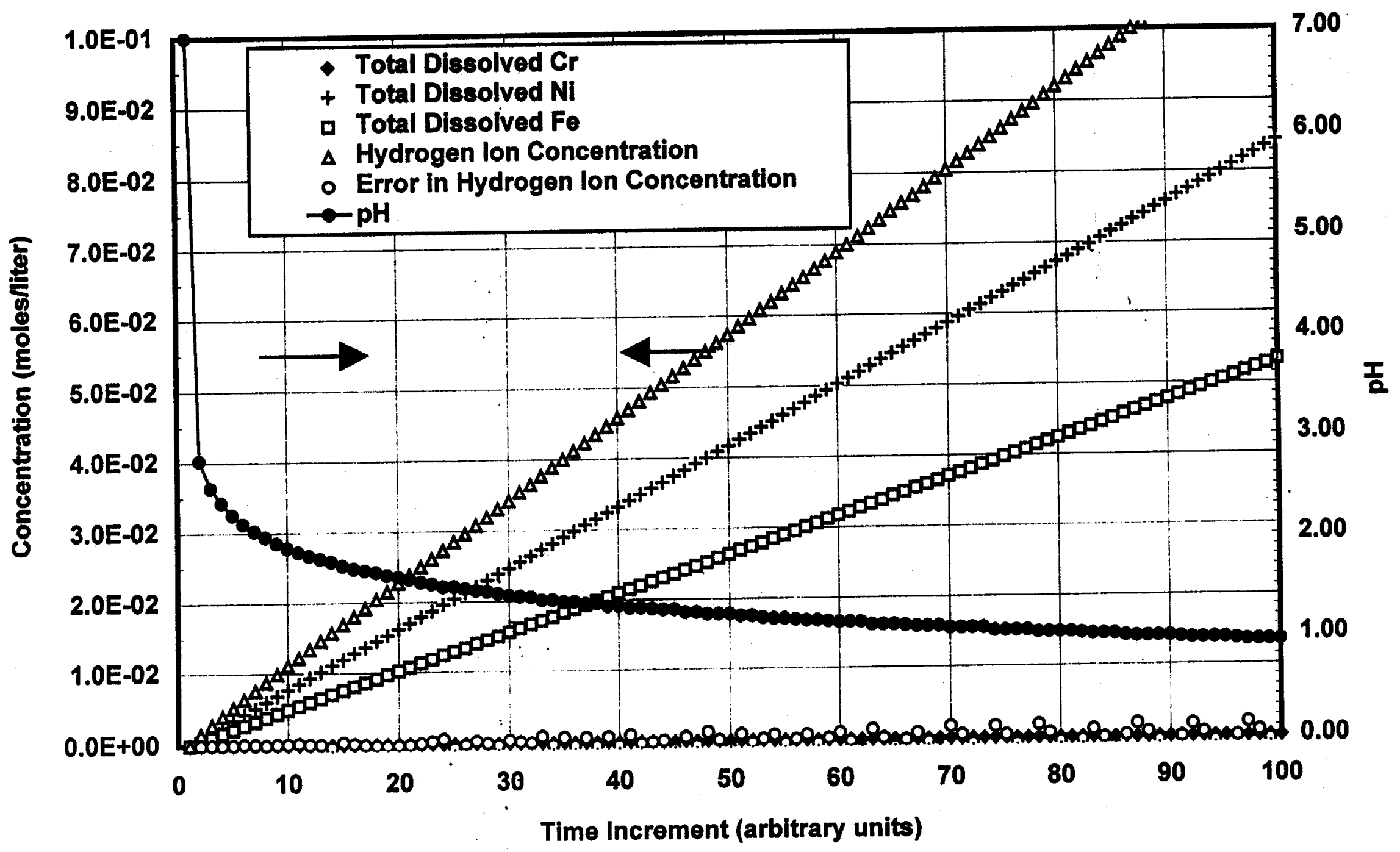

Figure 7. PH-07A.FOR - Assumed Dissolution of Alloy 825 


\section{Effect of Hydrolysis on Crevice Solution Chemistry}

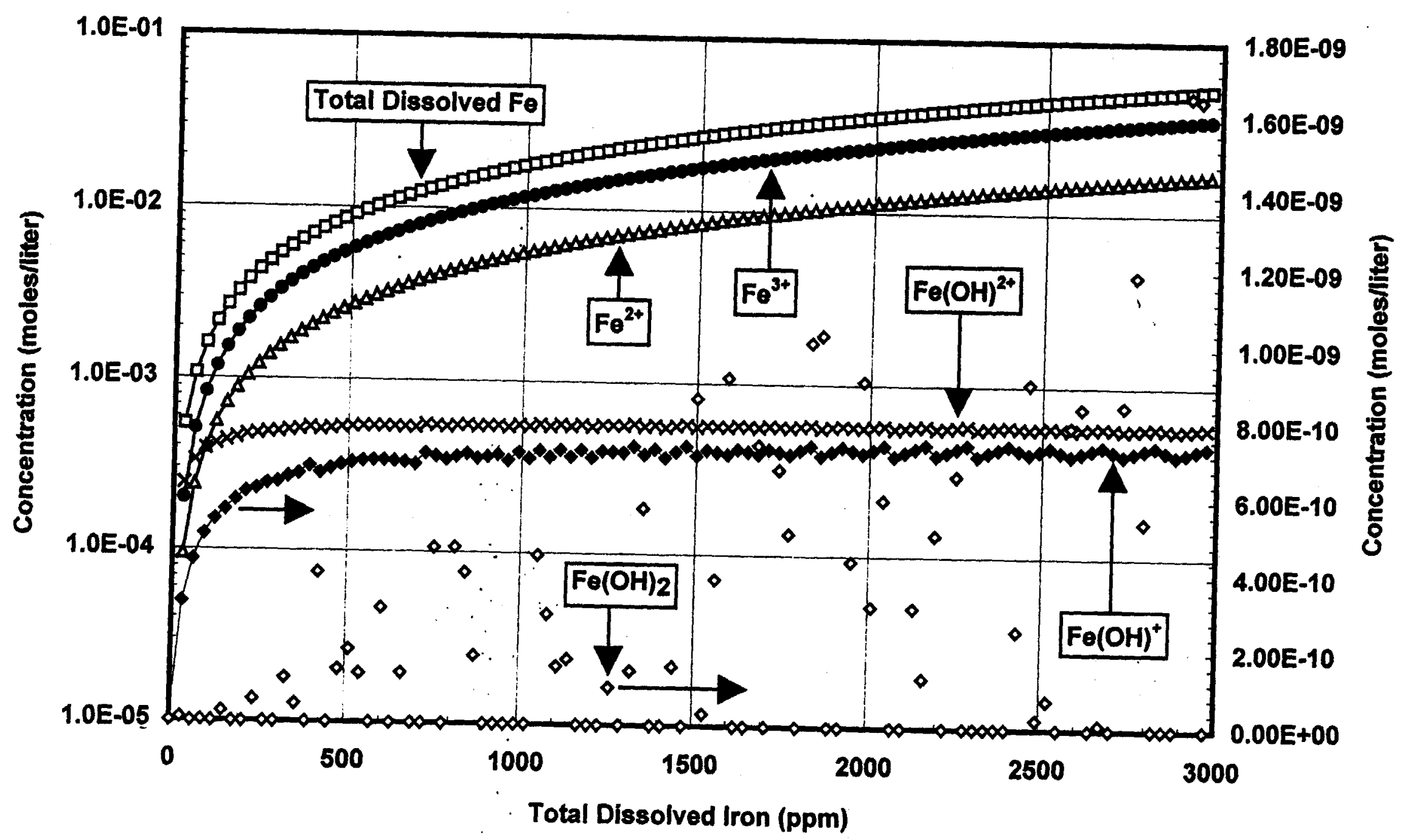

Figure 8. PH-07A.FOR - Assumed Dissolution of Alloy 825 


\section{Effect of Hydrolysis on Crevice Solution Chemistry}

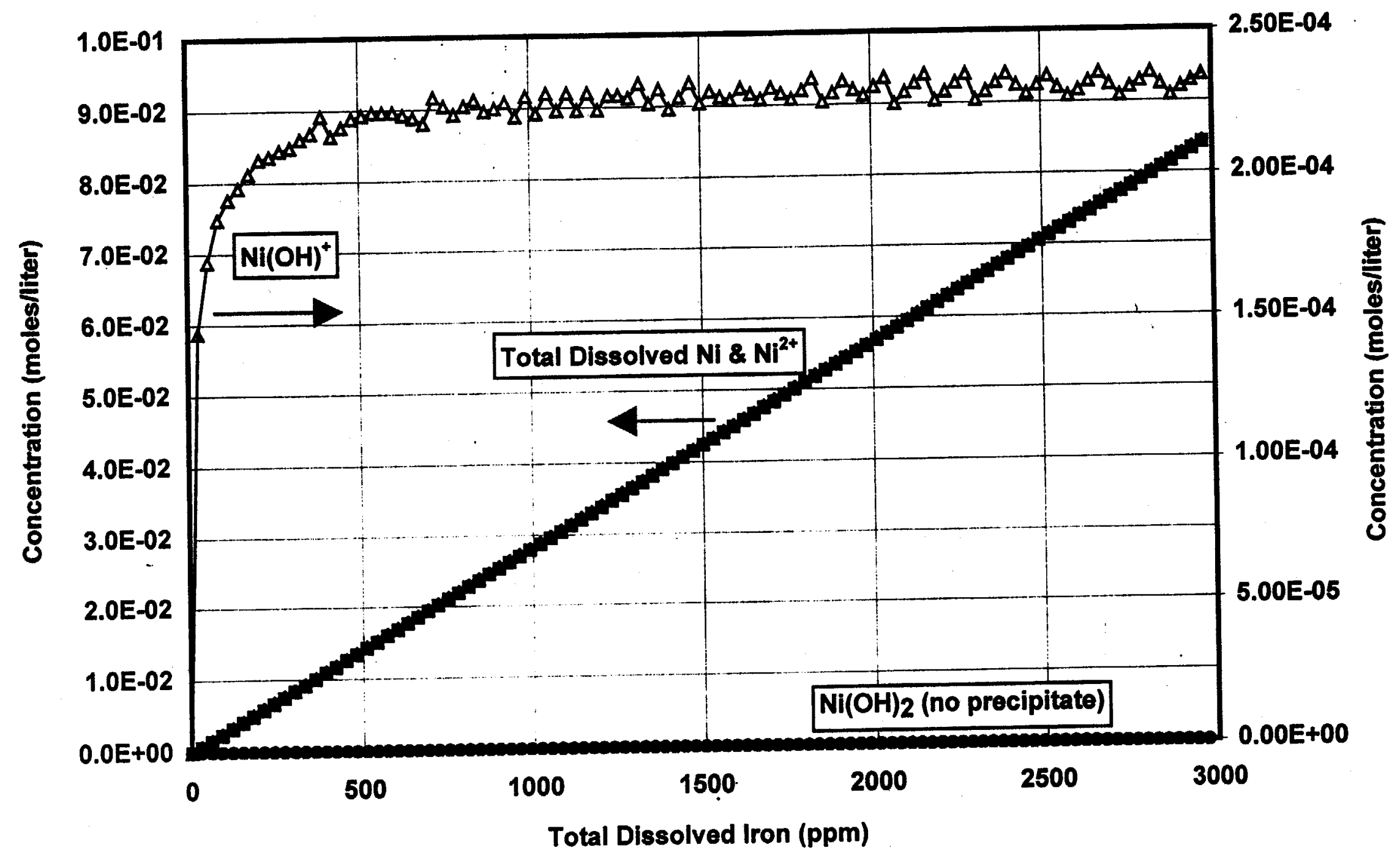

Figure 9. PH-07A.FOR - Assumed Dissolution of Alloy 825 


\section{Effect of Hydrolysis on Crevice Solution Chemistry}

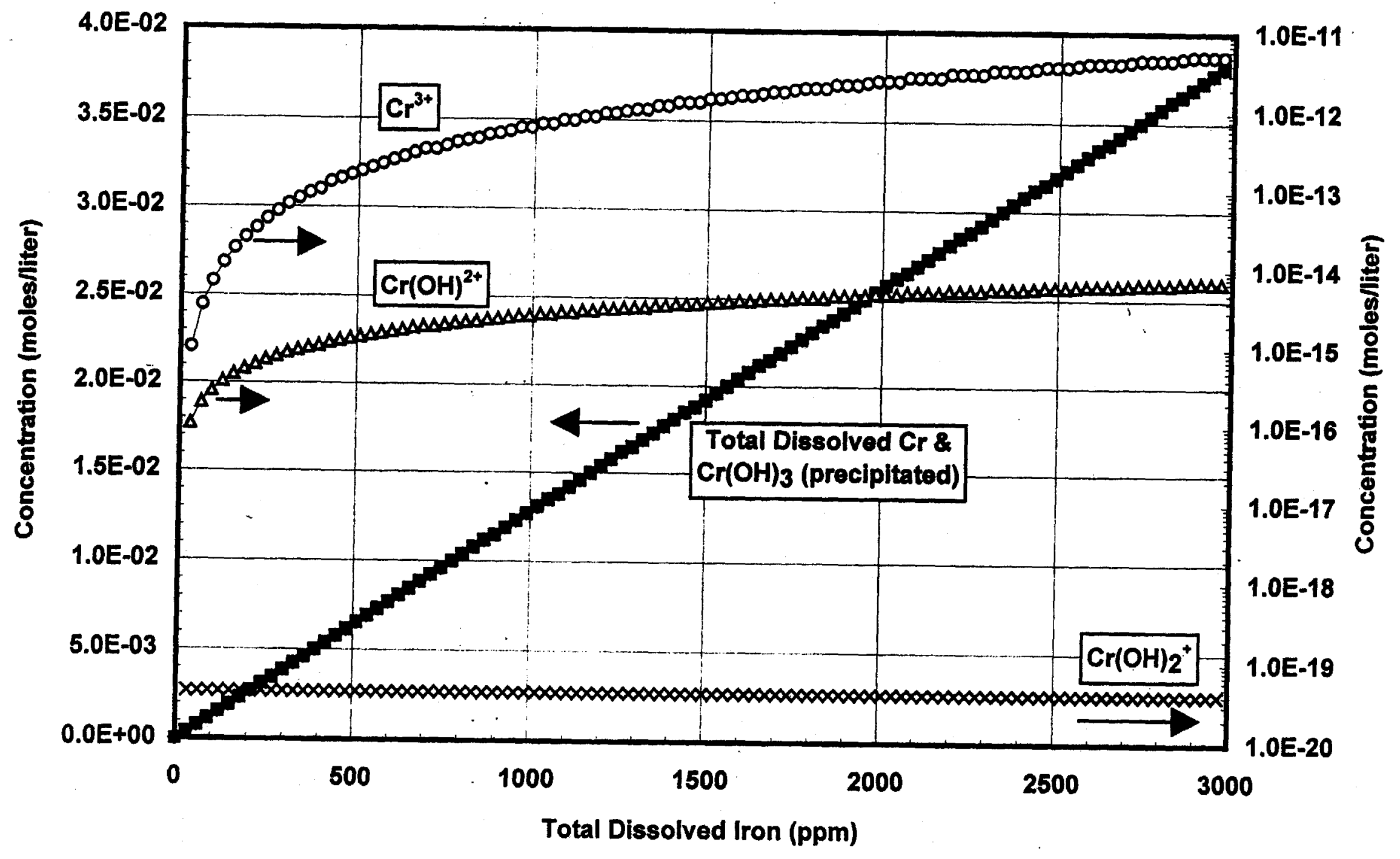

Figure 10. PH-07A.FOR - Assumed Dissolution of Alloy 825 


\section{Effect of Hydrolysis on pH of Metal Chloride Solutions}

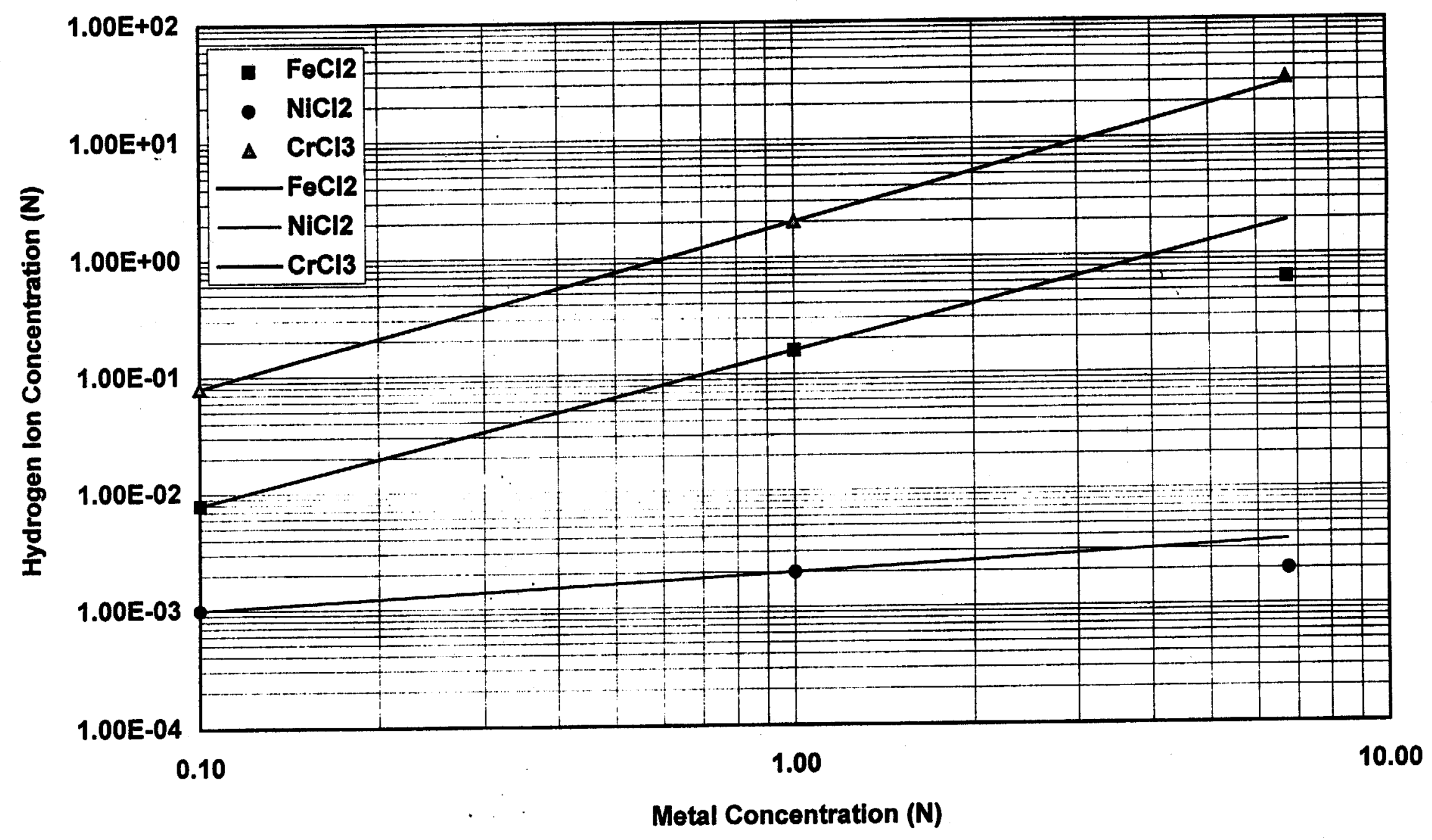

Figure 11. Experimental pH Suppression Data 


\section{Modified Stochastic Probability Theory of Pitting}

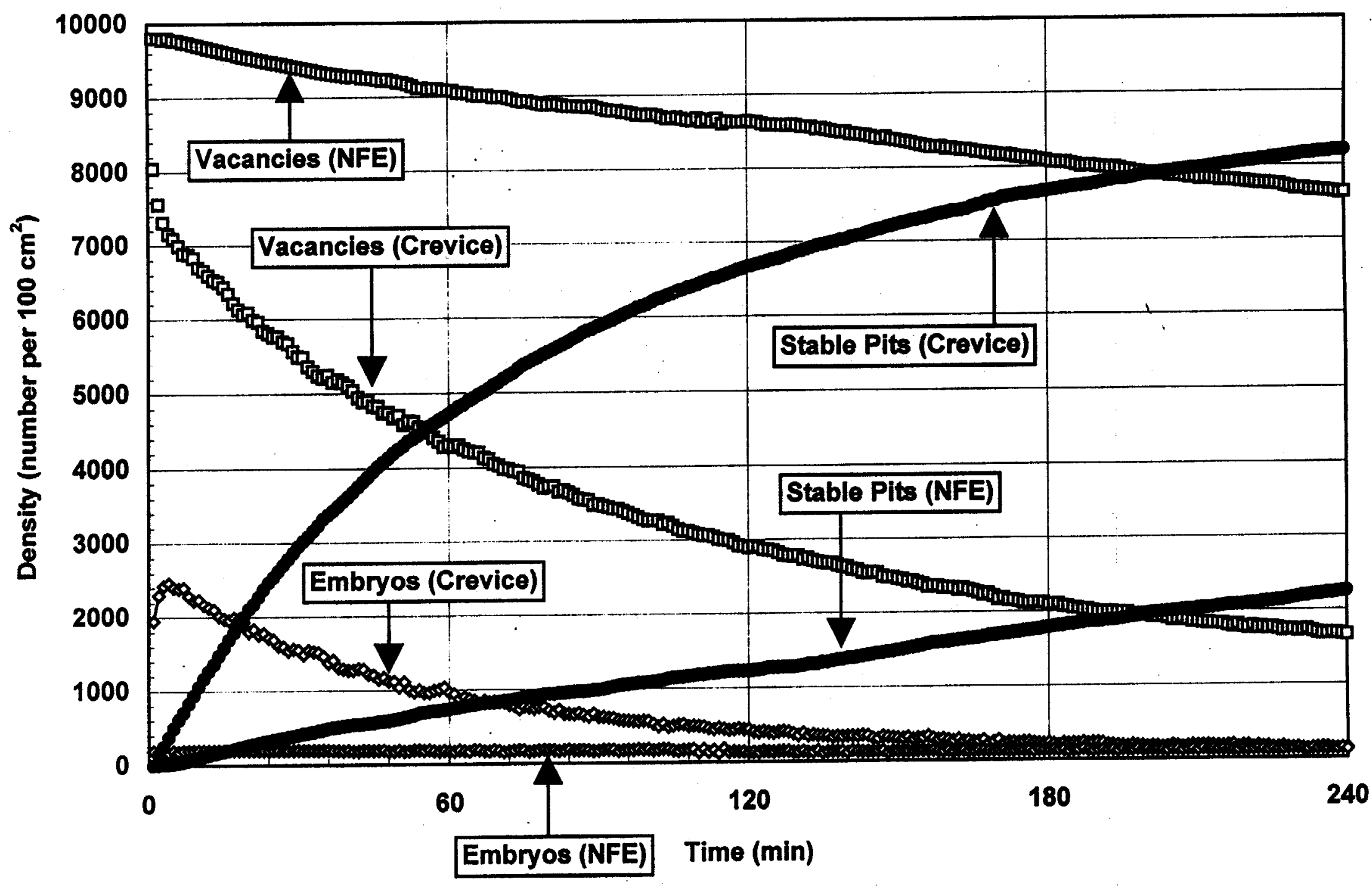

Figure 12. PIT999P.FOR - Effect of pH Suppression in Crevice on Pitting 


\section{Modified Stochastic Probability Theory of Pitting}

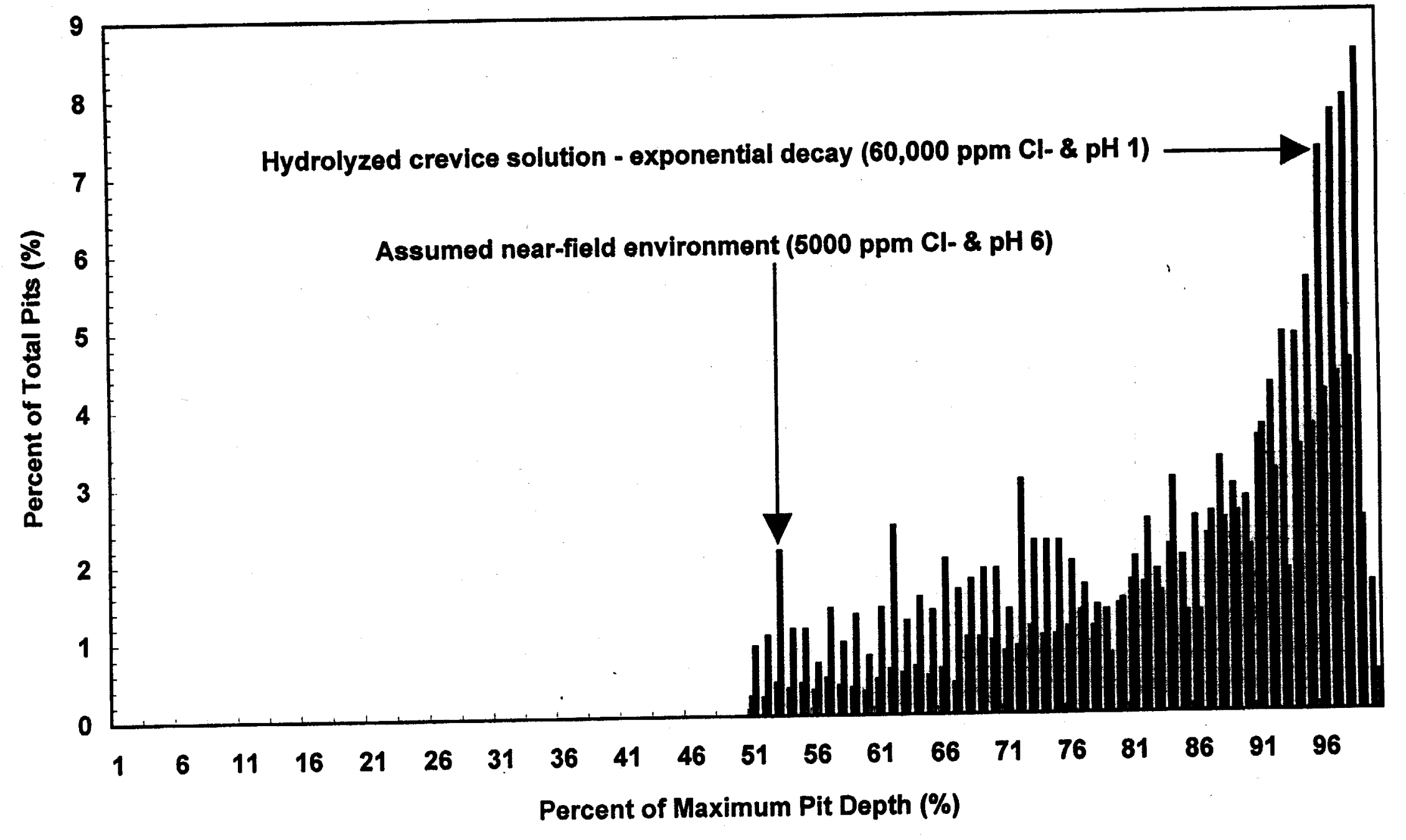

Figure 13. P.IT999P.FOR - Effect of pH Suppression in Crevice on Pitting 


\section{Application of Heterogeneous Kinetics to Pitting: Effects of Chloride \& pH}

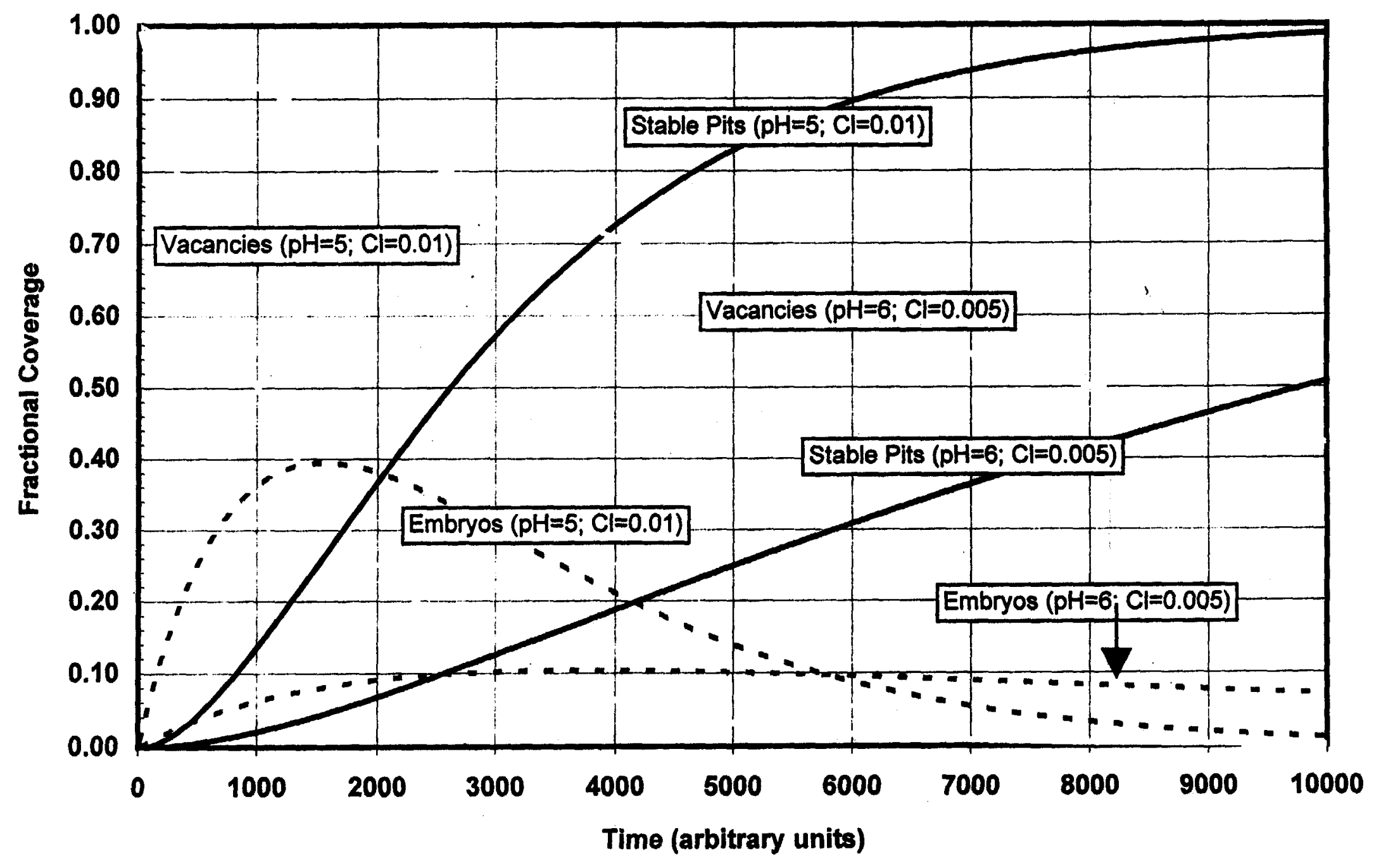

Figure 14. RK-PIT-C.FOR - Default Values of Adjustable Parameters 


\section{Application of Heterogeneous Kinetics to Pitting: Effects of Chloride \& pH}

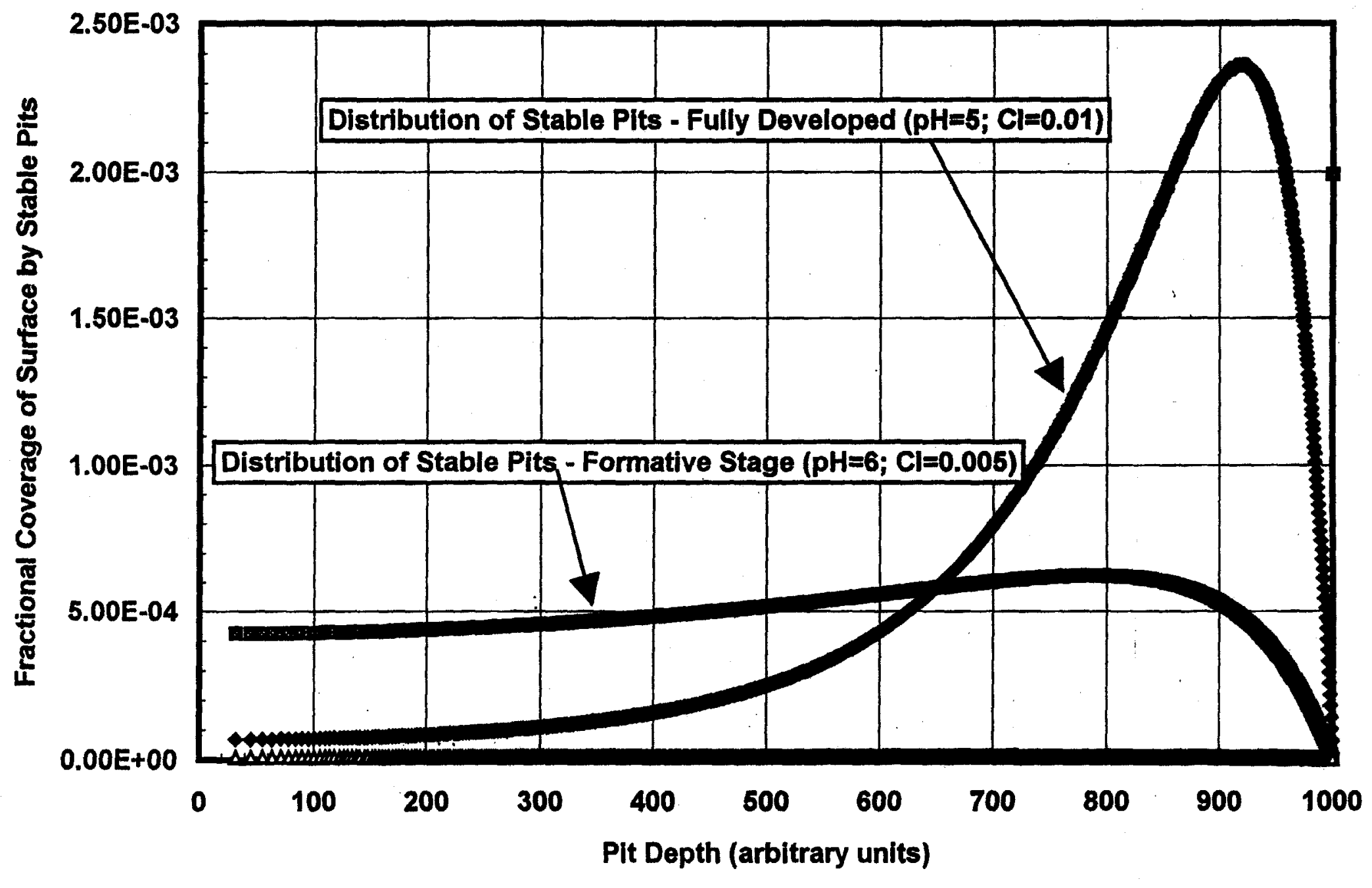

Figure 15. RK-PIT-C.FOR - Default Values of Adjustable Parameters 


\section{Modified Stochastic Probability Theory of Pitting}

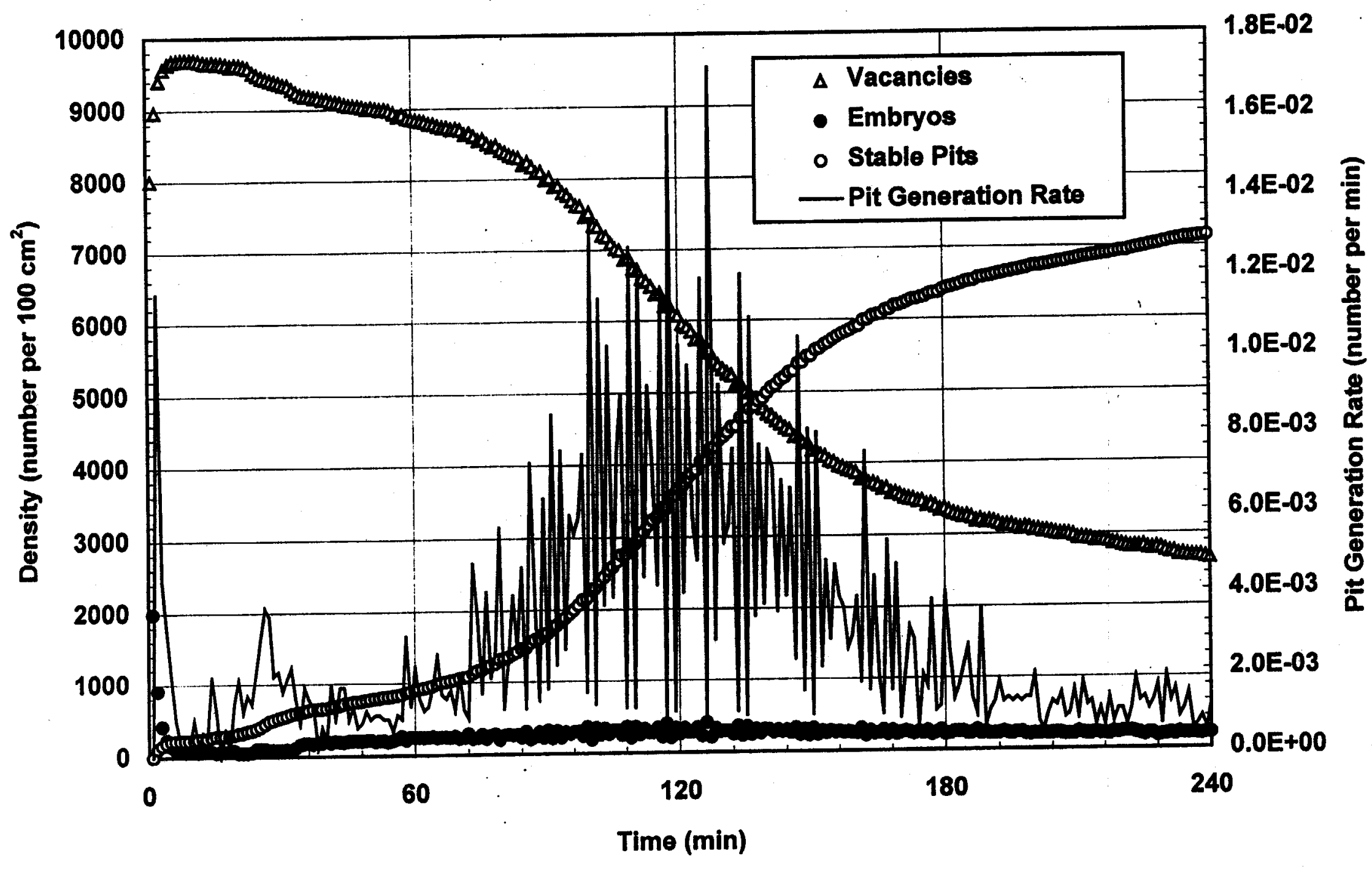

Figure 16. PIT999K.FOR - Default Values 


\section{Modified Stochastic Probability Theory of Pitting}

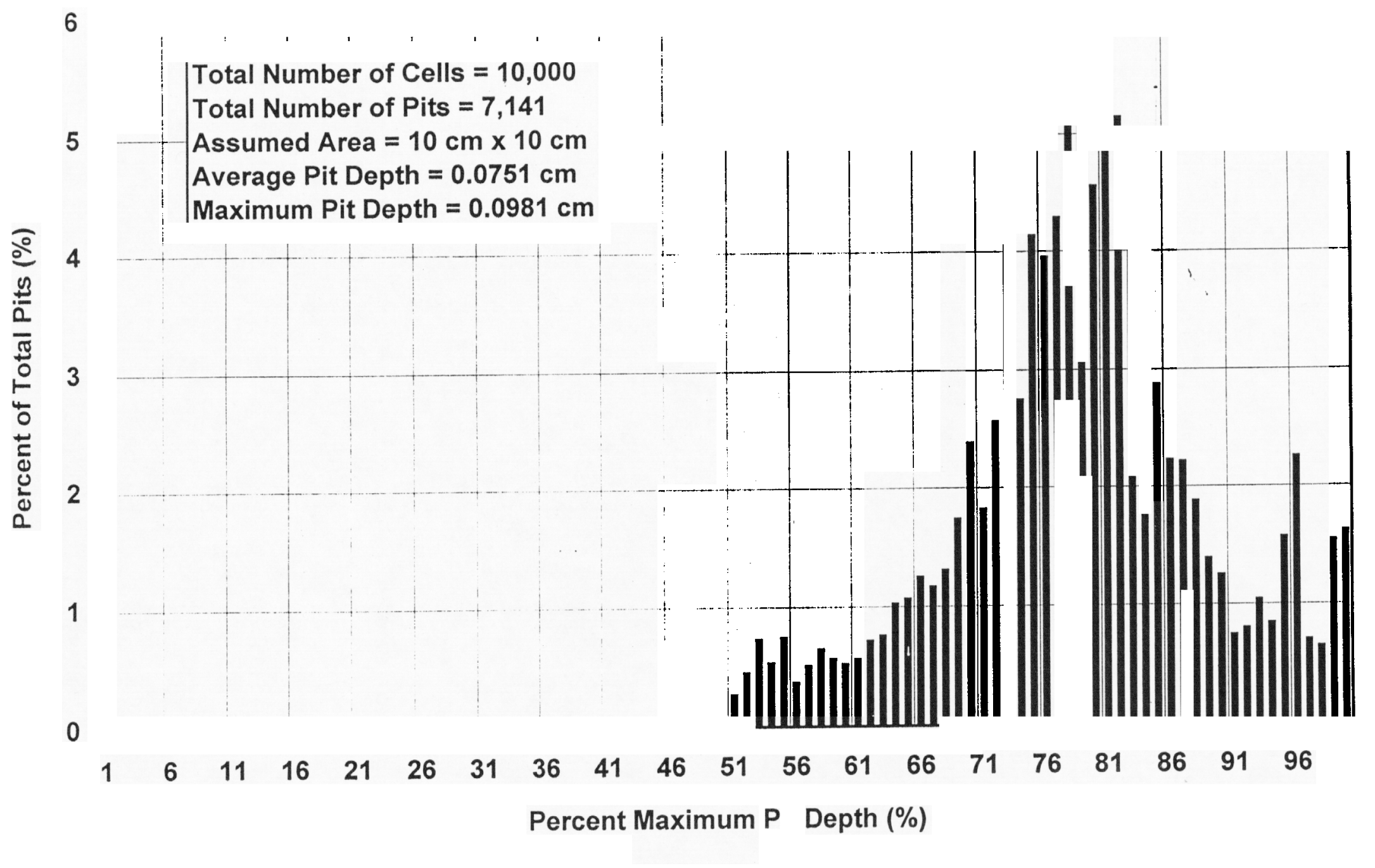

Figure 17. PIT999K.FOR - Default Values 


\section{Modified Stochastic Probability Theory of Pitting}

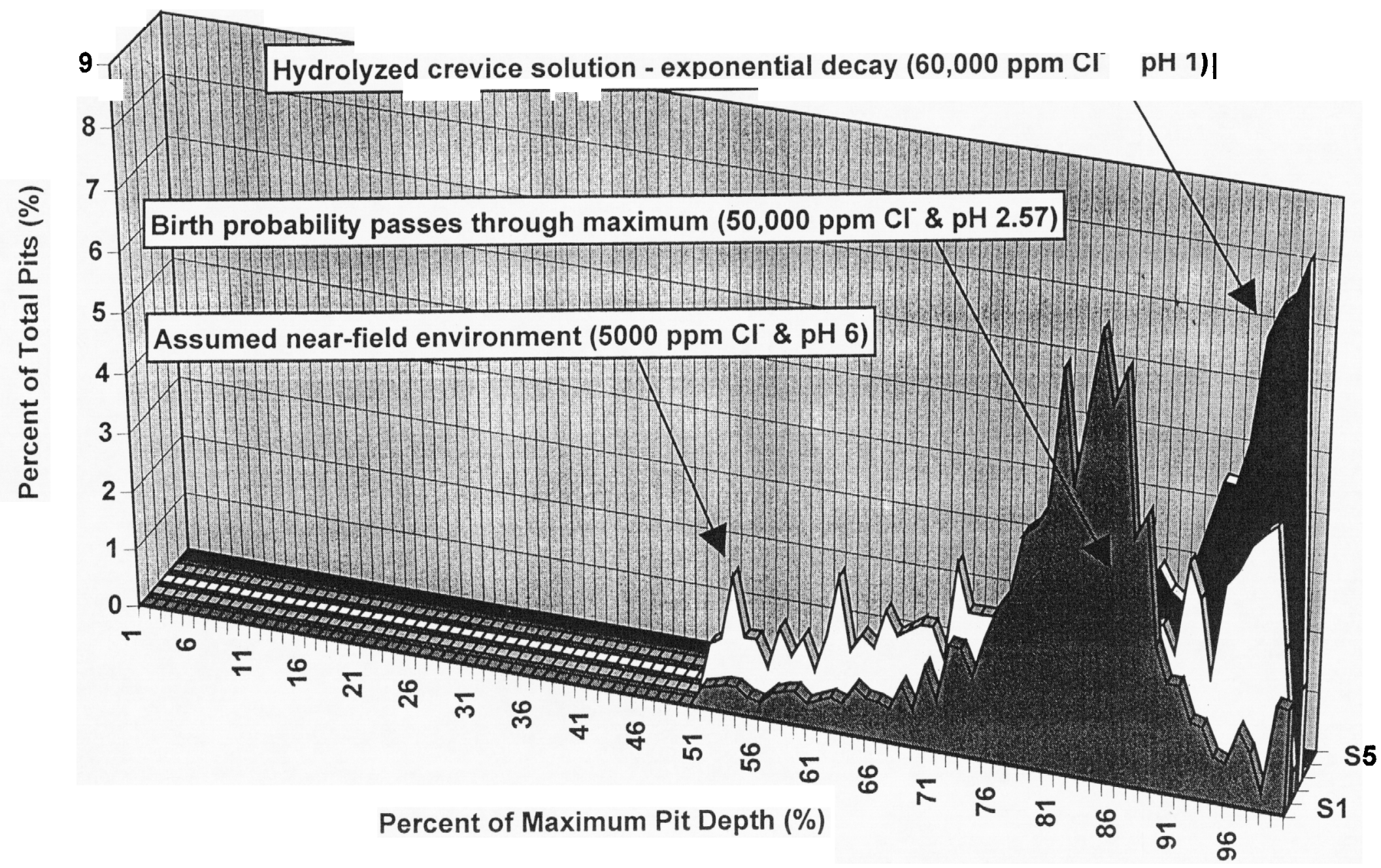




\section{Extrapolation $\left(t^{1 / 2}\right)$ of Penetration Rates Observed with Alloy 625 and C-276}

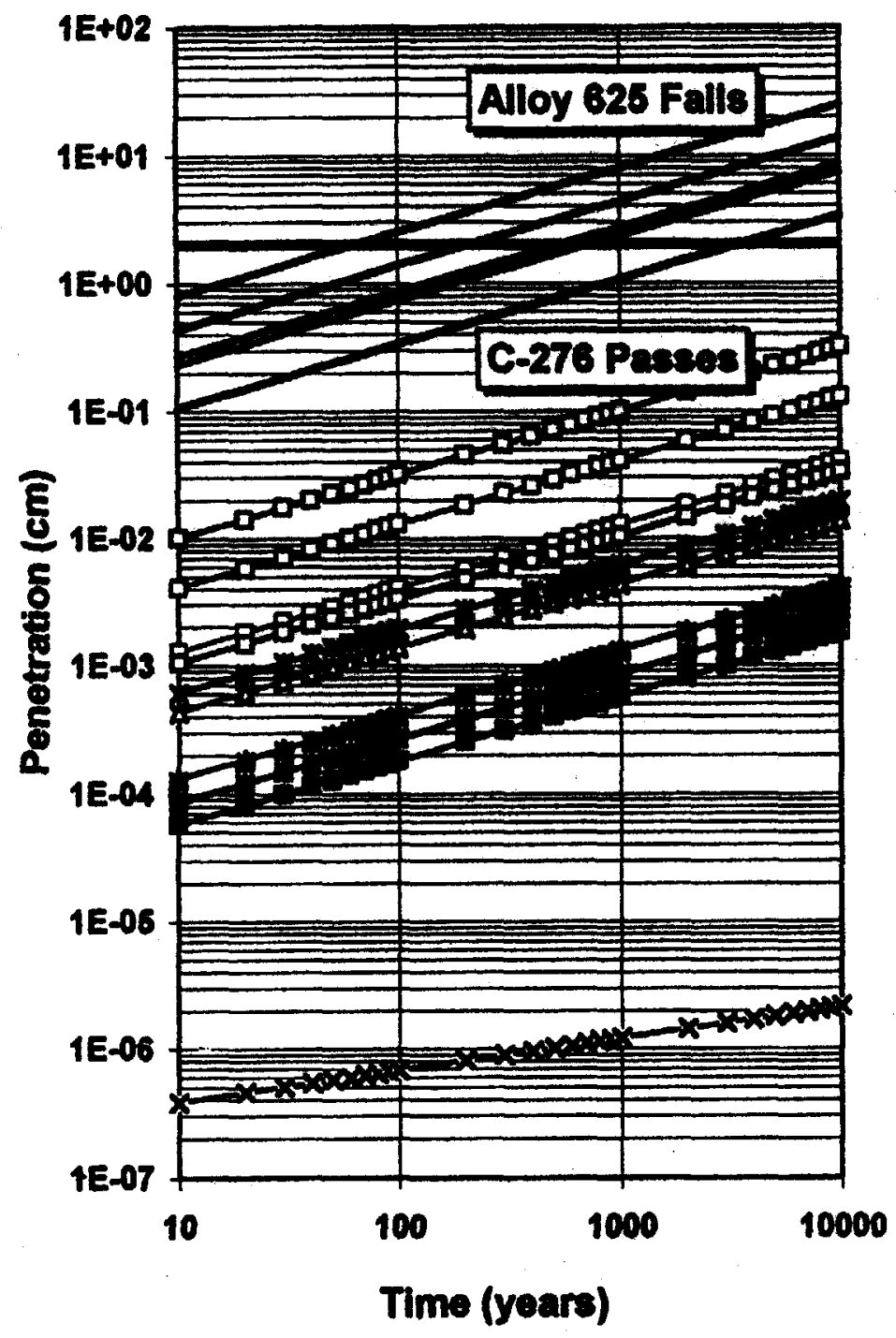

Uniling Valuo Inner Bentor Whall

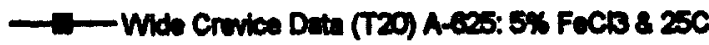

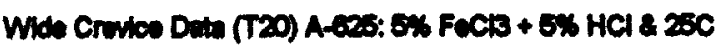

$x$ Wha Crovico Data (T20) A-625: S\% Facis a b0C

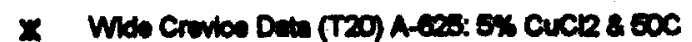

$\rightarrow$ Who Crevion Ditu (T20) A-625: 5\% NaOCl a 50C

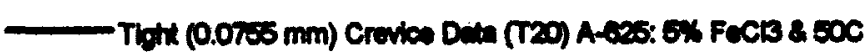

- O-Grooved Block Crevice Data (T22) A-625: 10\% FoC1B \& 25C

- Grooud Block Crovica Date (T22) A-025: 10\% FeC13 \& 50C

- Grooved Block Crowles Ditu (T22) A-e25: 10\% FoC18 8 75C

D Grooved Block Crovicos Dats (T22) C-27\%: 10\% Focts \& 250

- Grooved Block Crevice Deta (T22) C-27\%: 10\% Fec13 \& 50C

$x$ Grooud Block Crevioe Dewa (T22) C-270: 10\% FuCB \& TOC

$x$ General Corrodion (T23) A-625: 7\% H28O4 + 3\% HCl + 1\% FOCB + 1\% CUCR \& 25C

-Putting Attack (T23) A-e25: 7\% H28O4 + 3\% HCI + 1\% FACB + 1\% CuCR \& $102 \mathrm{C}$

+ Generel Corrosion (T23) C-276: 7\% H2SO4 + 3\% HCl + 1\% FoCl3 + 1\% CuCL \& 25C

- G- General Corrotion (T23) C-278: $7 \%$ H2SO4 + 3\% HCl + 1\% FACB + 1\% CuCL \& $102 \mathrm{C}$ - See Water - Crovice (T30) A-625: $0.01 \mathrm{mb} 8 \mathrm{BW}$ \& $25 \mathrm{C}$

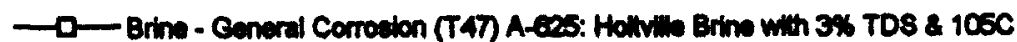

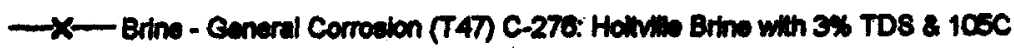

$\rightarrow$ - General, Crevice \& Priting Atteok (TEO) A-625: Brime A with 306,000 ppon TOS \& 250C -

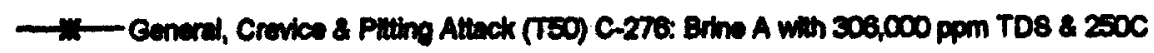
- Goneral, Crovice \& Pluing Altack (T5O) C-270: SW \& 2500

Flgure 19. Data Taken from UCRL-ID-108330 


\section{Extrapolation $\left(t^{1.0}\right)$ of Penetration Rates Observed with Alloy 625 and C-276}

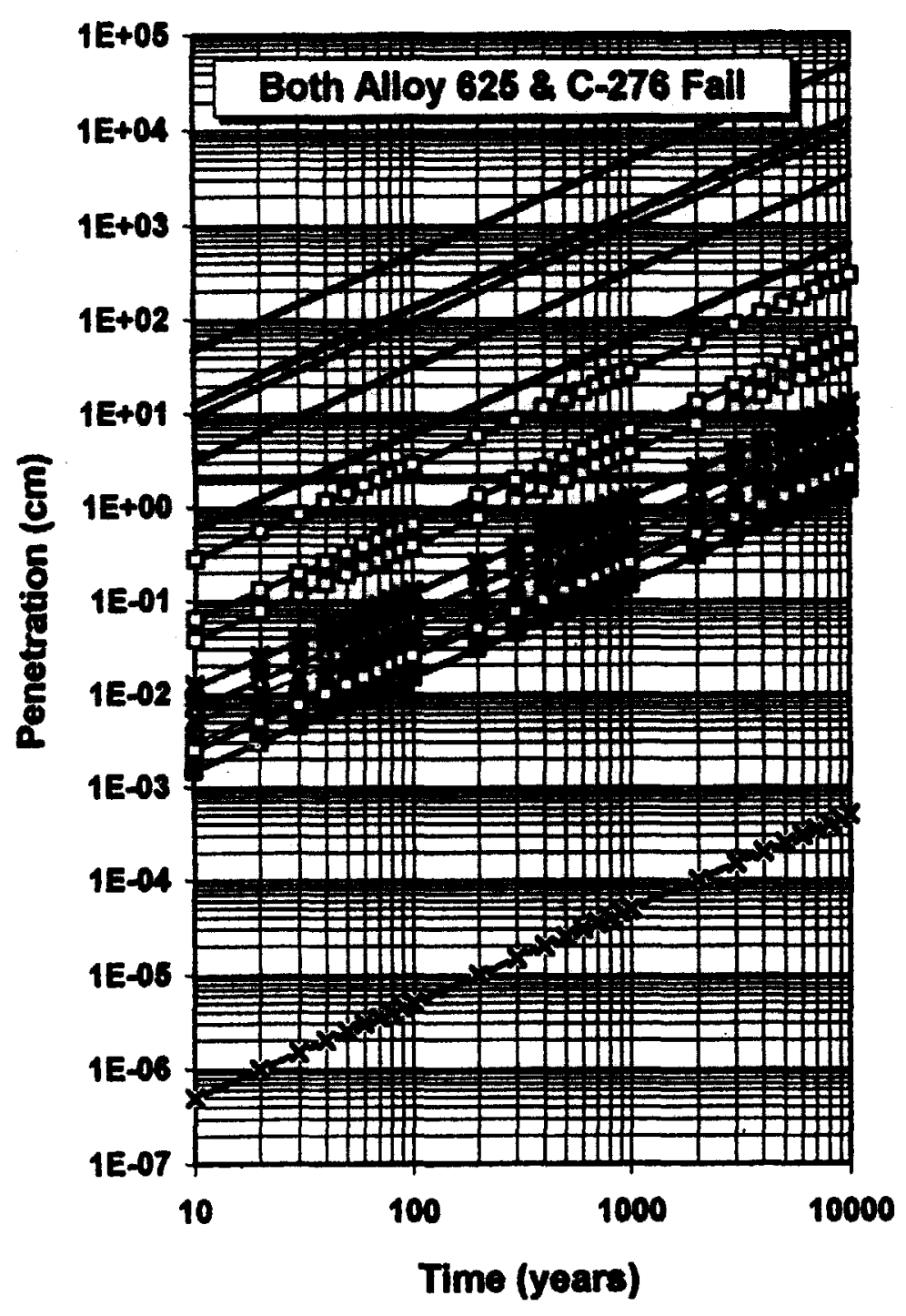

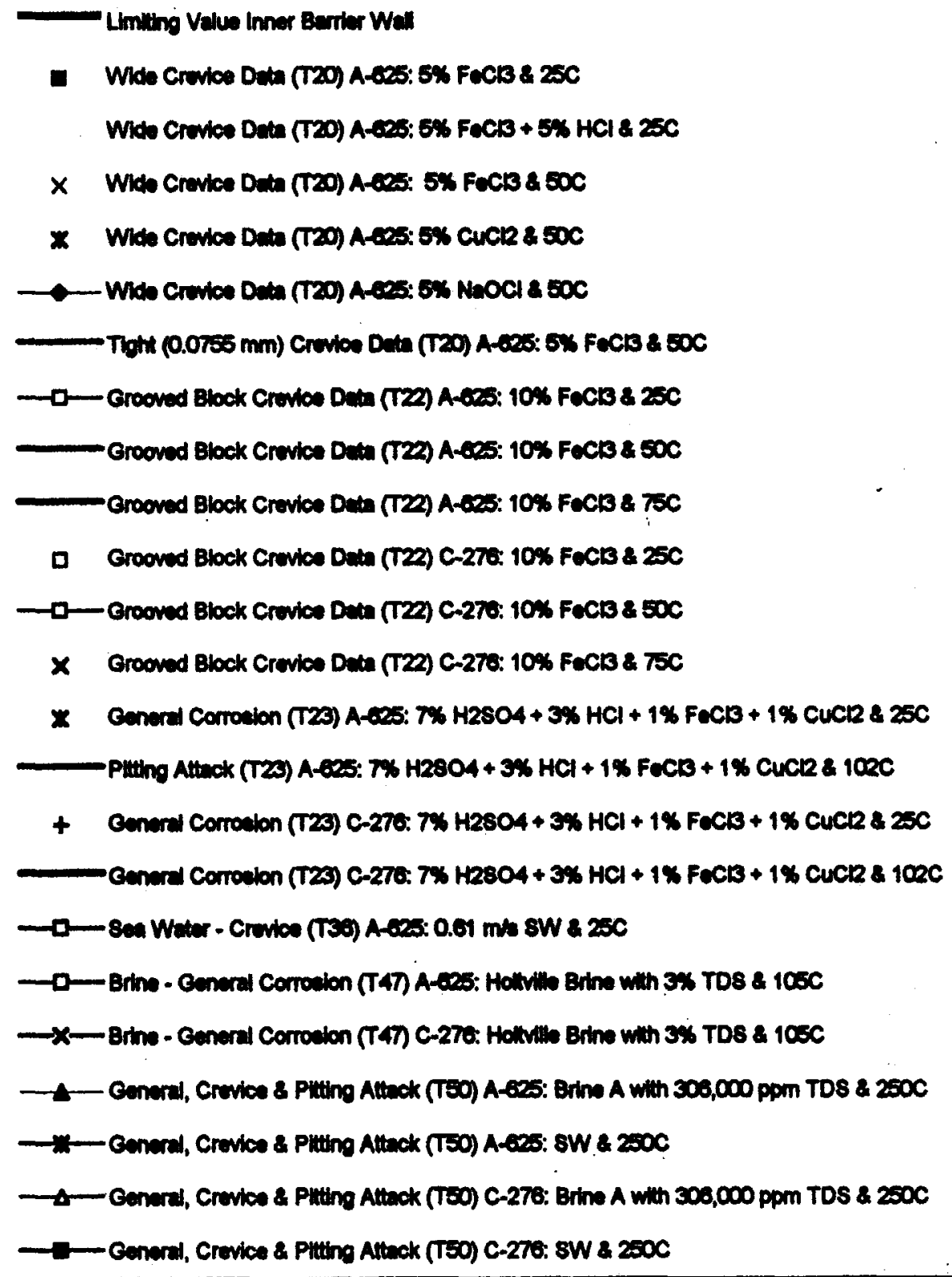

Figure 20. Data Taken from UCRL-1D-108330 


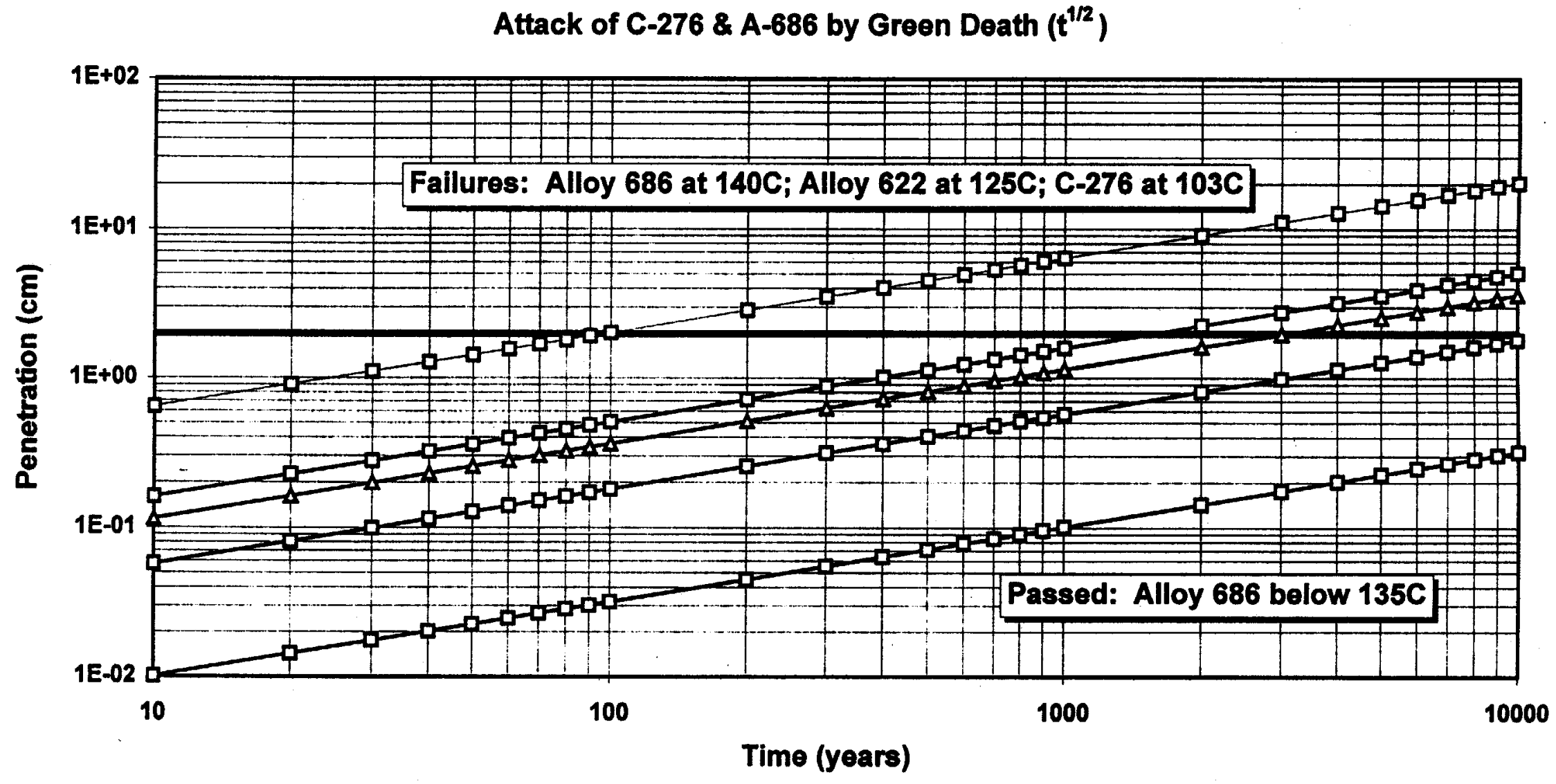

Limiting Value Inner Barrier Wall

$\rightarrow$ General Corrosion (LLNL T23) C-276: $7 \% \mathrm{H} 2 \mathrm{SO} 4+3 \% \mathrm{HCl}+1 \% \mathrm{FeCl} 3+1 \% \mathrm{CuCl} 2$ \& $102 \mathrm{C}$

$\triangle$ Crevice Corrosion Data (INCO T14) C-276: Green Death (11.9\% H2SO4 + 1.3\% HCl + 1\% FeCl3 + 1\% CuCl2) \& $103 \mathrm{C}$

- - --- Crevice Corrosion Data (INCO T14) A-622: Green Death \& 125C

* Crevice Corrosion Data (INCO T14) A-686: Green Death \& 125C

$\rightarrow-C r e v i c e$ Corrosion Data (INCO T14) A-686: Green Death \& 135C

$\rightarrow-C r e v i c e$ Corrosion Data (INCO T14) A-686: Green Death \& 140C

Figure 21. Data from INCO International 


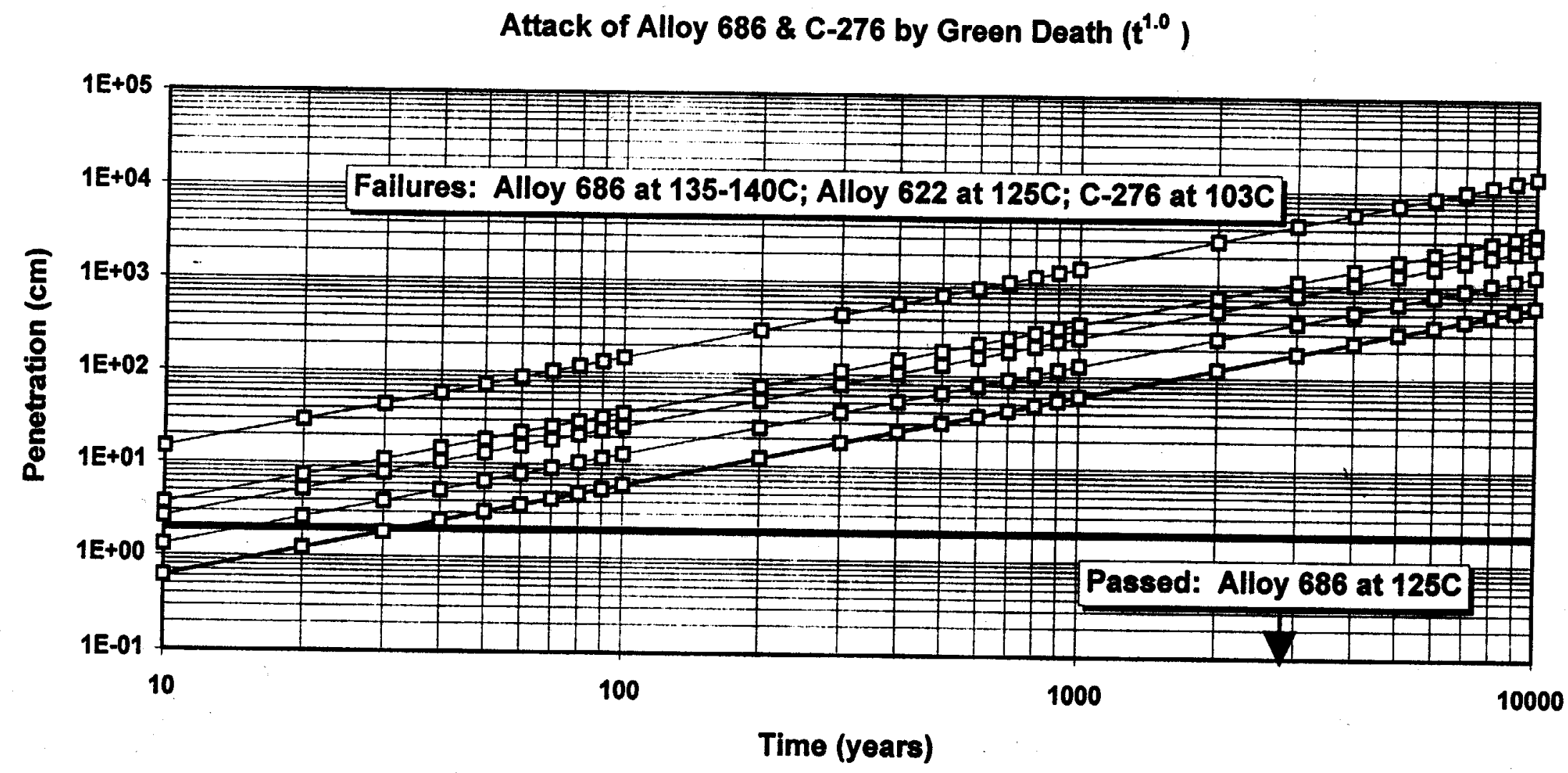

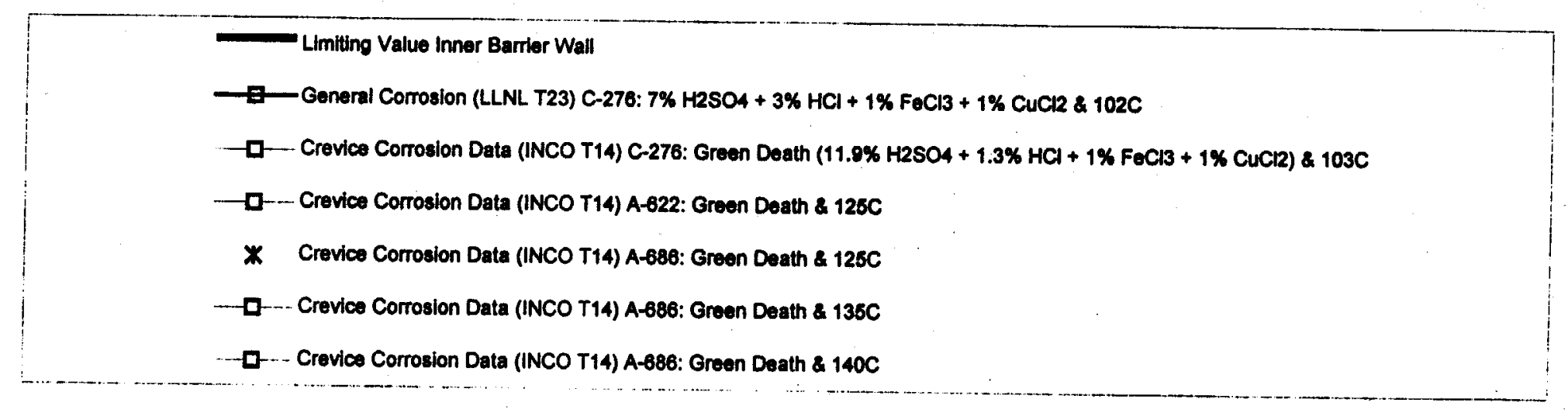

Figure 22. Data from INCO International 
Appendix 1. Source Code for Figures 2 and 3

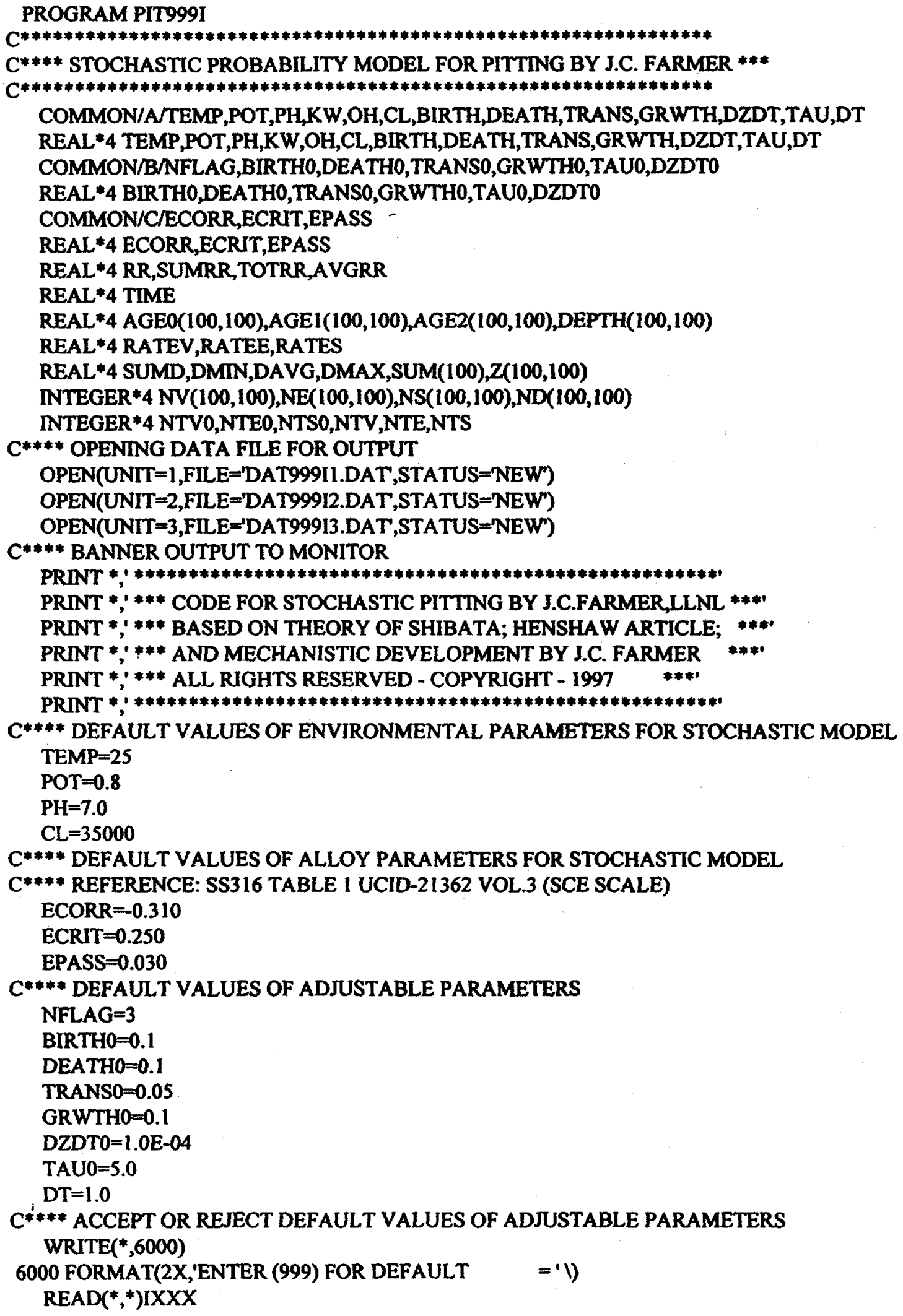


IF(IXXX.EQ.999)GOTO 9800

7000 CONTINUE

C**** INPUT ENVIRONMENTAL CONDITIONS

WRITE $(*, 8100)$

8100 FORMAT(2X,'TEMPERATURE (DEGREES CENTIGRADE) $=$ ' $)$

READ(*,*)TEMP

WRITE $(*, 8200)$

8200 FORMAT(2X,'PH (DIMENSIONLESS) $\quad=' 1$ )

$\operatorname{READ}(*, *)$ PH

WRITE $(*, 8300)$

8300 FORMAT(2X,'CHLORIDE (PPM) - = ' $)$

READ $(*, *) C L$

WRITE $(*, 8400)$

8400 FORMAT(2X,'POTENTIAL (VOLTS VS SCE) =

$\operatorname{READ}(*, *) P O T$

WRITE $(*, 8500)$

8500 FORMAT(2X,'CORROSION POTENTIAL (VOLTS VS SCE) $={ }^{\prime}$ )

READ(*,*)ECORR

WRITE $(*, 8600)$

8600 FORMAT(2X,'PITTING POTENTIAL (VOLTS VS SCE) $=' \emptyset$ )

READ(*,*)ECRIT

WRITE $(*, 8700)$

8700 FORMAT(2X,'REPASSIVE POTENTIAL (VOLTS VS SCE) $=$ ',

READ $\left.{ }^{*}, *\right)$ EPASS

C**** INPUT ADJUSTABLE MODEL PARAMETERS

WRITE $(*, 9100)$

9100 FORMAT(2X,MODEL $(1,2,3) \quad=' 1)$

READ $(*, *)$ NFLAG

WRITE $(*, 9200)$

9200 FORMAT(2X,'BIRTHO (EVENTS/TIME OR PROBABILITY) = ' $)$

READ(*,*)BIRTHO

WRITE $(*, 9300)$

9300 FORMAT(2X,'DEATHO (EVENTSTTIME OR PROBABILITY) = ' )

READ(*,*)DEATHO

WRITE $(*, 9400)$

9400 FORMAT(2X,'TRANSO (EVENTS/TIME OR PROBABILITY) = 'v)

READ $(*, *)$ TRANSO

WRITE $(*, 9500)$

9500 FORMAT(2X,'GRWTHO (EVENTS/TIME OR PROBABILITY) = ' )

READ $(*, *)$ GRWTHO

WRITE $(*, 9550)$

9550 FORMAT(2X,'PENETRATION RATE (DEPTH/TIME) $=?$ ')

READ $(*, *)$ DZDTO

WRITE $(*, 9600)$

9600 FORMAT(2X,'TAU0 (TIME) $\left.\quad={ }^{\prime} \mathrm{V}\right)$

READ(*,*)TAU0

WRITE $(*, 9700)$

9700 FORMAT(2X,'DT (TIME) = =

READ $(*, *) D T$

9800 CONTINUE

C**** ECHO INPUT FOR POSSIBLE CORRECTIONS

PRINT *,' BIRTHO (EVENTS/TIME OR PROBABILITY) = ',BIRTHO

PRINT *', DEATHO (EVENTS/TIME OR PROBABILITY) = ',DEATHO

PRINT *,' TRANSO (EVENTS/TIME OR PROBABILITY) = ',TRANSO 
PRINT *, GRWTHO (EVENTS/TIME OR PROBABILITY) = ',GRWTHO

PRINT *, TAUO (TIME)

PRINT *,' DT (TIME)

$=$ ',TAUO

PRINT *; TEMPERATURE (DEGREES CENTIGRADE) = ',TEMP

PRINT *,' PH (DIMENSIONLESS) = ',PH

PRINT *; CHLORIDE (PPM) $\quad=$ ',CL

PRINT *,' POTENTIAL (VOLTS VS SCE) = ',POT

PRINT *, CORROSION POTENTIAL (VOLTS VS SCE) $=$ ',ECORR

PRINT *;' PITTING POTENTIAL (VOLTS VS SCE) =',ECRIT

PRINT *,' REPASSIVATION POT (VOLTS VS SCE) $\quad=$ ',EPASS

WRITE $(*, 9900)$

9900 FORMAT(2X,'ENTER (999) TO ACCEPT VALUES =' )

READ $(*, *)$ IXXX

IF(IXXX.NE.999)GOTO 7000

$C^{* * * *}$ OUTPUT ADJUSTABLE PARAMETERS TO ARCHIEVE FILE

WRITE $(1,9950)$

WRITE(1,9951)BIRTH0

WRITE(1,9952)DEATH0

WRITE(1,9953)TRANSO

WRITE(1,9954)GRWTHO

WRITE $(1,9955)$ TAUO

WRITE(1,9956)DT

WRITE $(1,9957)$ TEMP

WRITE(1,9958)PH

WRITE $(1,9959)$ CL

WRITE $(1,9960)$ POT

WRITE(1,9961)ECORR

WRITE(1,9962)ECRIT

WRITE $(1,9963)$ EPASS

9950 FORMAT(1X,'AS INPUT **************************)

9951 FORMAT(1X,'BIRTH0 (EVENTS/TIME OR PROBABILITY) = ',E12.6)

9952 FORMAT(1X,'DEATHO (EVENTS/TIME OR PROBABILITY) $='$, E12.6)

9953 FORMAT(1X,'TRANSO (EVENTSITIME OR PROBABILITY) $='$, E12.6)

9954 FORMAT(1X,'GRWTHO (EVENTS/TIME OR PROBABILITY) =',E12.6)

9955 FORMAT(1X,'TAU0 (TIME) =',E12.6)

9956 FORMAT(1X,'DT (TIME) =',E12.6)

9957 FORMAT(1X,TEMP (DEGREES CENTIGRADE) = ',E12.6)

9958 FORMAT(1X,'PH (DIMENSIONLESS) = ',E12.6)

9959 FORMAT(1X,'CL (PPM)

9960 FORMAT(1X,'POT (VOLTS VS SCE)

9961 FORMAT(IX,'ECORR (VOLTS VS SCE)

9962 FORMAT(1X,'ECRIT (VOLTS VS SCE)

9963 FORMAT(1X,'EPASS (VOLTS VS SCE)

$={ }^{\prime}$, E12.6)

$=', E 12.6)$

$='$,E12.6)

$='$ 'E12.6)

C**** CONVERSION OF ENVIRONMENTAL PARAMETER INPUT VALUES

TEMP $=$ TEMP+273.0

$C L=C L *(1.0 E-03) /(58.44277)$

C**** CONVERSION OF PITTING \& REPASSIVATION FROM SCE TO NHE

POT $=$ POT -0.2412

ECORR $=E C O R R-0.2412$

ECRIT $=$ ECRIT -0.2412

EPASS=EPASS- 0.2412

C**** INITIALIZE RANDOM NUMBER GENERATOR

$\mathrm{KK}=1$

SUMRR $=0.0$ 
TOTRR $=0.0$

AVGRR $=0.0$

CALL RANDOM(KK,RR,SUMRR,TOTRR,AVGRR)

C**** CALCULATE MAX BIRTH, DEATH, \& GROWTH PROBABILITIES

TIME $=0.0$

C**** CALCULATION OF PITTING PROBABILITIES BASED UPON INPUT

CALL PROBABLE

C**** OUTPUT RESULTS OF INITIAL CALCULATION TO MONITOR \& DATA FILE

PRINT *; INITIAL TIME (TIME)

PRNT *;'TEMPERATURE (KELVINS) . = ',TEMP

PRINT *, PH (DIMENSIONLESS) - = ',PH

PRINT *,' CHLORIDE (MOLES/LITER) = ',CL

PRINT *; POTENTIAL (VOLTS VS NHE) $\quad=$ ',POT

PRINT *,' CORROSION POTENTIAL (VOLTS VS NHE) = ',ECORR

PRINT *;' PITTING POTENTIAL (VOLTS VS NHE) $=$ ',ECRIT

PRINT *, REPASSIVATION POT (VOLTS VS NHE) $=$ ',EPASS

PRINT *', BIRTH (EVENTS/TIME OR PROBABILITY) = ',BIRTH

PRINT *,' DEATH (EVENTS/TIME OR PROBABILITY) = ',DEATH

PRINT *,' TRANS (EVENTS/TIME OR PROBABILITY) = ',TRANS

PRINT *;' GRWTH (EVENTS/TIME OR PROBABILITY) = ',GRWTH

PRINT *,' PENETRATION RATE (DEPTH/TIME) =',DZDT

PRINT *, TAU (TIME) = ',TAU

$C^{* * * *}$ OUTPUT ADJUSTABLE PARAMETERS TO ARCHIEVE FILE

WRITE $(1,1000)$

WRITE(1,1001)BIRTHO

WRITE $(1,1002)$ DEATHO

WRITE $(1,1003)$ TRANSO

WRITE $(1,1004)$ GRWTHO

WRITE $(1,1005)$ TAUO

WRITE $(1,1006)$ DT

WRITE $(1,1007)$ TEMP

WRITE $(1,1008) \mathrm{PH}$

WRITE $(1,1009)$ CL

WRITE $(1,1010)$ POT

WRITE $(1,1011)$ ECORR

WRITE $(1,1012)$ ECRIT

WRITE $(1,1013)$ EPASS

1000 FORMAT(IX,'AFTER UNIT CONVERSIONS **************')

1001 FORMAT(1X,'BIRTHO (EVENTS/TIME OR PROBABILITY) = ',E12.6)

1002 FORMAT(1X,'DEATH0 (EVENTS/TIME OR PROBABILITY) = ',E12.6)

1003 FORMAT(IX, TRANSO (EVENTS/TIME OR PROBABILITY) $=$ ',E12.6)

1004 FORMAT(IX,'GRWTHO (EVENTS/TIME OR PROBABILITY) = ',E12.6)

1005 FORMAT( $1 X$, TAUO (TIME)

1006 FORMAT(1X,'DT (TIME)

1007 FORMAT(1X,'TEMP (KELVINS)

1008 FORMAT(1X,'PH (DIMENSIONLESS)

1009 FORMAT(1X,'CL (MOLES/LITER)

1010 FORMAT(1X,'POT (VOLTS VS NHE)

$=$ 'E12.6)

$=$ 'E12.6)

$=$ ',E12.6)

$=$ ',E12.6)

1011 FORMAT(1X,'ECORR (VOLTS VS NHE)

$=', E 12.6)$

$=$ ',E12.6)

1012 FORMAT(1X,'ECRIT (VOLTS VS NHE)

1013 FORMAT(1X,'EPASS (VOLTS VS NHE)

$=$ ',E12.6)

$=$ ',E12.6)

$=$ ',E12.6)

$C^{* * * *}$ INITIALIZE NUMBER OF VACANCIES, EMBRYOS, \& STABLE PITS

$\mathrm{NTV}=\mathrm{NI} * \mathrm{NJ}$

NTE $=0$ 
NTS $=0$

$C^{* * * *}$ SPECIFICATION OF NUMBER OF CELLS (AREA)

$\mathrm{NI}=100$

$\mathrm{NJ}=100$

$C^{* * * *}$ INITIALIZE EMBRYO \& SUSTAINED GROWTH COUNT

$\mathrm{DO} 2 \mathrm{~J}=1, \mathrm{NJ}$

DO $1 \mathrm{I}=1, \mathrm{NI}$

$\mathrm{NV}(\mathrm{I}, \mathrm{J})=1$

$\mathrm{NE}(\mathrm{I}, \mathrm{J})=0$

$\mathrm{NS}(\mathrm{I}, \mathrm{J})=0$

$\mathrm{ND}(\mathrm{I}, \mathrm{J})=0$

1 DEPTH $(I, J)=0.0$

2 CONTINUE

$C^{* * * *}$ WRITE HEADING TO OUTPUT FILE

WRITE $(2,2000)$

2000 FORMAT(7X,'TIME',1X,'VACANCY',2X,'EMBRYO',4X,'PITS',5X,'PIT RATE')

$C^{* * * *}$ INITIALIZATION OF TIME

TIME $=0.0$

$C^{* * * *}$ SPECIFICATION OF TIME STEPS

$\mathrm{NK}=150$

C**** OUTER LOOP - BEGIN TIME STEPS

DO $300 \mathrm{~K}=1, \mathrm{NK}$

$C * * * *$ INITIALIZE NUMBER OF VACANCIES, EMBRYOS, \& STABLE PITS

NTV $0=$ NTV

NTE0 $=$ NTE

NTSO $=$ NTS

SUMV $=0$

SUME $=0$

SUMS $=0$

TIME $=K * D T$

$C^{* * * *}$ CALCULATE BIRTH, DEATH, \& GROWTH PROBABILITIES, ETC.

CALL PROBABLE

$C^{* * * *}$ SCANNING I-J CELLS FOR EVENTS DURING K-TH TIME STEP

DO $200 \mathrm{~J}=1, \mathrm{NJ}$

DO $100 \mathrm{l}=1, \mathrm{NI}$

$C^{* * * *}$ DETECT STABLE PIT

IF(NS(I,J).EQ.1)GOTO 50

C**** DETECT VACANCY

IF(NV(I,J).EQ.1.AND.NE(I,J).EQ.0)GOTO 60

C**** DETECT EMBRYO

IF(NV(I,J).EQ.0.AND.NE(I,J).EQ.1)GOTO 70

C**** THE PROGRAM SHOULD NOT COME DIRECTLY TO THIS POINT

PRINT *,' STATE DETECTION ERROR!'

C**** CELL CALCULATIONS FOR DETECTED STABLE PIT

50 CONTINUE

AGE2(I,J)=TIME-AGE1(I,J)

CALL RANDOM(KK,RR,SUMRR,TOTRR,AVGRR)

IF(RR.LE.GRWTH.OR.ND(I,J).EQ.1)GOTO 51

GOTO 52

51 CONTINUE

$C^{* * * *}$ THE STABLE PIT CEASES TO GROW (DEATH OF STABLE PIT)

$N V(I, J)=0$

$\mathrm{NE}(\mathrm{l}, \mathrm{J})=0$

NS $(I, J)=1$ 
Appendix 1

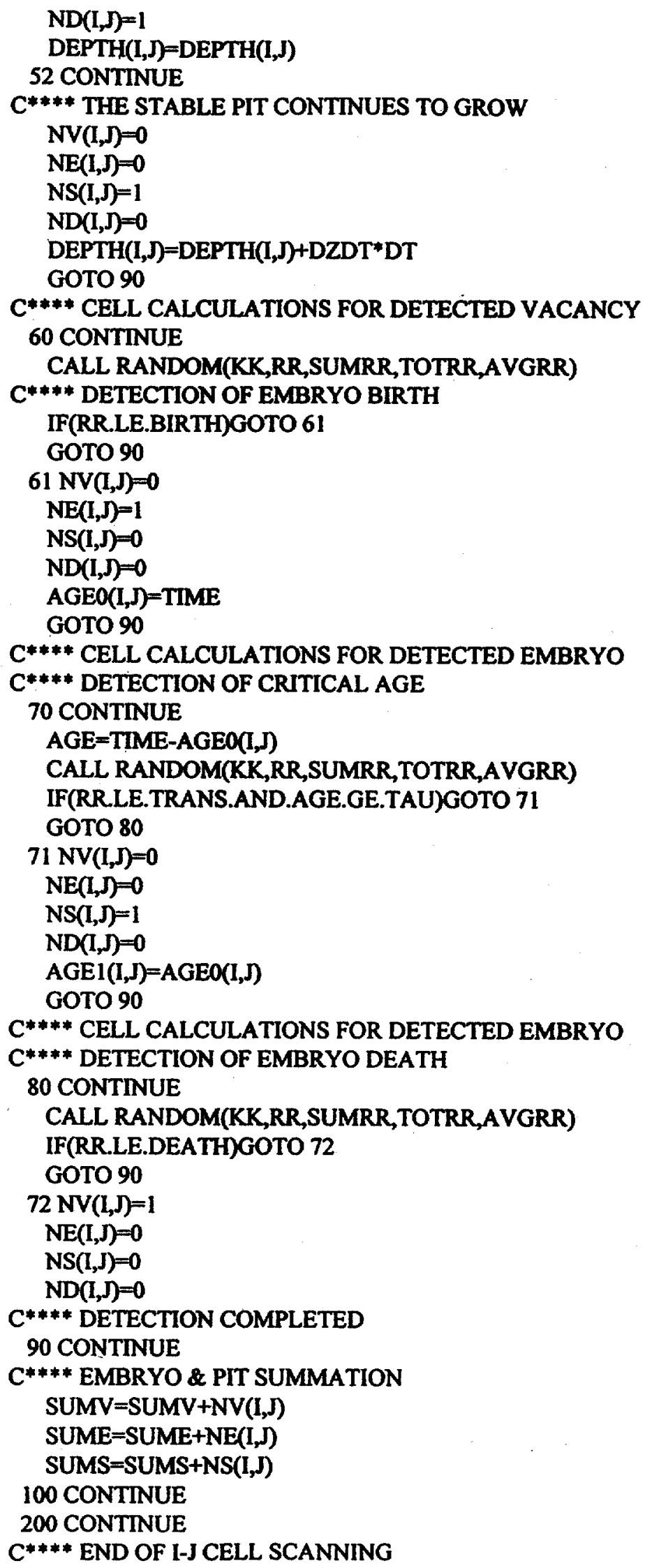




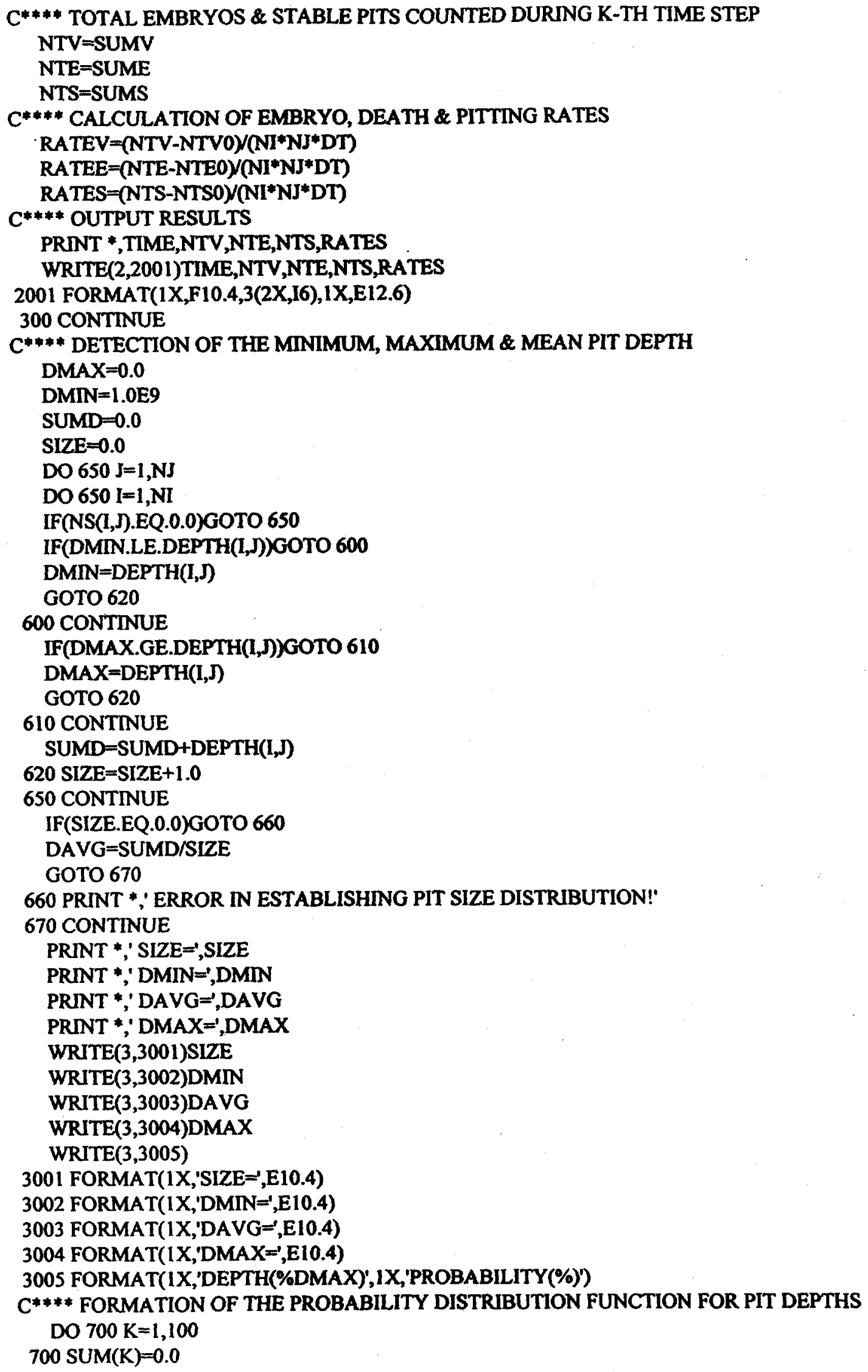




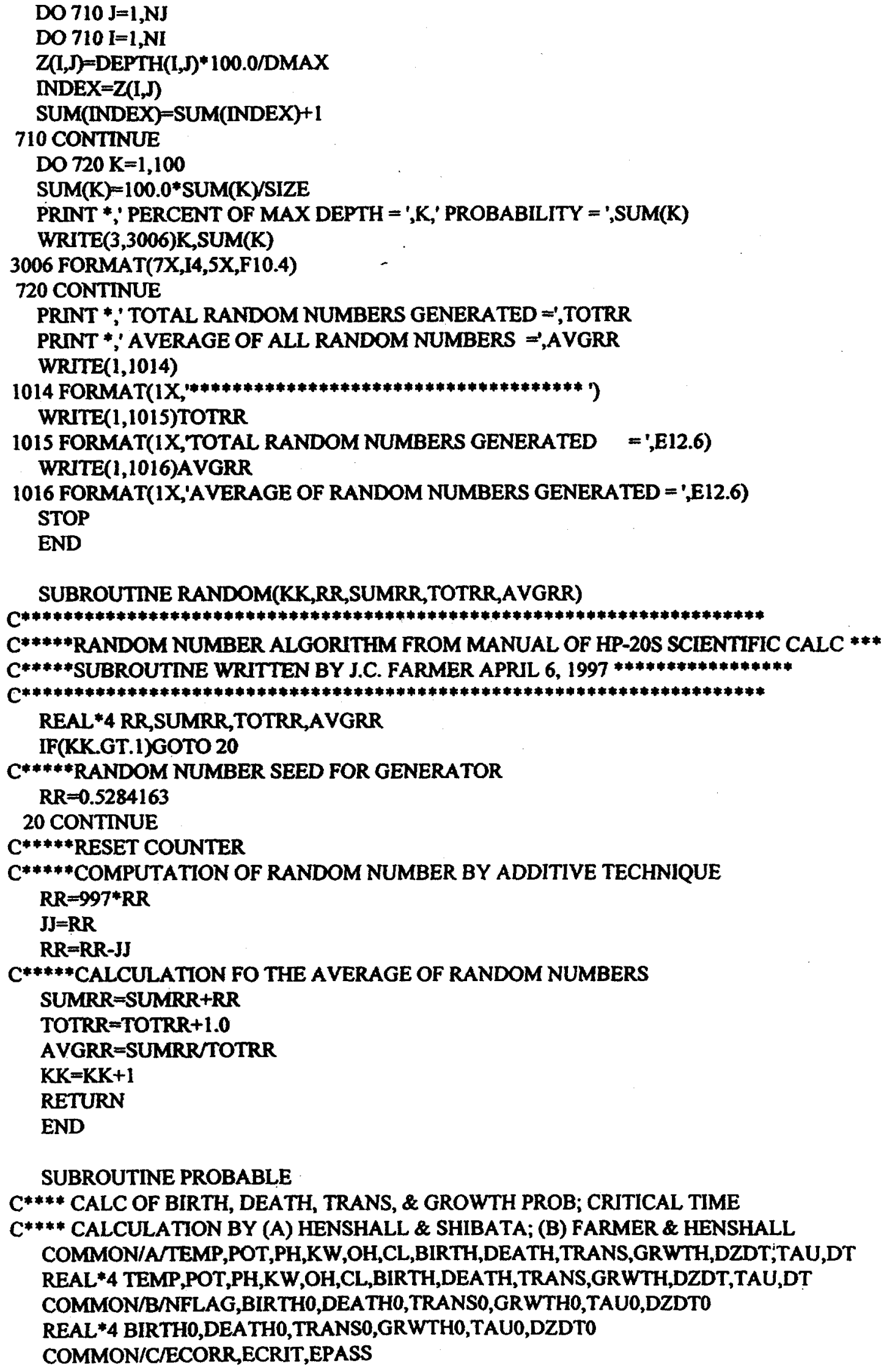




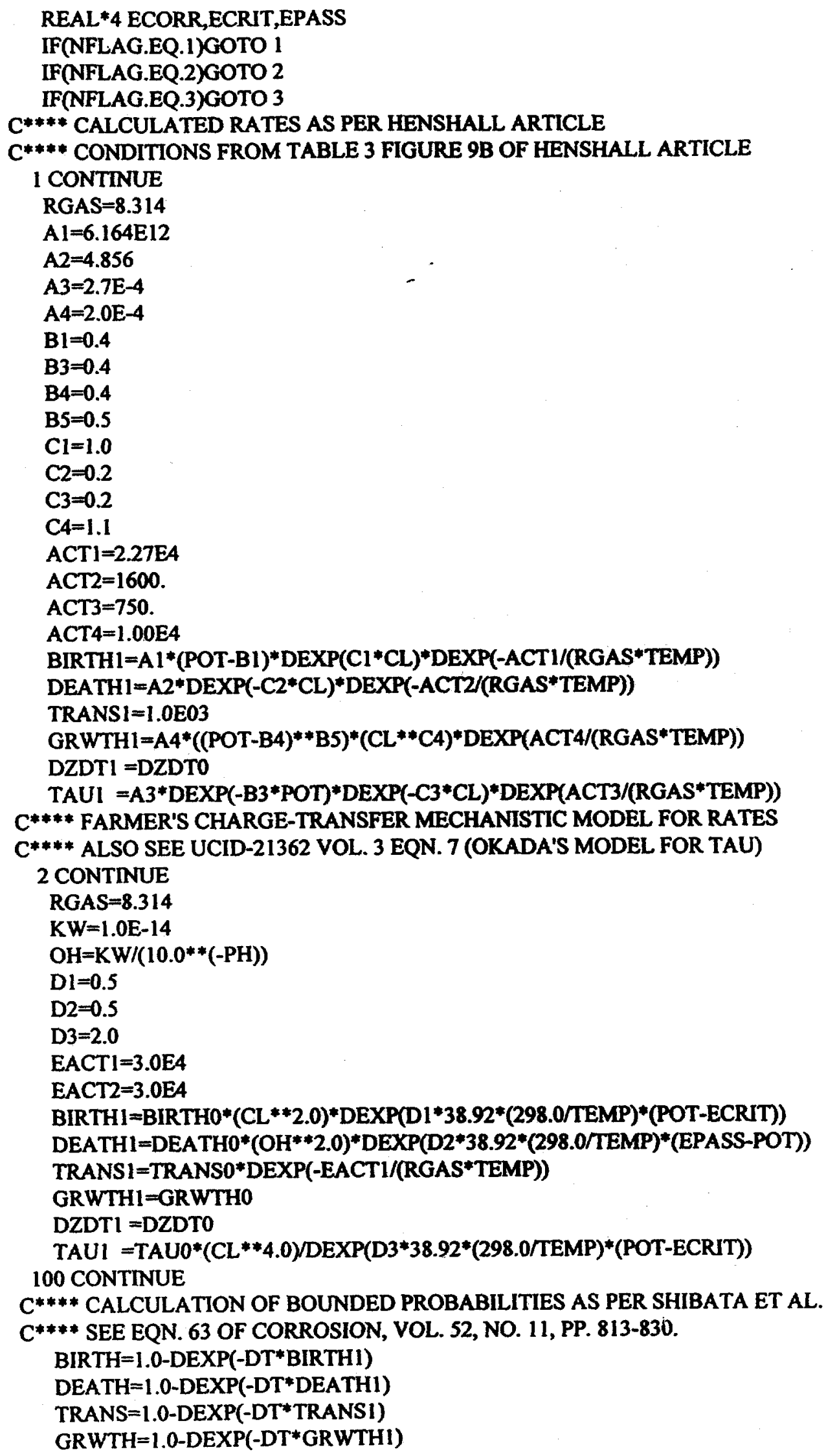




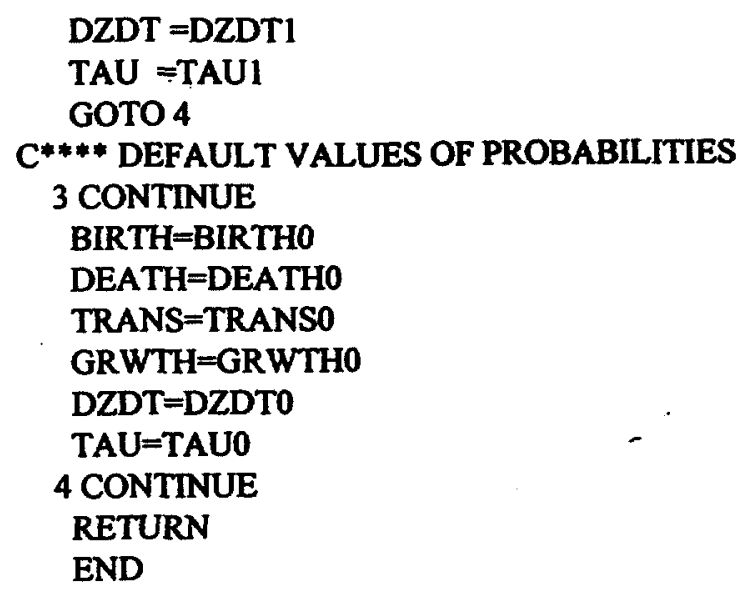

Input Data for Source Code

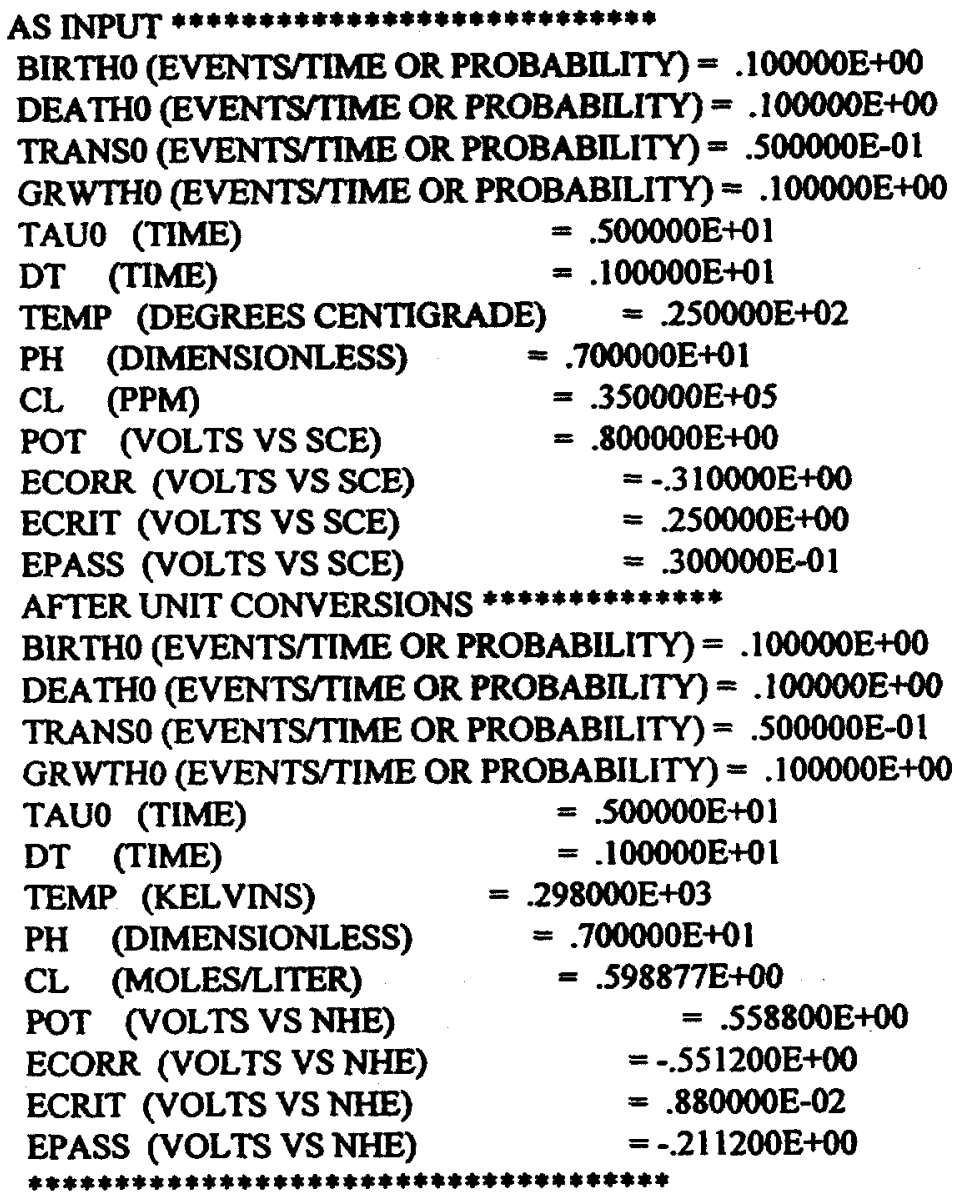

TOTAL RANDOM NUMBERS GENERATED $=.179458 \mathrm{E}+07$

AVERAGE OF RANDOM NUMBERS GENERATED $=.500125 E+00$ 
Appendix 2. Source Code for Figures 4 and 5

PROGRAM RKSPIT\$B

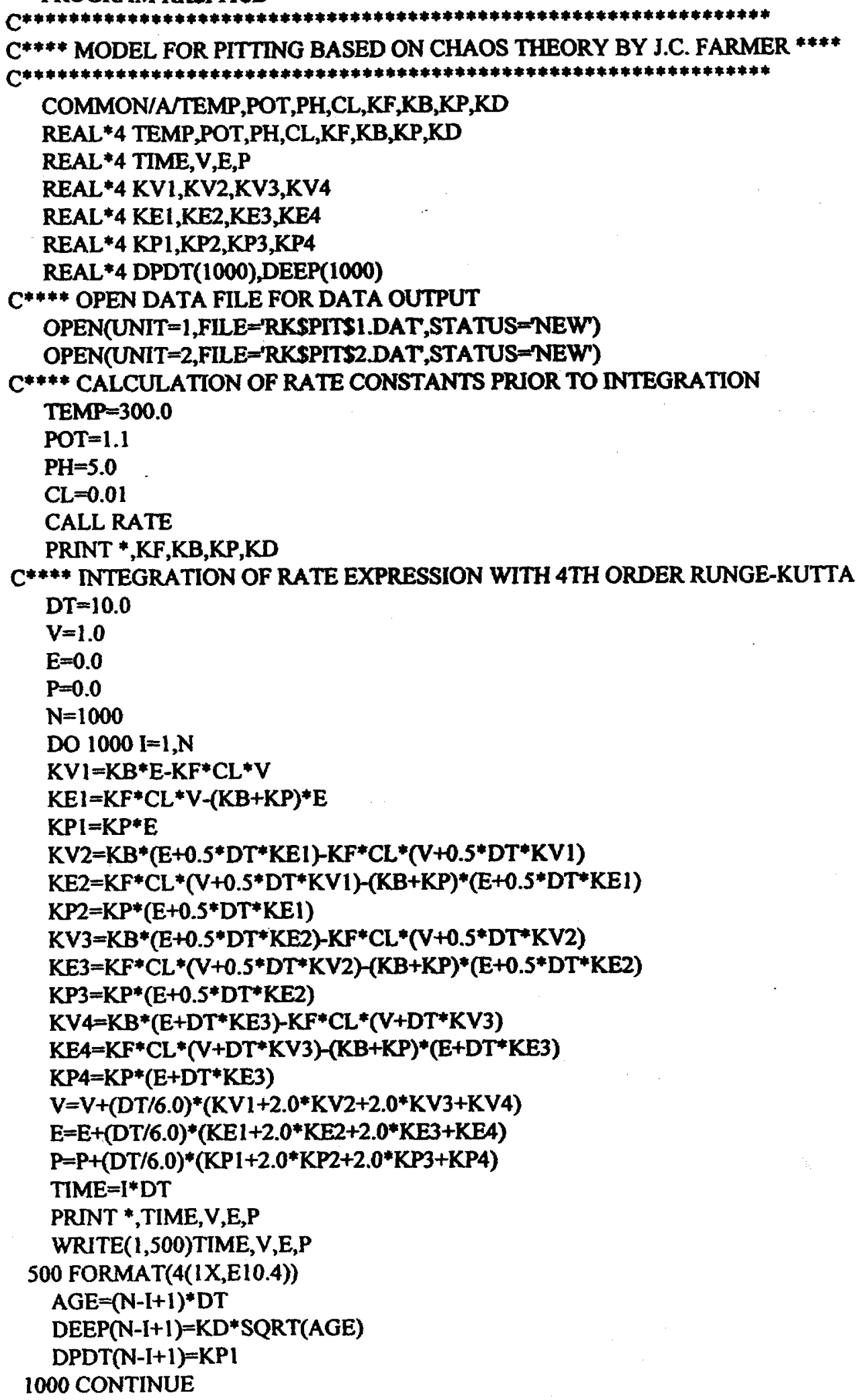




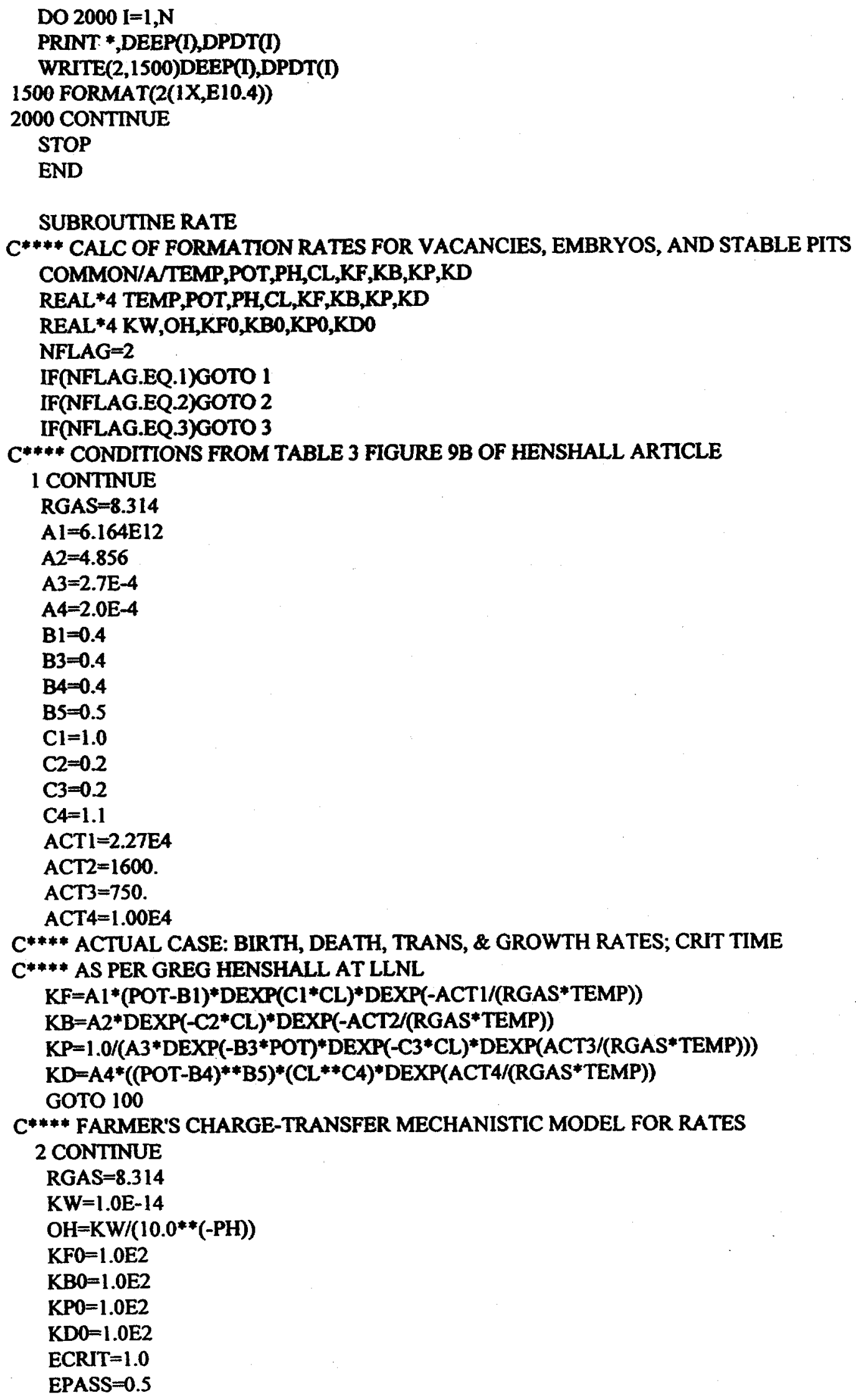




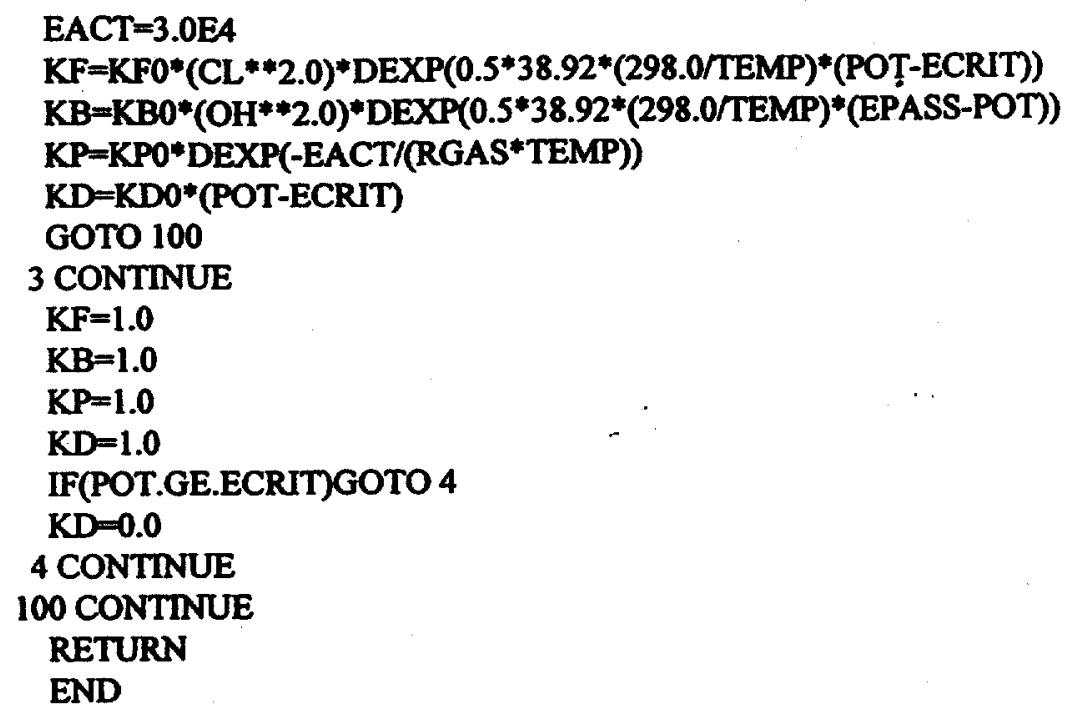

END 
Appendix 3. Source Code for Figures 7 through 10

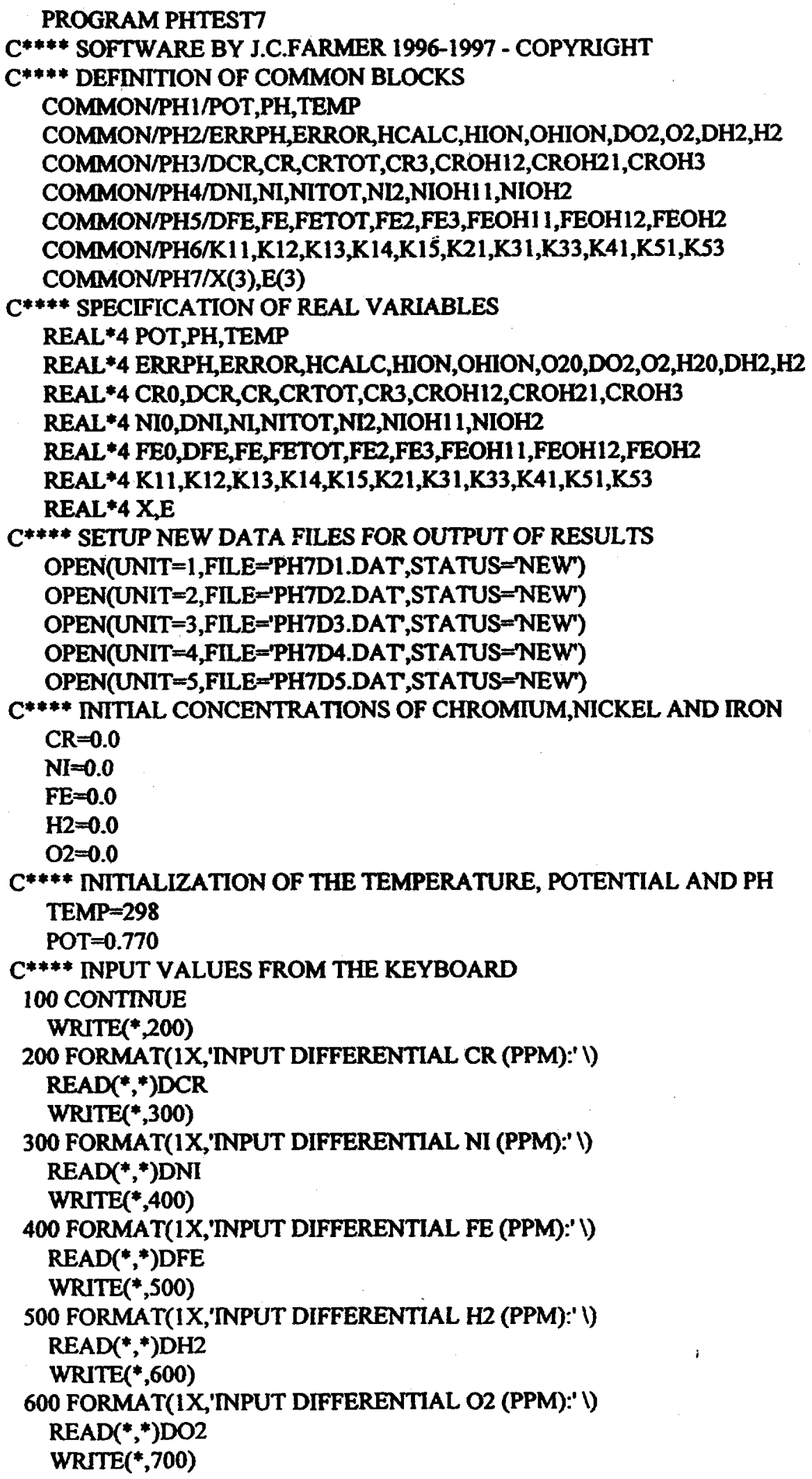


700 FORMAT(1X,'INPUT TEMPERATURE (C): 1$)$

READ(*,*)TEMP

WRITE $(*, 800)$

800 FORMAT(IX,'INPUT POTENTIAL (V):' り)

READ(*,*)POT

$\mathrm{C}^{* * * *}$ ECHO INPUT FOR POSSIBLE CORRECTIONS

PRINT *; DISSOLVED CR (PPM) $=$ ',CR

PRINT *; DISSOLVED NI (PPM) $=;$,NI

PRINT *,' DISSOLVED FE (PPM) $=$ ',FE

PRINT *; DISSOLVED H2 (PPM) $=$ ', H2

PRINT *; DISSOLVED O2 (PPM) $=;, 02$

PRINT *; TEMPERATURE (C) $=$ ',TEMP

PRINT *,' POTENTIAL $(V)=$ ',POT

WRITE $(*, 999)$

999 FORMAT(1X,'INPUT: (1) FOR CHANGE; (2) FOR CONTINUE:' )

READ(*,*)DXXX

IF(IXXX.EQ.1)GOTO 100

$C^{* * * *}$ LABELS \& FORMAT STATEMENTS FOR EACH DATA OUTPUT FILE WRITE $(1,8001)$

8001 FORMAT(1X,'I,CRTOT,NITOT,FETOT,PH,HCALC,ERROR')

WRITE $(2,8002)$

8002 FORMAT(1X,'CR0,CR,CR3,CROH12,CROH21,CROH3')

WRITE $(3,8003)$

8003 FORMAT(1X, NIO,N1,NI2,NIOH1 1,NIOH2')

WRITE $(4,8004)$

8004 FORMAT(1X,'FE0,FE,FE2,FE3,FEOH11,FEOH12,FEOH2')

WRITE $(5,8005)$

8005 FORMAT(1X,'I,O2,H2')

$C^{* * * *}$ BEGIN INCREMENTING THE CONCENTRATIONS

DO $1000 \mathrm{I}=1,100$

$\mathrm{CRO}=(\mathrm{I}-1) * \mathrm{DCR}$

$\mathrm{NIO}=(\mathrm{I}-1)^{*} \mathrm{DNI}$

FE $0=(1-1)^{*}$ DFE

$\mathrm{O} 20=(\mathrm{I}-1)^{*} \mathrm{DO} 2$

$\mathrm{H} 2 \mathrm{O}=(\mathrm{I}-1)^{*} \mathrm{DH} 2$

$\mathrm{C}^{* * * *}$ CONVERSION OF PPM TO MOLE PER LITER

$\mathrm{CR}=\mathrm{CR0} *(1.0 \mathrm{E}-06) *(1000.0) / 51.996$

$\mathrm{NI}=\mathrm{NIO} *(1.0 \mathrm{E}-06) *(1000.0) / 58.700$

$\mathrm{FE}=\mathrm{FE} 0 *(1.0 \mathrm{E}-06) *(1000.0) / 55.847$

$\mathrm{O} 2=020 *(1.0 \mathrm{E}-06) *(1000.0) /(2.0 * 15.9994)$

$\mathrm{H} 2=\mathrm{H} 2 \mathrm{O}^{*}(1.0 \mathrm{E}-06)^{*}(1000.0) /(2.0 * 1.0079)$

$C^{* * * *}$ THE SUBROUTINE FOR PH SUPPRESSION IS CALLED

CALL PHCALC

$C^{* * * *}$ OUTPUT OF RESULTS FROM CALCULATION

PRINT *, $; * * * * * * * * * * * * * * * * * * * * * * * * * * * * * * * * * * * * * * * 1$

PRINT *,'HION HCALC ERROR :,HION,HCALC,ERROR

PRINT *,'PH H+ OH- :,PH,HION,OHION

PRINT *,'FE2+ FE3+ :',FE2,FE3

PRINT *,NI2+ :,'NI2

PRINT *,CR3+ :,CR3

PRINT *,'FETOT NITOT CRTOT :',FETOT,NITOT,CRTOT

PRINT *,'FEOH2 FEOH11 FEOH12 :',FEOH2,FEOH11,FEOH12

PRINT *,'NIOH2 NIOH11 :,NIOH2,NIOH11

PRINT *,'CROH3 CROH12 CROH21 :,'CROH3,CROH12,CROH21 


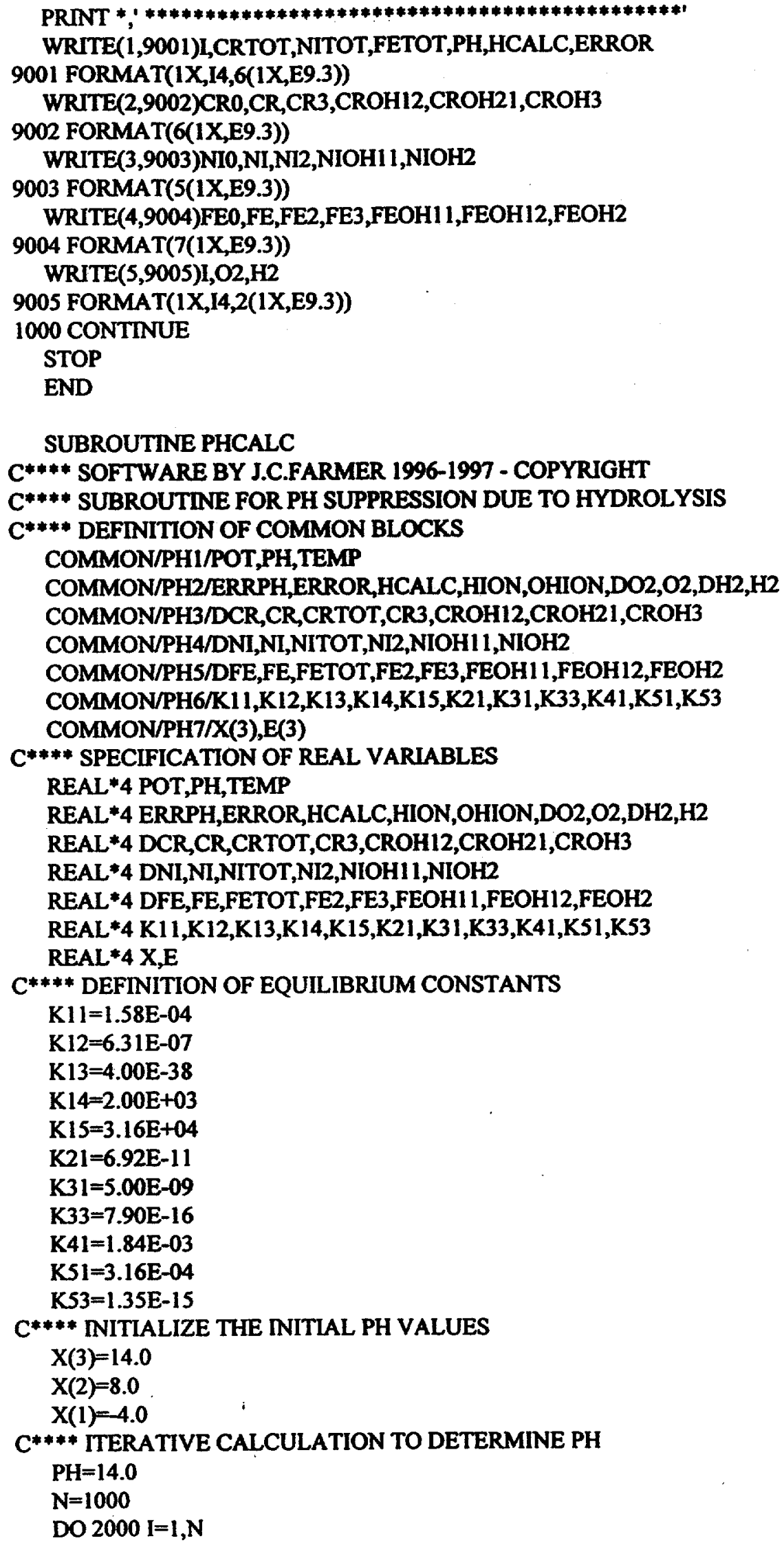




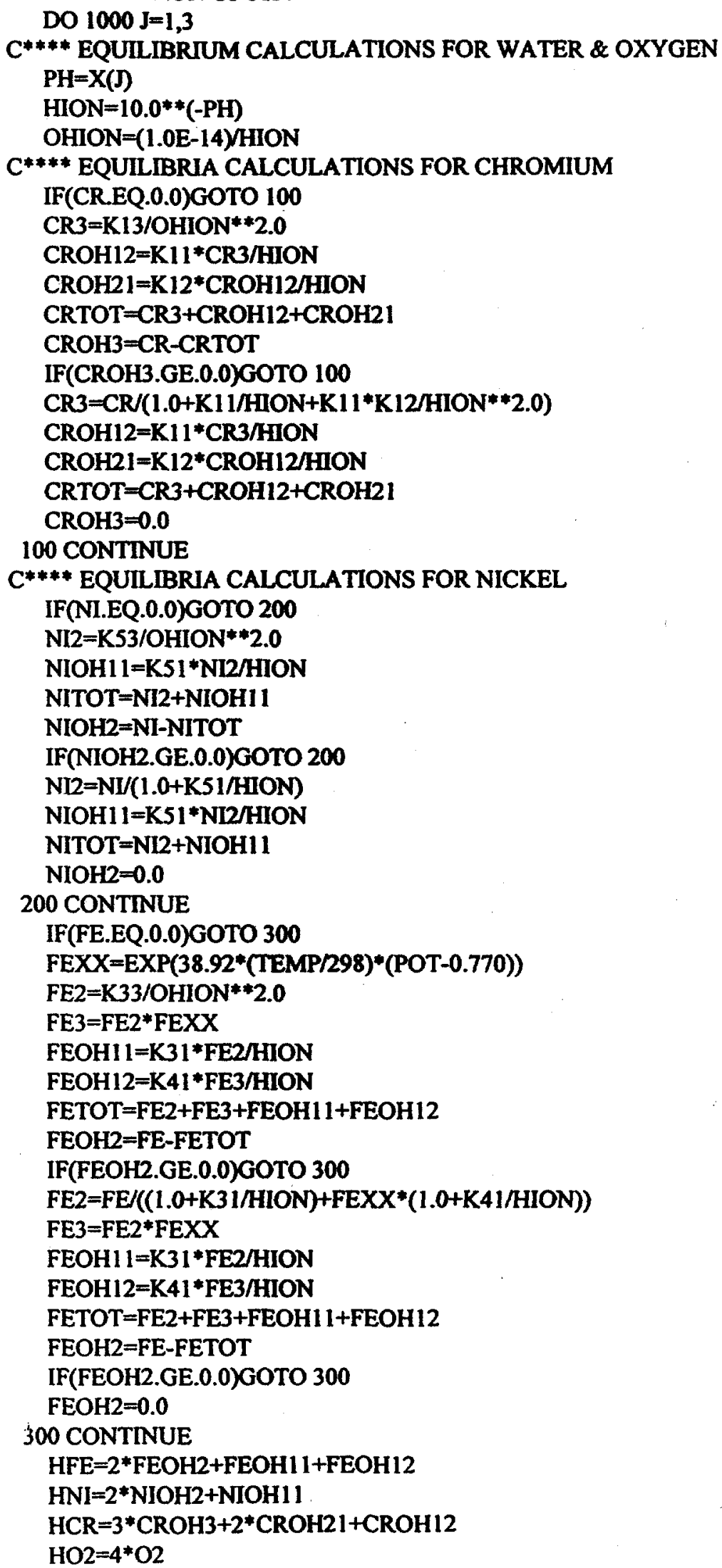




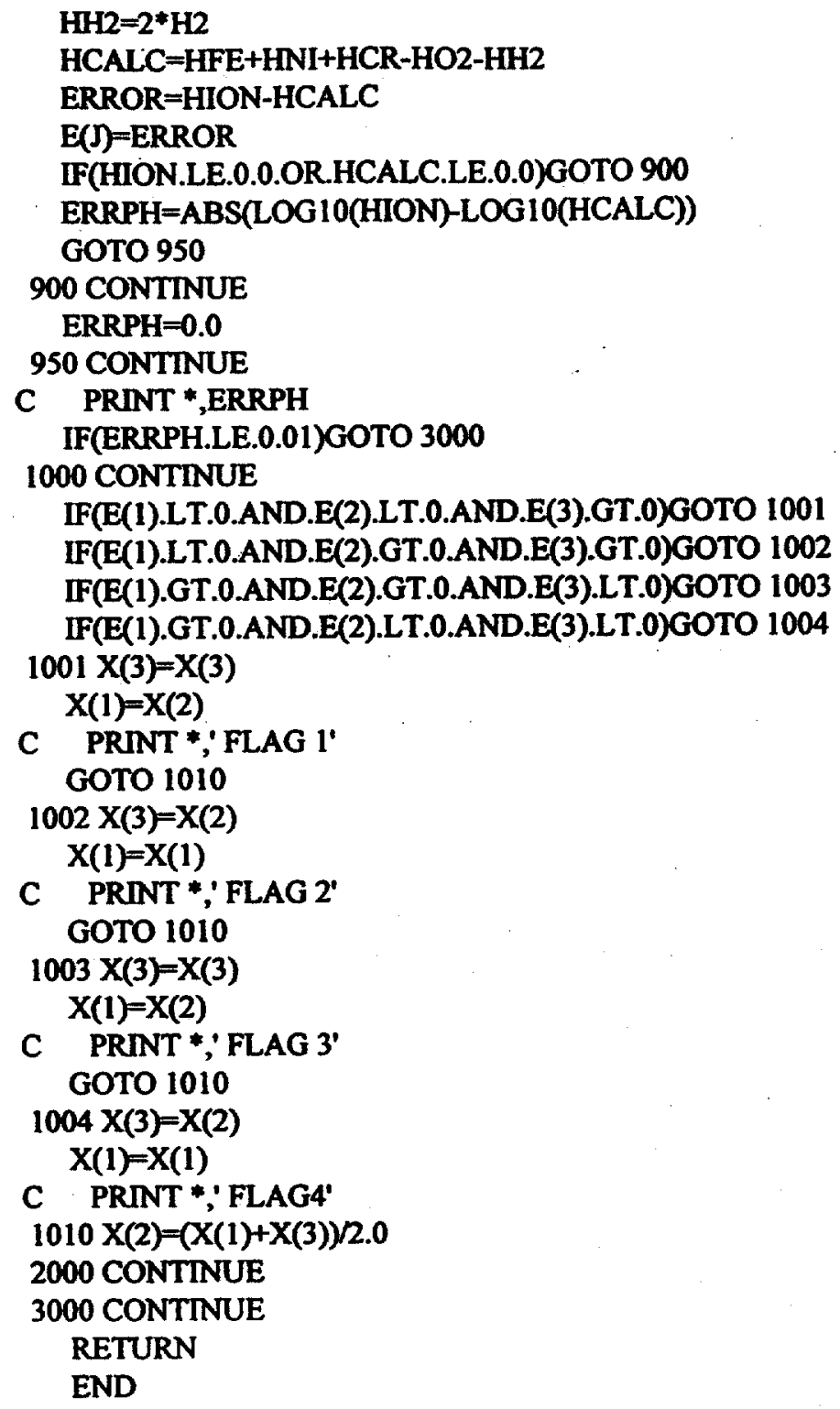


Appendix 4. Source Code for Figures 12 and 13

PROGRAM PIT999P

C

C*** STOCHASTIC PROBABILITY MODEL FOR PITTING BY J.C. FARMER ***

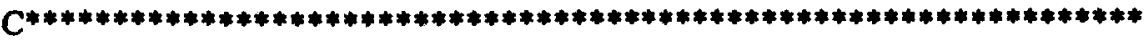

COMMON/A/TEMP,POT,PH,KW,OH,CL,BIRTH,DEATH,TRANS,GRWTH,DZDT,TAU,DT

REAL * 4 TEMP,POT,PH,KW,OH,CL,BIRTH,DEATH,TRANS,GRWTH,DZDT,TAU,DT

COMMON/B/NFLAG,BIRTHO,DEATH0,TRANS0,GRWTH0,TAU0,DZDTO

REAL*4 BIRTH0,DEATH0,TRANS0,GRWTH0,TAU0,DZDTO

COMMON/C/ECORR,ECRT,EPASS

REAL*4 ECORR,ECRIT,EPASS

COMMON/D/TIME,NTV,NTE,NTS

REAL * 4 TIME

COMMON/E/ALPHA1,ALPHA2

REAL 4 ALPHA1,ALPHA2

REAL*4 RR,SUMRR,TOTRR,AVGRR

REAL *4 AGEO(100,100),AGE1(100,100),AGE2(100,100),DEPTH(100,100)

REAL *4 RATEV,RATEE,RATES

REAL*4 SUMD,DMIN,DAVG,DMAX,SUM(100),Z(100,100)

INTEGER * 4 NV(100,100),NE(100,100),NS(100,100),ND $(100,100)$

INTEGER *4 NTV0,NTE0,NTSO,NTV,NTE,NTS

$C^{* * * *}$ OPENING DATA FILE FOR OUTPUT

OPEN(UNIT $=1$,FILE=DAT999P1.DAT,STATUS=NEW')

OPEN(UNIT $=2$,FILE='DAT999P2.DAT,STATUS=NEW)

OPEN(UNIT=3,FILE='DAT999P3.DAT,STATUS $=$ NEW)

C**** BANNER OUTPUT TO MONITOR

PRINT *, $; * * * * * * * * * * * * * * * * * * * * * * * * * * * * * * * * * * * * * * * * * * * * * * * * * 1$

PRINT *,'*** CODE FOR STOCHASTIC PITTING BY J.C.FARMER,LLNL ****

PRINT *,'*** BASED ON THEORY OF SHIBATA; HENSHAW ARTICLE; ***'

PRINT *; *** AND MECHANISTIC DEVELOPMENT BY J.C. FARMER ***

PRINT *; *** ALL RIGHTS RESERVED - COPYRIGHT - 1997 ***"

PRINT *, *************************************************1

C**** DEFAULT VALUES OF ENVIRONMENTAL PARAMETERS FOR STOCHASTIC MODEL

C**** REFERENCE: ALLOY 825 TABLE 1 \& FIGURE 13 UCID-125300

TEMP $=90$

POT $=0.6432$

$\mathrm{PH}=2.57$

$\mathrm{CL}=50000$

C**** DEFAULT VALUES OF ALLOY PARAMETERS FOR STOCHASTIC MODEL

$C^{* * * *}$ REFERENCE: SS3 16 TABLE 1 UCID-21362 VOL.3 (SCE SCALE)

$E C O R R=0.280$

ECRIT $=0.230$

EPASS $=0.0$

$C^{* * * *}$ DEFAULT VALUES OF ADJUSTABLE PARAMETERS

NFLAG $=3$

BIRTH0 $=0.30$

BIRTH $0=0.20$

DEATH $0=0.20$

DEATHO $=0.50$

TRANSO $=0.10$

TRANS $0=0.05$

GRWTH0 $=0.10$ 
DZDT0 $=3.0 \mathrm{E}-04$

TAU $0=1.0$

$C * * * *$ DEFAULT VALUE FOR TIME STEPS

DT $=1.0$

$\mathrm{NK}=240$

$C^{* * * *}$ SELECT MODEL (1=HENSHALL; 2=FARMER; 3=FIXED PROBABILITIES)

5000 CONTINUE

WRITE $(*, 5100)$

5100 FORMAT(2X,'MODEL $(1,2,3) \quad=$ ' $)$

READ(*,*)NFLAG

$C^{* * * *}$ SET TIME STEP FOR SIMULATION

WRITE $(*, 5200)$

5200 FORMAT(2X,'DT (TTME/STEP) $\quad=' \backslash$

READ(*,*)DT

WRITE $(*, 5300)$

5300 FORMAT(2X, TIME STEPS $\quad=', 1)$

READ(*,*)NK

$C^{* * * *}$ ECHO MODEL, TIME STEP, AND INCREMENTS FOR POSSIBLE CORRECTION

PRINT *,' NFLAG (1=HENSHALL;2=FARMER;3=FIXED) = ',NFLAG

PRINT *; DT (TIME/STEP) $\quad=$ ',DT

PRINT *,' TIME STEPS = ',NK

WRITE $(*, 5400)$

5400 FORMAT(2X,'ENTER (999) TO ACCEPT VALUES $=' v)$

READ(*,*)IXXX

IF(IXXX.NE.999)GOTO 5000

C**** ACCEPT OR REJECT DEFAULT VALUES OF ADJUSTABLE PARAMETERS

WRITE $(*, 6000)$

6000 FORMAT(2X,'ENTER (999) FOR DEFAULT = ' )

READ $(*, *) I X X X$

IF(IXXX.EQ.999)GOTO 9800

IF(NFLAG.EQ.3)GOTO 9000

$C^{* * * *}$ INPUT ENVIRONMENTAL CONDITIONS

8000 CONTINUE

WRITE $(*, 8100)$

8100 FORMAT(2X,'TEMPERATURE (DEGREES CENTIGRADE) $=' \eta$

READ(*,*)TEMP

WRITE $(*, 8200)$

8200 FORMAT(2X,'PH (DIMENSIONLESS) $\quad={ }^{\prime}$ )

READ(*,*)PH

WRITE $(*, 8300)$

8300 FORMAT(2X,'CHLORIDE (PPM) =

$\operatorname{READ}(*, *) \mathrm{CL}$

WRITE $(*, 8400)$

8400 FORMAT(2X,'POTENTIAL (VOLTS VS SCE) $\quad={ }^{\prime}$ )

READ $\left.{ }^{*},{ }^{*}\right)$ POT

WRITE $(*, 8500)$

8500 FORMAT(2X,'CORROSION POTENTIAL (VOLTS VS SCE) = ' )

READ(*,*)ECORR

WRITE $(*, 8600)$

8600 FORMAT(2X,'PITTING POTENTIAL (VOLTS VS SCE) $=$ ' $)$

READ $(*, *) E C R I T$

WRITE $(*, 8700)$

8700 FORMAT(2X,'REPASSIVE POTENTIAL (VOLTS VS SCE) $=$ ', l)

READ(*,*)EPASS 


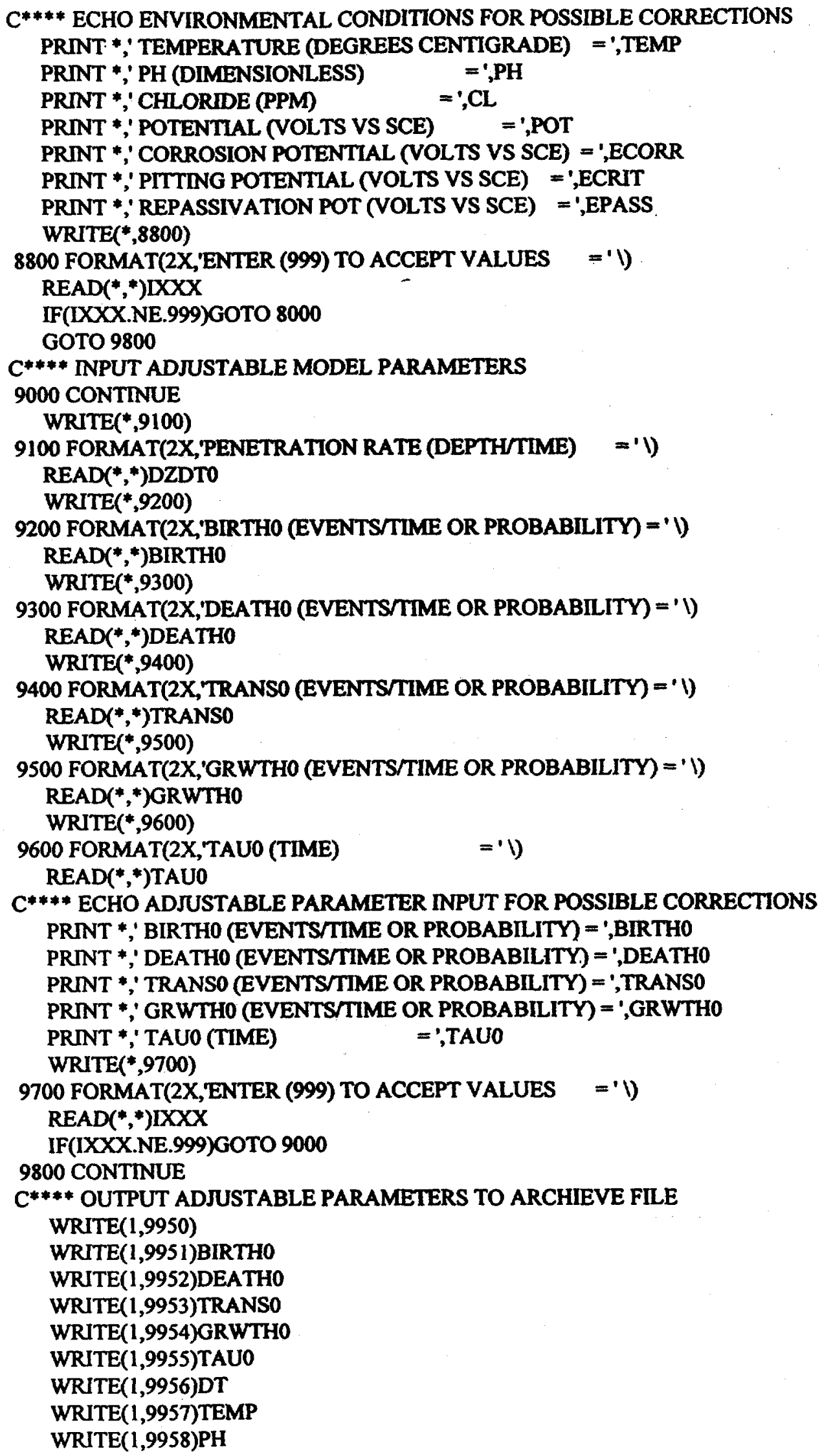




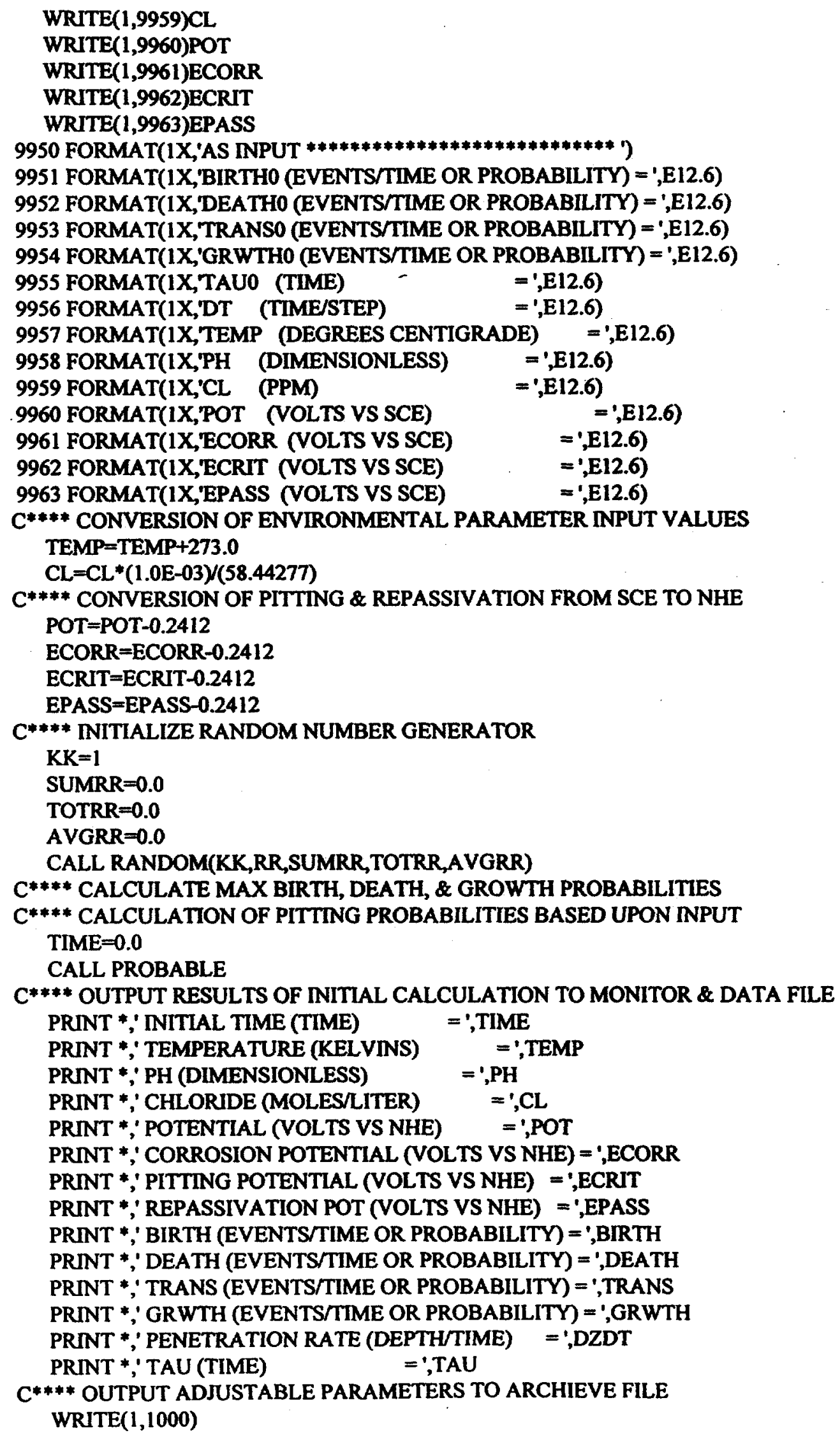




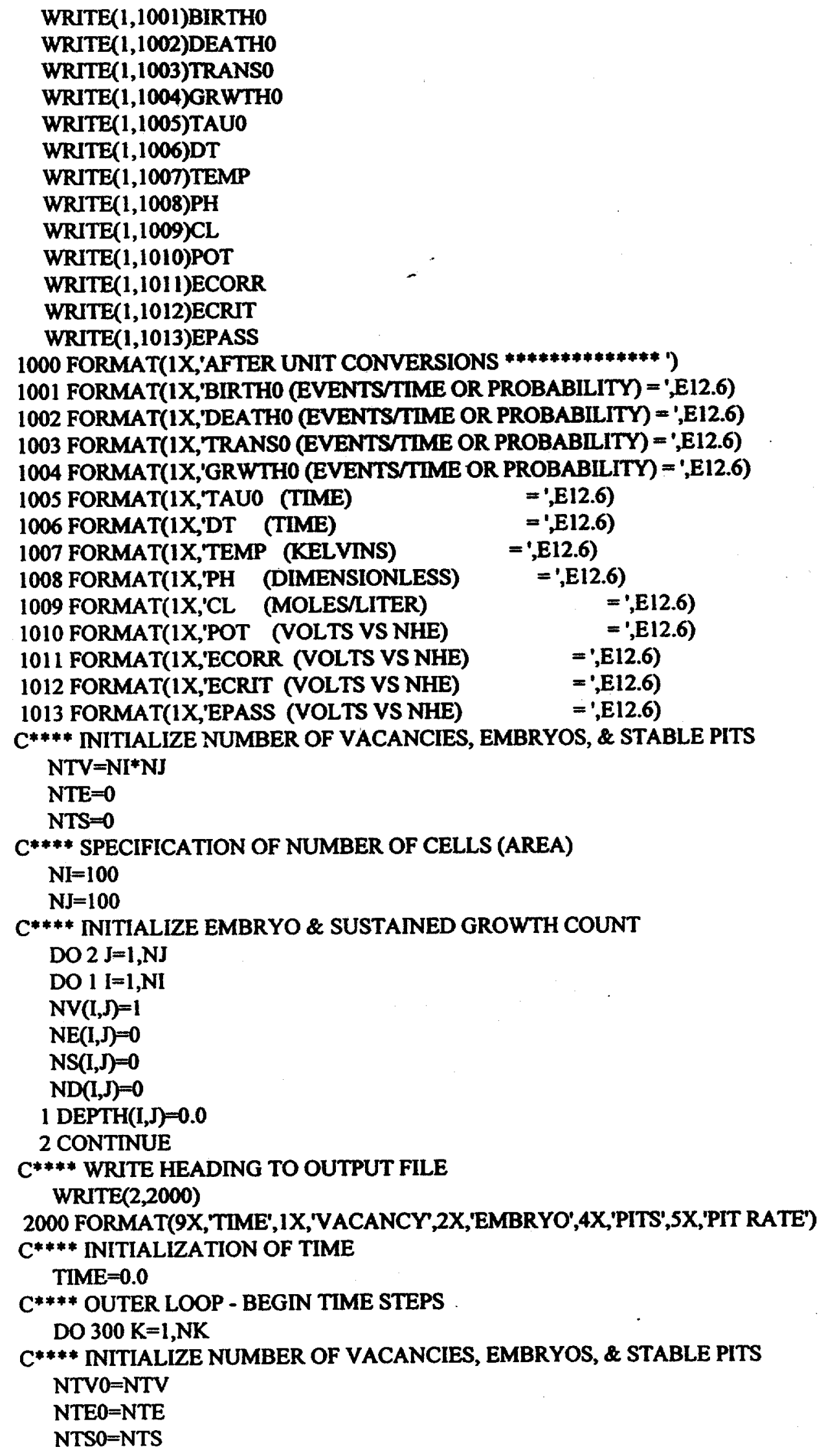


SUMV $=0$

SUME $=0$

SUMS $=0$

TIME $=\mathrm{K} * \mathrm{DT}$

C**** CALCULATE BIRTH, DEATH, \& GROWTH PROBABILITIES, ETC.

CALL PROBABLE

$C^{* * * *}$ SCANNING I-J CELLS FOR EVENTS DURING K-TH TIME STEP

$\mathrm{DO} 200 \mathrm{~J}=1, \mathrm{NJ}$

DO $100 \mathrm{I}=1, \mathrm{NI}$

C**** DETECT STABLE PIT

IF(NS(1,J).EQ.1)GOTO 50

$C^{* * * *}$ DETECT VACANCY

IF(NV(I,J).EQ.1.AND.NE(I,J).EQ.0)GOTO 60

$C^{* * * *}$ DETECT EMBRYO

IF(NV(I,J).EQ.0.AND.NE(I,J).EQ.1)GOTO 70

$C^{* * * *}$ THE PROGRAM SHOULD NOT COME DIRECTLY TO THIS POINT

PRINT *; STATE DETECTION ERROR!'

C**** CELL CALCULATIONS FOR DETECTED STABLE PIT

50 CONTINUE

AGE2 $(1, J)=$ TIME-AGE1 $(1, \sqrt{ })$

CALL RANDOM(KK,RR,SUMRR,TOTRR,AVGRR)

IF(RR.LE.GRWTH.OR.ND(1,J).EQ.1)GOTO 51

GOTO 52

51 CONTINUE

C**** THE STABLE PIT CEASES TO GROW (DEATH OF STABLE PIT)

$\mathrm{NV}(\mathrm{I}, \mathrm{J})=0$

$\mathrm{NE}(\mathrm{I}, \mathrm{J})=0$

$\mathrm{NS}(\mathrm{I}, \mathrm{J})=1$

$\mathrm{ND}(\mathrm{I}, \mathrm{J})=1$

DEPTH $(\mathrm{l}, \mathrm{J})=\mathrm{DEPTH}(\mathrm{I}, \mathrm{J})$

52 CONTINUE

$C^{* * * *}$ THE STABLE PIT CONTINUES TO GROW

$\mathrm{NV}(\mathrm{I}, \mathrm{J})=0$

$\mathrm{NE}(\mathrm{I}, \mathrm{J})=0$

$\mathrm{NS}(\mathrm{I}, \mathrm{J})=1$

- $\quad \mathrm{ND}(\mathrm{I}, \mathrm{J})=0$

IF(DEPTH(I,J).EQ.0.0)GOTO 53

$C^{* * * *}$ THE GROWTH RATE FOR PIT DEPTH IS A FUNCTION OF DEPTH

$\mathrm{DREF}=0.05$

$\mathrm{DEPTH}(\mathrm{I}, \mathrm{J})=\mathrm{DEPTH}(\mathrm{I}, \mathrm{J})+\mathrm{DT}{ }^{*} \mathrm{DZDT} * \mathrm{DREF} / \mathrm{DEPTH}(\mathrm{l}, \mathrm{J})$

GOTO 54

53 CONTINUE

DEPTH $(\mathrm{I}, \mathrm{J})=\mathrm{DEPTH}(\mathrm{I}, \mathrm{D})+\mathrm{DT} * \mathrm{DZDT}$

54 CONTINUE

GOTO 90

$C^{* * * *}$ CELL CALCULATIONS FOR DETECTED VACANCY

60 CONTINUE

CALL RANDOM(KK,RR,SUMRR,TOTRR,AVGRR)

C**** DETECTION OF EMBRYO BIRTH

IF(RR.LE.BIRTH)GOTO 61

GOTO 90

$61 \mathrm{NV}(1, \mathrm{~J})=0$

$\mathrm{NE}(\mathrm{I}, \mathrm{J})=1$

$\mathrm{NS}(\mathrm{I}, \mathrm{J})=0$ 


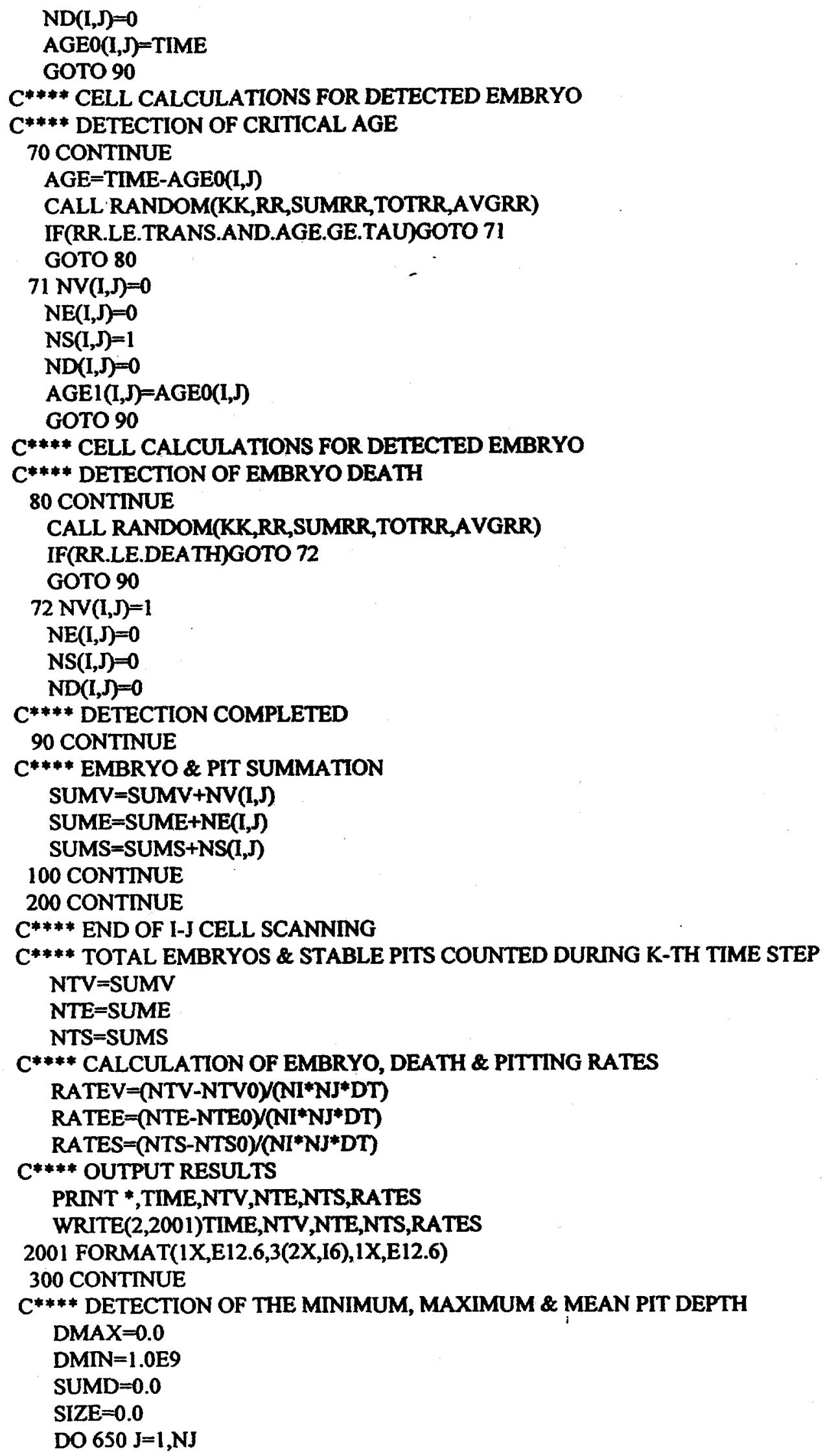




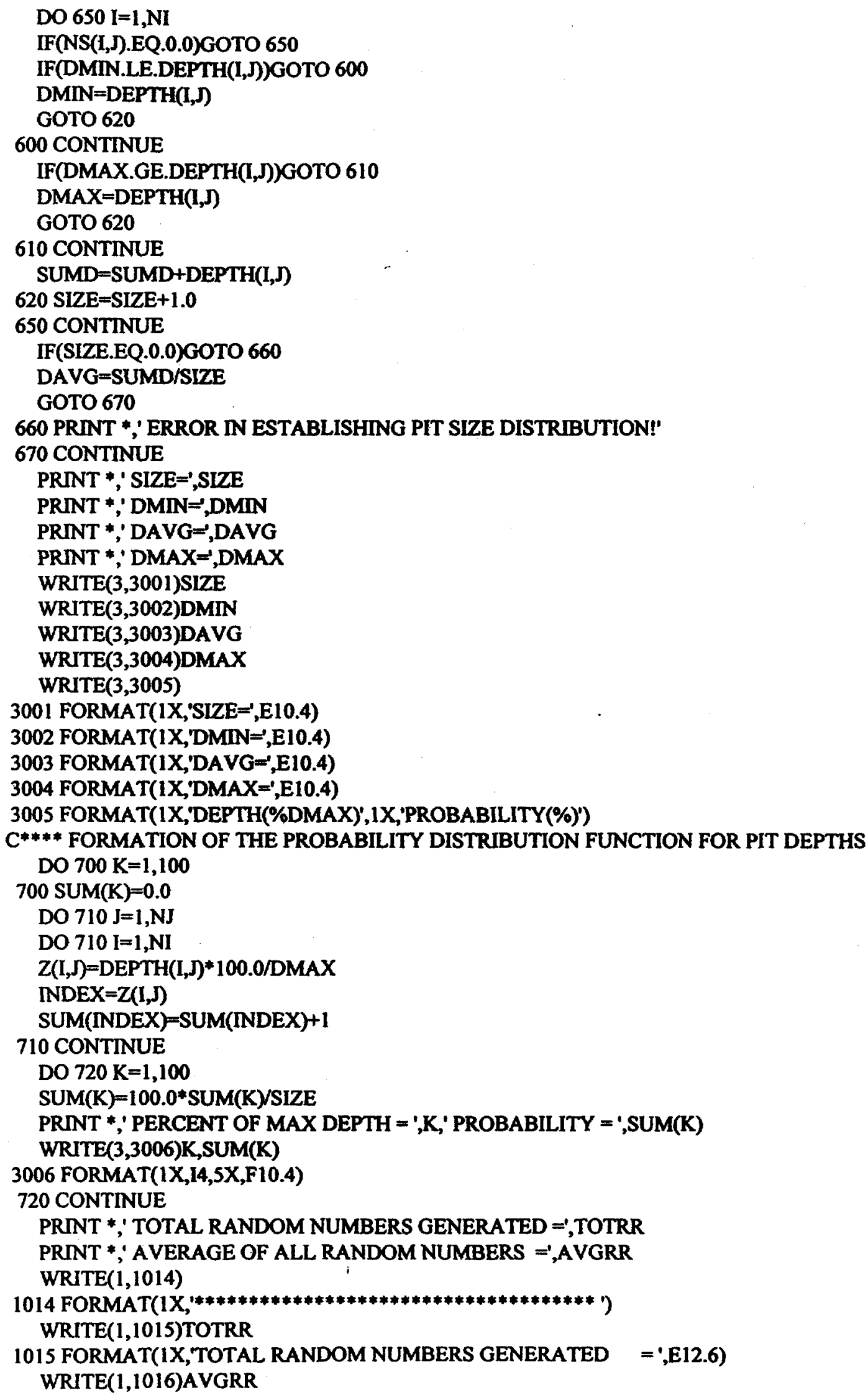


1016 FORMAT(1X,'AVERAGE OF RANDOM NUMBERS GENERATED = ',E12.6)

STOP

END

SUBROUTINE RANDOM(KK,RR,SUMRR,TOTRR,AVGRR)

C**********************************************************************

$C * * * *$ RANDOM NUMBER ALGORITHM FROM MANUAL OF HP-20S SCIENTIFIC CALC ***

C*****SUBROUTINE WRITTEN BY J.C. FARMER APRIL 6, $1997 * * * * * * * * * * * * * * *$

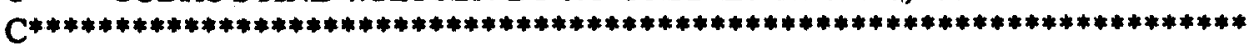

REAL*4 RR,SUMRR,TOTRR,AVGRR

IF(KK.GT.1)GOTO 20

$C^{* * * * * R A N D O M}$ NUMBER SEED FOR GENERATOR

$\mathrm{RR}=0.5284163$

20 CONTINUE

C*****RESET COUNTER

C*****COMPUTATION OF RANDOM NUMBER BY ADDITIVE TECHNIQUE

$R R=997 * R R$

$\mathrm{JJ}=\mathrm{RR}$

$\mathbf{R R}=\mathbf{R} \mathbf{R}-\mathbf{J} \mathbf{J}$

C*****CALCULATION FO THE AVERAGE OF RANDOM NUMBERS

SUMRR $=S U M R R+R R$

TOTRR $=$ TOTRR+1.0

AVGRR=SUMRR/TOTRR

$\mathrm{KK}=\mathrm{KK}+1$

RETURN

END

SUBROUTINE PROBABLE

C**** CALC OF BIRTH, DEATH, TRANS, \& GROWTH PROB; CRITICAL TIME

$C^{* * * *}$ CALCULATION BY (A) HENSHALL \& SHIBATA; (B) FARMER \& HENSHALL

COMMON/ATEMP,POT,PH,KW,OH,CL,BIRTH,DEATH,TRANS,GRWTH,DZDT,TAU,DT

REAL*4 TEMP,POT,PH,KW,OH,CL,BIRTH,DEATH,TRANS,GRWTH,DZDT,TAU,DT

COMMON/B/NFLAG,BIRTH0,DEATH0,TRANSO,GRWTHO,TAU0,DZDTO

REAL*4 BIRTHO,DEATHO,TRANS0,GRWTH0,TAU0,DZDTO

COMMON/C/ECORR,ECRIT,EPASS

REAL*4 ECORR,ECRIT,EPASS

COMMON/D/TIME,NTV,NTE,NTS

REAL *4 TIME

COMMON/E/ALPHA1,ALPHA2

REAL*4 ALPHA1,ALPHA2

IF(NFLAG.EQ.1)GOTO 1

IF(NFLAG.EQ.2)GOTO 2

IF(NFLAG.EQ.3)GOTO 3

C**** CALCULATED RATES AS PER HENSHALL ARTICLE

C**** CONDITIONS FROM TABLE 3 FIGURE 9B OF HENSHALL ARTICLE

1 CONTINUE

RGAS $=8.314$

$\mathrm{Al}=6.164 \mathrm{E} 12$

$\mathrm{A} 2=4.856$

$\mathrm{A} 3=2.7 \mathrm{E}-4$

$\mathrm{A} 4=2.0 \mathrm{E}-4$

$\mathrm{Bl}=0.4$

B3 $=0.4$

$\mathrm{B} 4=0.4$ 


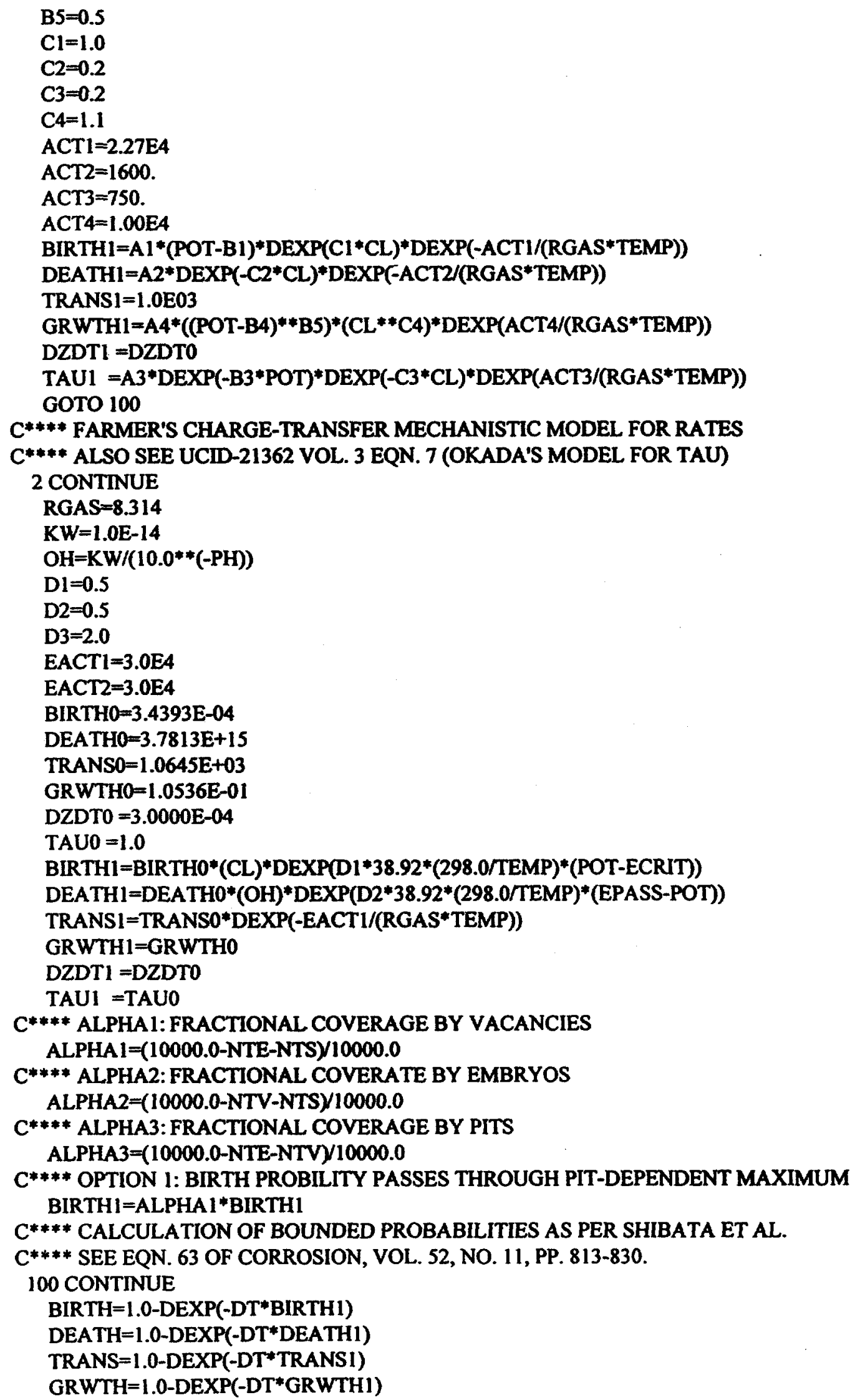




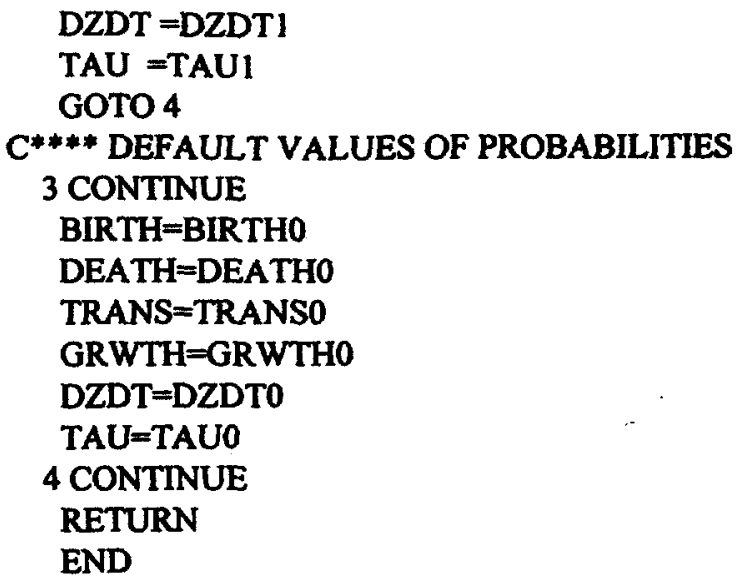

\section{Input Data for Source Code - Case 1}

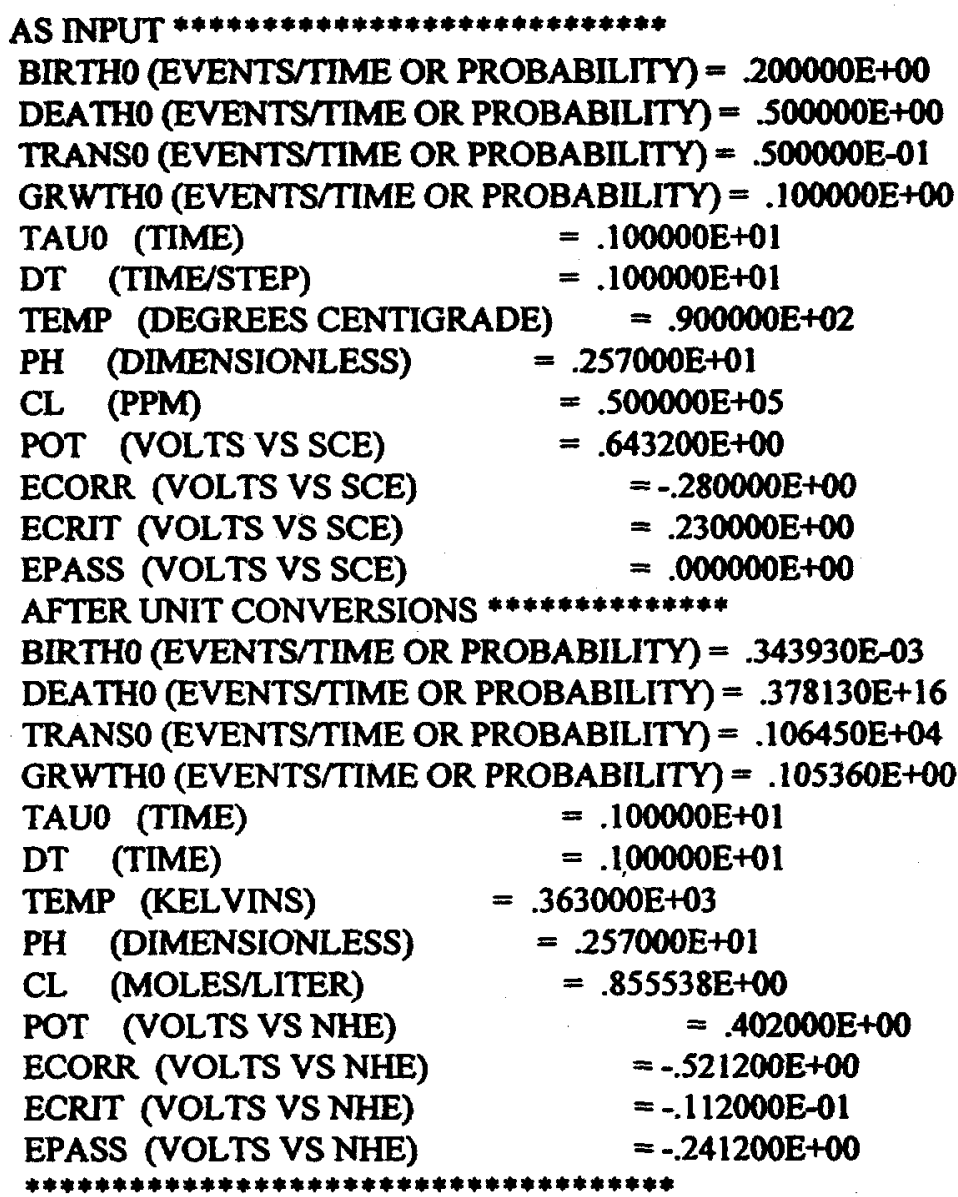

TOTAL RANDOM NUMBERS GENERATED $=.255494 \mathrm{E}+07$ AVERAGE OF RANDOM NUMBERS GENERATED $=.500088 E+00$ 
Input Data for Source Code - Case 2

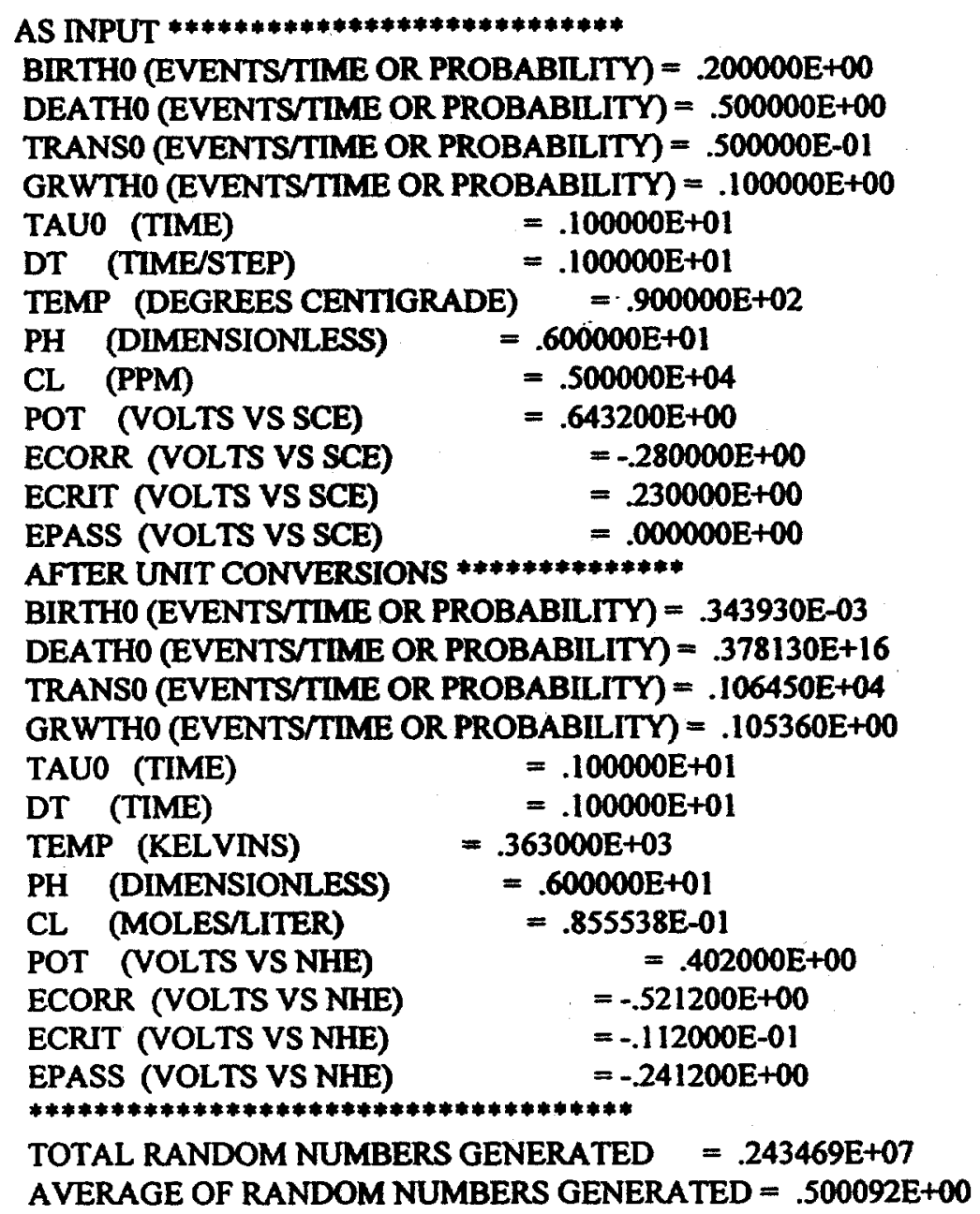


Appendix 5. Source Code for Figures 14 and 15

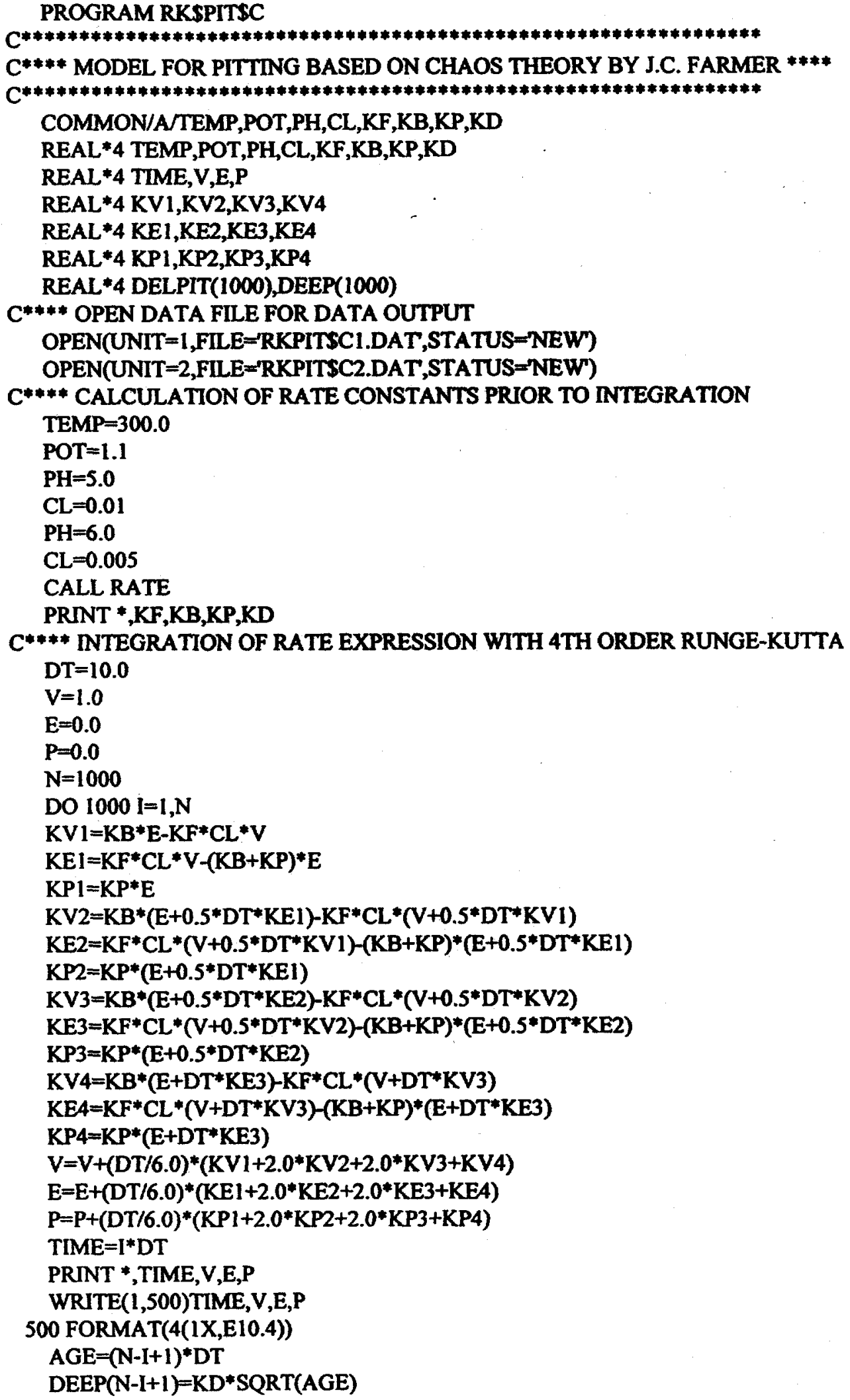




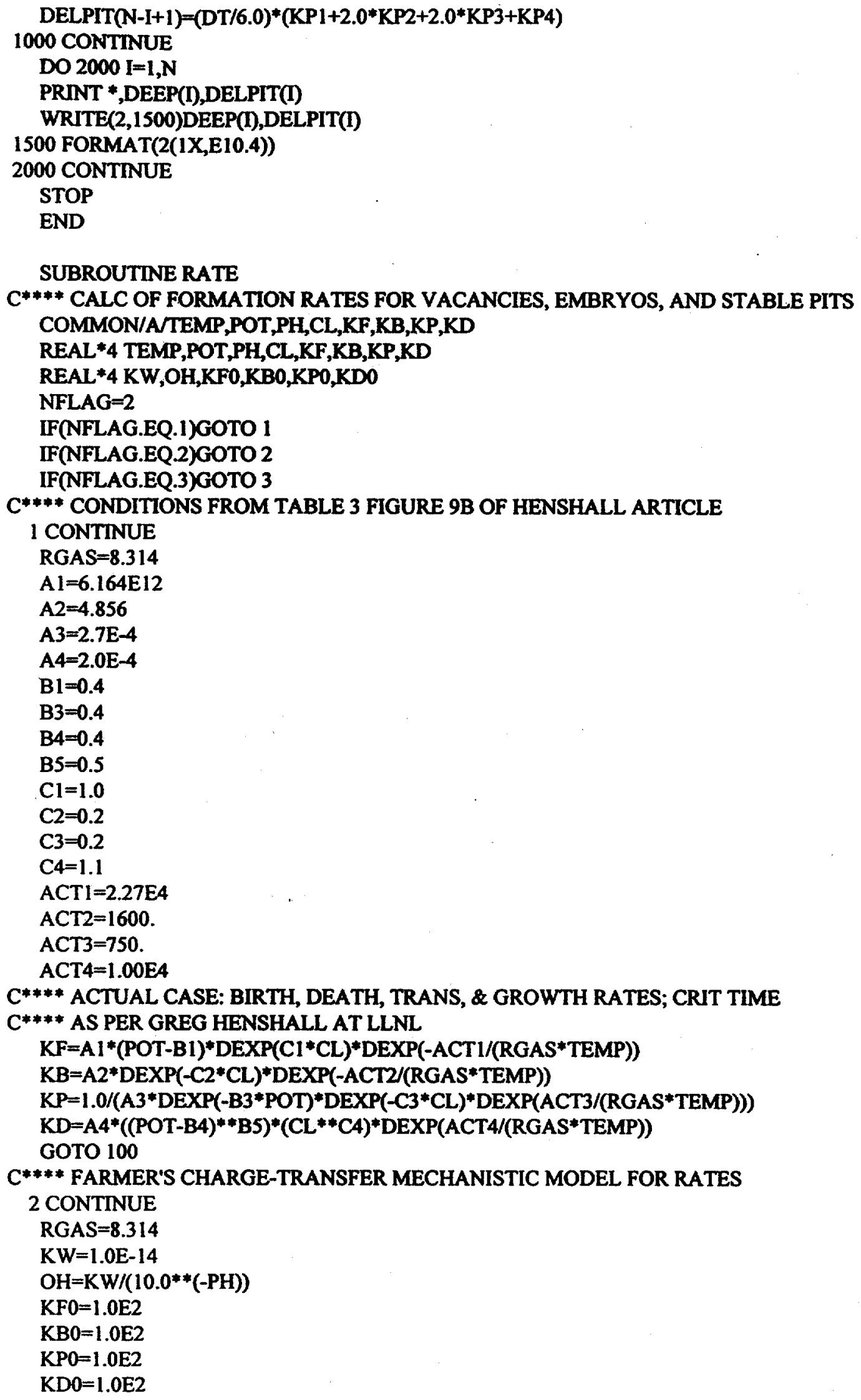


Appendix 5

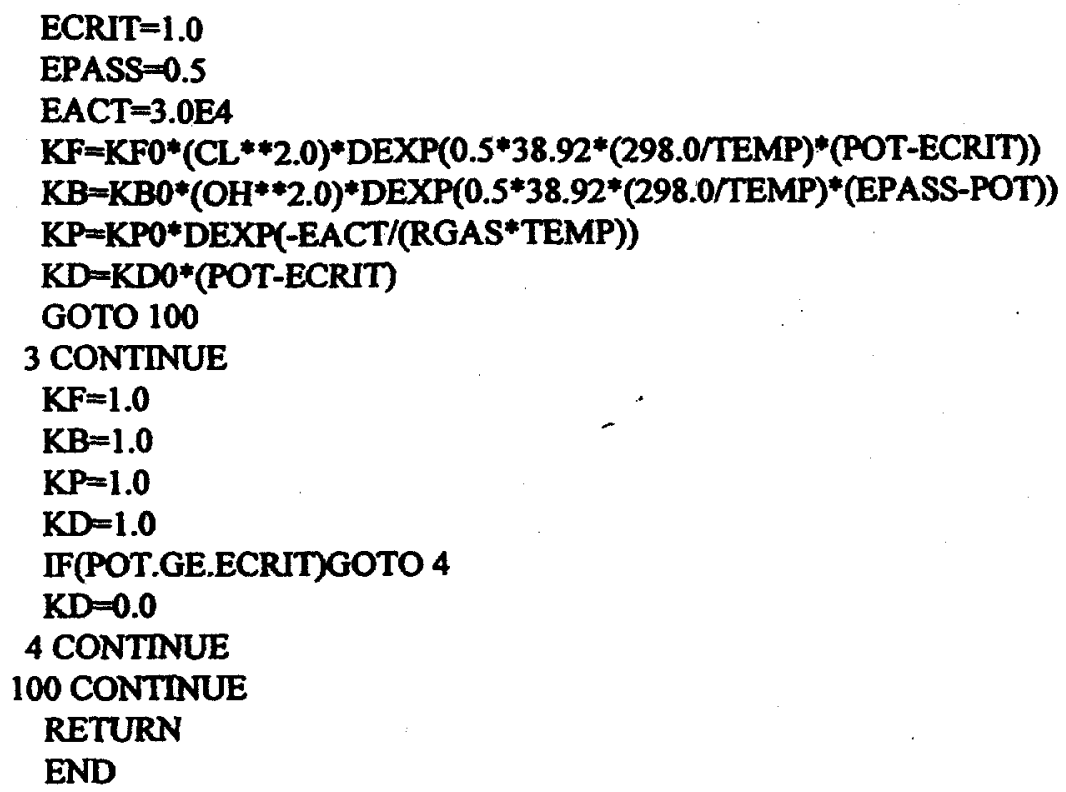


Appendix 6. Source Code for Figures 16 and 17

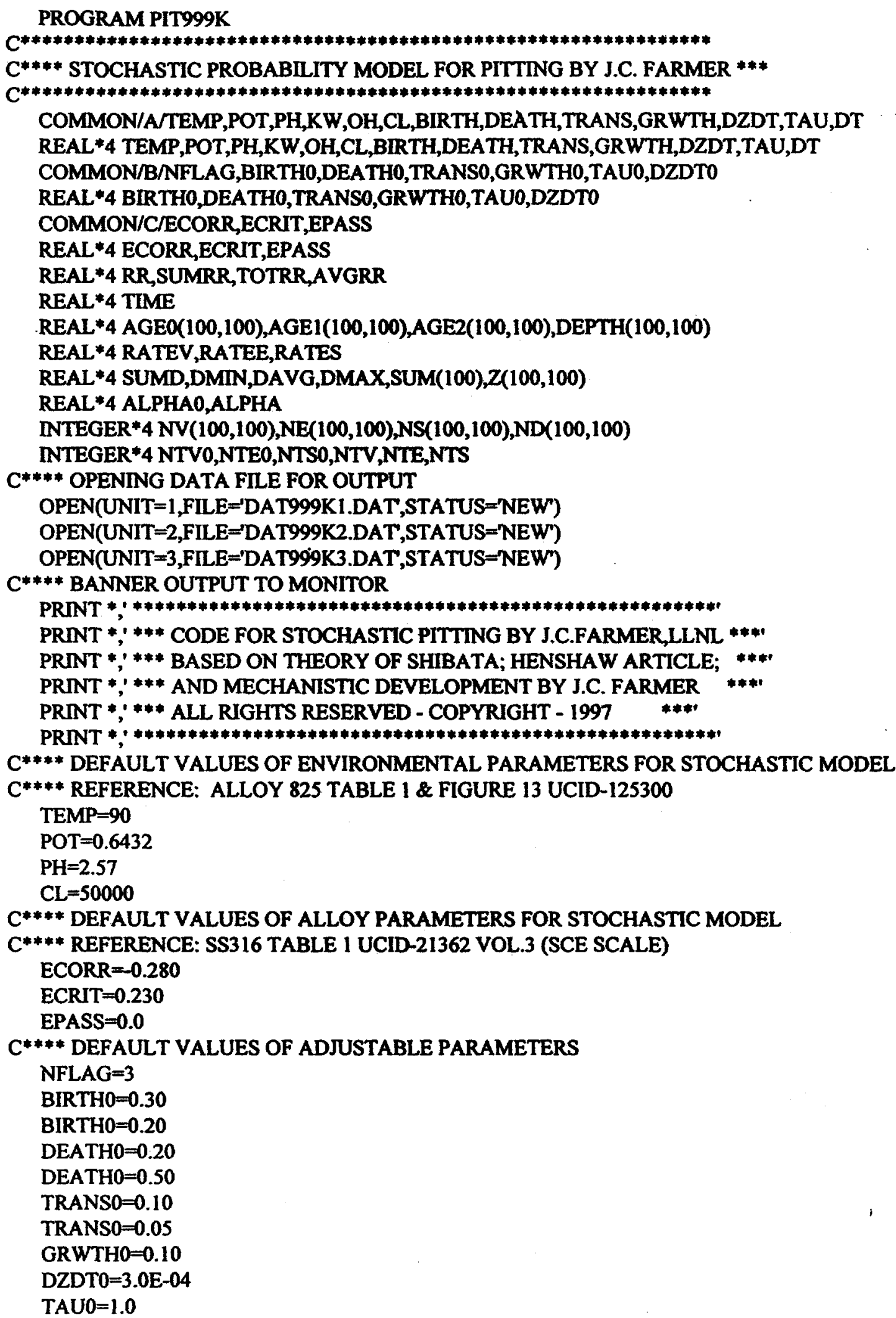




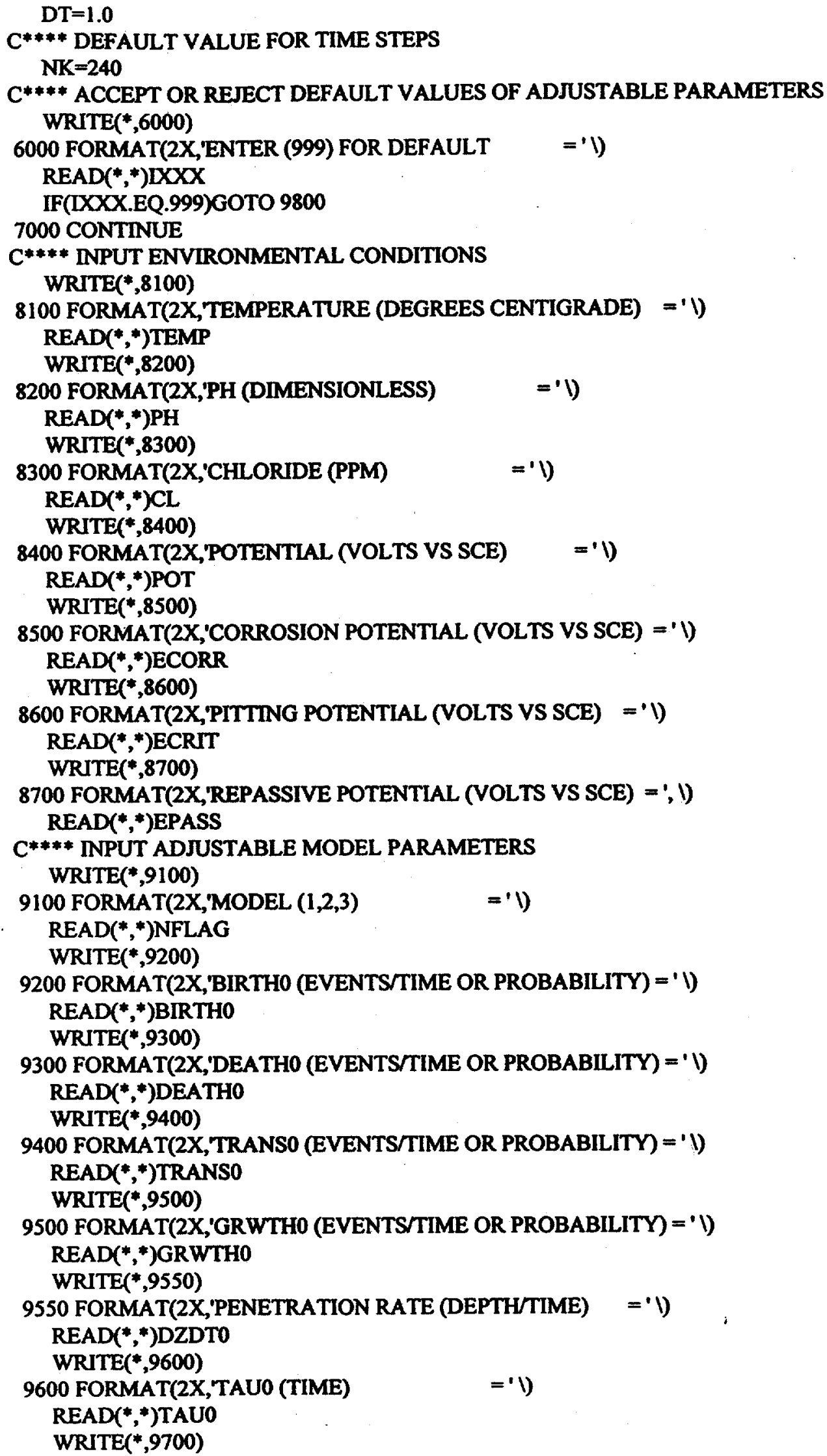




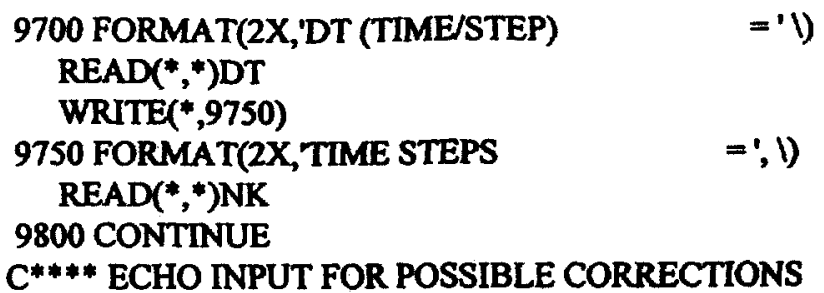

$$
\begin{aligned}
& \text { PRINT *,' BIRTHO (EVENTS/TIME OR PROBABILITY) = ',BIRTHO } \\
& \text { PRINT *', DEATHO (EVENTS/TIME OR PROBABLITY) =',DEATHO } \\
& \text { PRINT *,' TRANSO (EVENTS/TIME OR PROBABILITY) }=\text { ',TRANSO } \\
& \text { PRNT *; GRWTHO (EVENTS/TIME OR PROBABILITY) = ',GRWTHO } \\
& \begin{array}{lc}
\text { PRINT *, TAUO (TIME) } & =\text { ', TAUO } \\
\text { PRINT *, DT (TIME/STEP) } & =\text { ',DT } \\
\text { PRINT *, TIME STEPS } & =\text { ',NK }
\end{array} \\
& \text { PRINT *,' TEMPERATURE (DEGREES CENTIGRADE) = ',TEMP }
\end{aligned}
$$$$
\text { PRINT *,' PH (DIMENSIONLESS) = ',PH }
$$$$
\begin{aligned}
& \text { PRINT *', CHLORIDE (PPM) } \\
& \text { PRINT *', POTENTIAL (VOLTS VS SCE) }=\text {;,CL }=\text { ',POT }
\end{aligned}
$$$$
\text { PRINT *,' CORROSION POTENTIAL (VOLTS VS SCE) }=\text { ',ECORR }
$$$$
\text { PRINT *,' PITTING POTENTIAL (VOLTS VS SCE) }=\text { ',ECRIT }
$$$$
\text { PRINT *', REPASSIVATION POT (VOLTS VS SCE) =',EPASS }
$$$$
\text { WRITE }(*, 9900)
$$$$
9900 \text { FORMAT(2X,'ENTER (999) TO ACCEPT VALUES = ' ) }
$$ 
$C^{* * * *}$ CONVERSION OF ENVIRONMENTAL PARAMETER INPUT VALUES TEMP=TEMP+273.0 $\mathrm{CL}=\mathrm{CL} *(1.0 \mathrm{E}-03) /(58.44277)$

$C^{* * * *}$ CONVERSION OF PITTING \& REPASSIVATION FROM SCE TO NHE POT=POT -0.2412

ECORR $=E C O R R-0.2412$

ECRIT=ECRIT -0.2412

EPASS $=$ EPASS-0.2412

C**** INITIALIZE RANDOM NUMBER GENERATOR

$\mathrm{KK}=1$

SUMRR $=0.0$

TOTRR $=0.0$

AVGRR $=0.0$

CALL RANDOM(KK,RR,SUMRR,TOTRR,AVGRR)

C**** CALCULATE MAX BIRTH, DEATH, \& GROWTH PROBABILITIES

TIME $=0.0$

$C^{* * * *}$ CALCULATION OF PITTING PROBABILITIES BASED UPON INPUT

CALL PROBABLE

C**** OUTPUT RESULTS OF INITIAL CALCULATION TO MONITOR \& DATA FILE

PRINT *', INITLAL TIME (TIME)

PRINT *; TEMPERATURE (KELVINS)

PRINT *;' PH (DIMENSIONLESS) $=$,, TIME

PRINT *', CHLORIDE (MOLES/LITER) = ',CL

PRINT *,' POTENTIAL (VOLTS VS NHE) = ',POT

PRINT *,' CORROSION POTENTIAL (VOLTS VS NHE) = ',ECORR

PRINT *,' PITTING POTENTIAL (VOLTS VS NHE) = ',ECRIT

PRINT *', REPASSIVATION POT (VOLTS VS NHE) $=$ ',EPASS

PRINT *; BIRTH (EVENTS/TIME OR PROBABILITY) = ',BIRTH

PRINT *,' DEATH (EVENTS/TIME OR PROBABILITY) $={ }^{\prime}$,DEATH

PRINT *,' TRANS (EVENTS/TIME OR PROBABILITY) = ',TRANS

PRINT *,' GRWTH (EVENTS/TIME OR PROBABILITY) $=$ ', GRWTH

PRINT *,' PENETRATION RATE (DEPTH/TIME) =',DZDT

PRINT *; TAU (TIME) = ',TAU

$C^{* * * *}$ OUTPUT ADJUSTABLE PARAMETERS TO ARCHIEVE FILE

WRITE $(1,1000)$

WRITE $(1,1001)$ BIRTHO

WRITE(1,1002)DEATHO

WRITE $(1,1003)$ TRANSO

WRITE $(1,1004)$ GRWTHO

WRITE $(1,1005)$ TAUO

WRITE $(1,1006)$ DT

WRITE $(1,1007)$ TEMP

WRITE $(1,1008)$ PH

WRITE $(1,1009) \mathrm{CL}$

WRITE $(1,1010)$ POT

WRITE(1,1011)ECORR

WRITE(1,1012)ECRIT

WRITE(1,1013)EPASS

1000 FORMAT(1X,'AFTER UNIT CONVERSIONS *************!)

1001 FORMAT(1X,'BIRTHO (EVENTSTTIME OR PROBABILITY) = ',E12.6)

1002 FORMAT(1X,'DEATHO (EVENTS/TIME OR PROBABILITY) $=$ ',E12.6)

1003 FORMAT(1X,'TRANS0 (EVENTS/TIME OR PROBABILITY) = ',E12.6)

1004 FORMAT(1X,'GRWTHO (EVENTSITIME OR PROBABILITY) = ',E12.6)

1005 FORMAT(1X,TAUO (TIME) =',E12.6) 
Appendix 6

$$
\begin{aligned}
& 1006 \text { FORMAT(1X,'DT (TIME) = ',E12.6) } \\
& 1007 \text { FORMAT(1X,TEMP (KELVINS) =',E12.6) } \\
& 1008 \text { FORMAT(1X,'PH (DIMENSIONLESS) =',E12.6) } \\
& 1009 \text { FORMAT(IX,'CL (MOLES/LITER) =',E12.6) } \\
& 1010 \text { FORMAT(IX,'POT (VOLTS VS NHE) = ',E12.6) } \\
& 1011 \text { FORMAT(1X,'ECORR (VOLTS VS NHE) = ',E12.6) } \\
& 1012 \text { FORMAT(1X,'ECRIT (VOLTS VS NHE) } \quad=\text { 'E12.6) } \\
& 1013 \text { FORMAT(1X,'EPASS (VOLTS VS NHE) = ',E12.6) }
\end{aligned}
$$

$C^{* * * *}$ INITIALIZE NUMBER OF VACANCIES, EMBRYOS, \& STABLE PITS

$\mathrm{NTV}=\mathrm{NI} * \mathrm{NJ}$

NTE $=0$

NTS $=0$

$C^{* * * *}$ SPECIFICATION OF NUMBER OF CELLS (AREA)

$\mathrm{NI}=100$

$\mathrm{NJ}=100$

C**** INITIALIZE EMBRYO \& SUSTANED GROWTH COUNT

DO $2 \mathrm{~J}=1, \mathrm{NJ}$

DO $1 \mathrm{I}=1, \mathrm{NI}$

$N V(1, J)=1$

NE(I, $)=0$

$\mathrm{NS}(1, \mathrm{~J})=0$

$\mathrm{ND}(\mathrm{I}, \mathrm{J})=0$

$1 \mathrm{DEPTH}(\mathrm{I}, \mathrm{J})=0.0$

2 CONTINUE

C**** WRITE HEADING TO OUTPUT FILE

WRITE $(2,2000)$

2000 FORMAT(7X,'TIME', 1X,'VACANCY',2X,'EMBRYO',4X,'PITS',5X,'PIT RATE')

C**** INITIALIZATION OF TIME

TIME $=0.0$

C**** OUTER LOOP - BEGIN TIME STEPS

DO $300 \mathrm{~K}=1$,NK

C**** INITIALIZE NUMBER OF VACANCIES, EMBRYOS, \& STABLE PITS

NTVO=NTV

NTEO $=$ NTE

NTSO $=$ NTS

SUMV $=0$

SUME $=0$

SUMS $=0$

$T I M E=K * D T$

C**** CALCULATE BIRTH, DEATH, \& GROWTH PROBABILITIES, ETC.

C**** OPTION 1: $\quad$ BIRTH PROBABILITY DECAYS EXPONENTIALLY WITH TIME

CALL PROBABLE

ALPHA0 $=240.0$

ALPHA $=$ EXP(-TIME/ALPHA0)

$C * * * *$ OPTION 2: BIRTH PROB DECAYS WITH NUMBER OF EMBRYOS \& PITS

ALPHAO $=1.0$

ALPHA $=$ ALPHA $* *(10000.0-N T E-N T S) / 10000.0$

$C^{* * * *}$ OPTION 3: BIRTH PROB PASSES THROUGH TIME-DEPENDENT MAXIMUM

ALPHAO $=$ TIME $/ 10.0$

ALPHA $=A$ ALPHA $0 *(10000.0-N T E-N T S) / 10000.0$

C**** OPTION 4: BIRTH PROB PASSES THROUGH SURFACE-DEPENDENT MAXIMUM

ALPHA0 $=(10000.0-\mathrm{NTE}-\mathrm{NTV}) / 10000.0$

ALPHA=ALPHA $0 *(10000.0-$ NTE-NTS $) / 10000.0$

$C^{* * * *}$ CALCULATION OF DECAY IN BIRTH PROBABILITY 


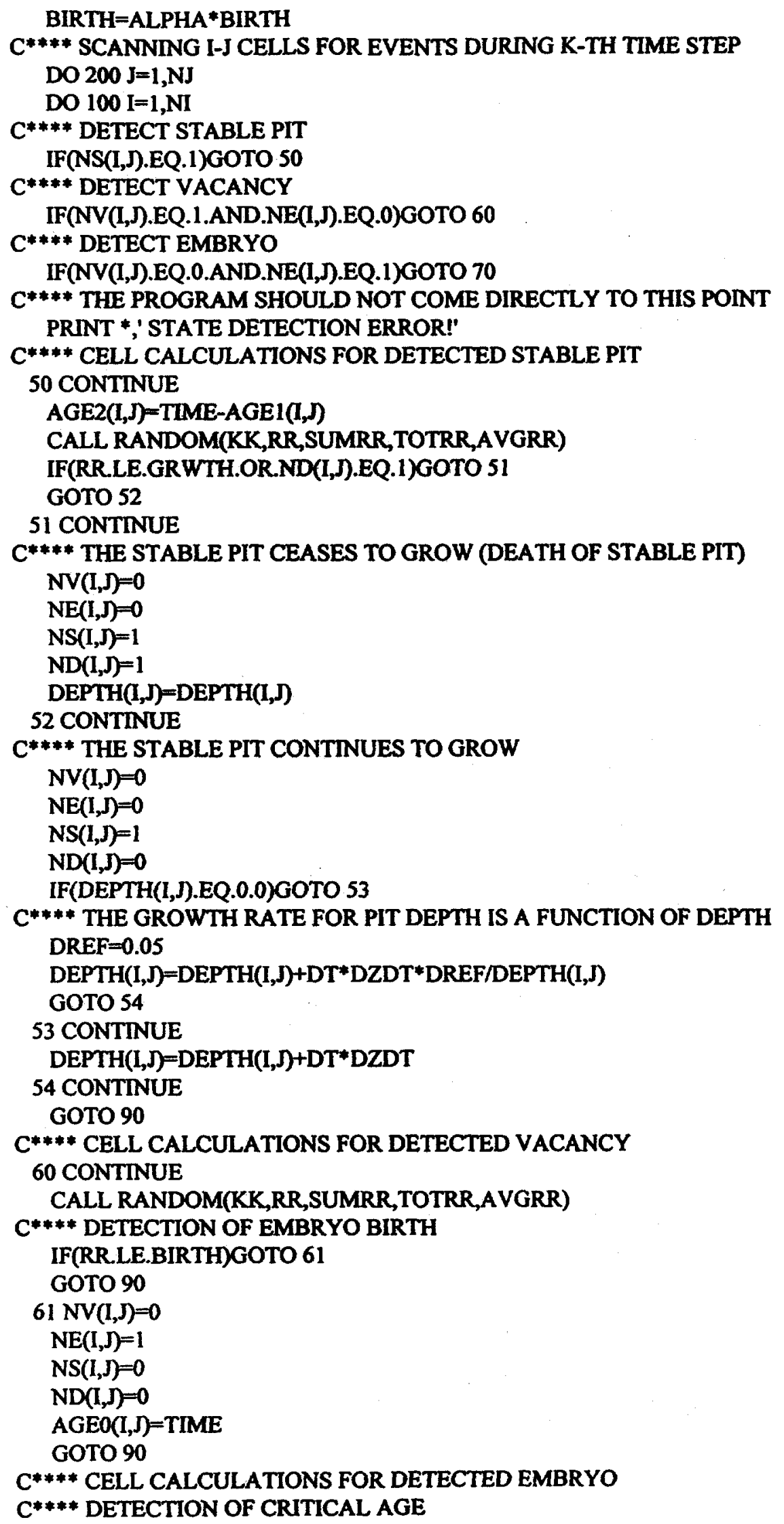




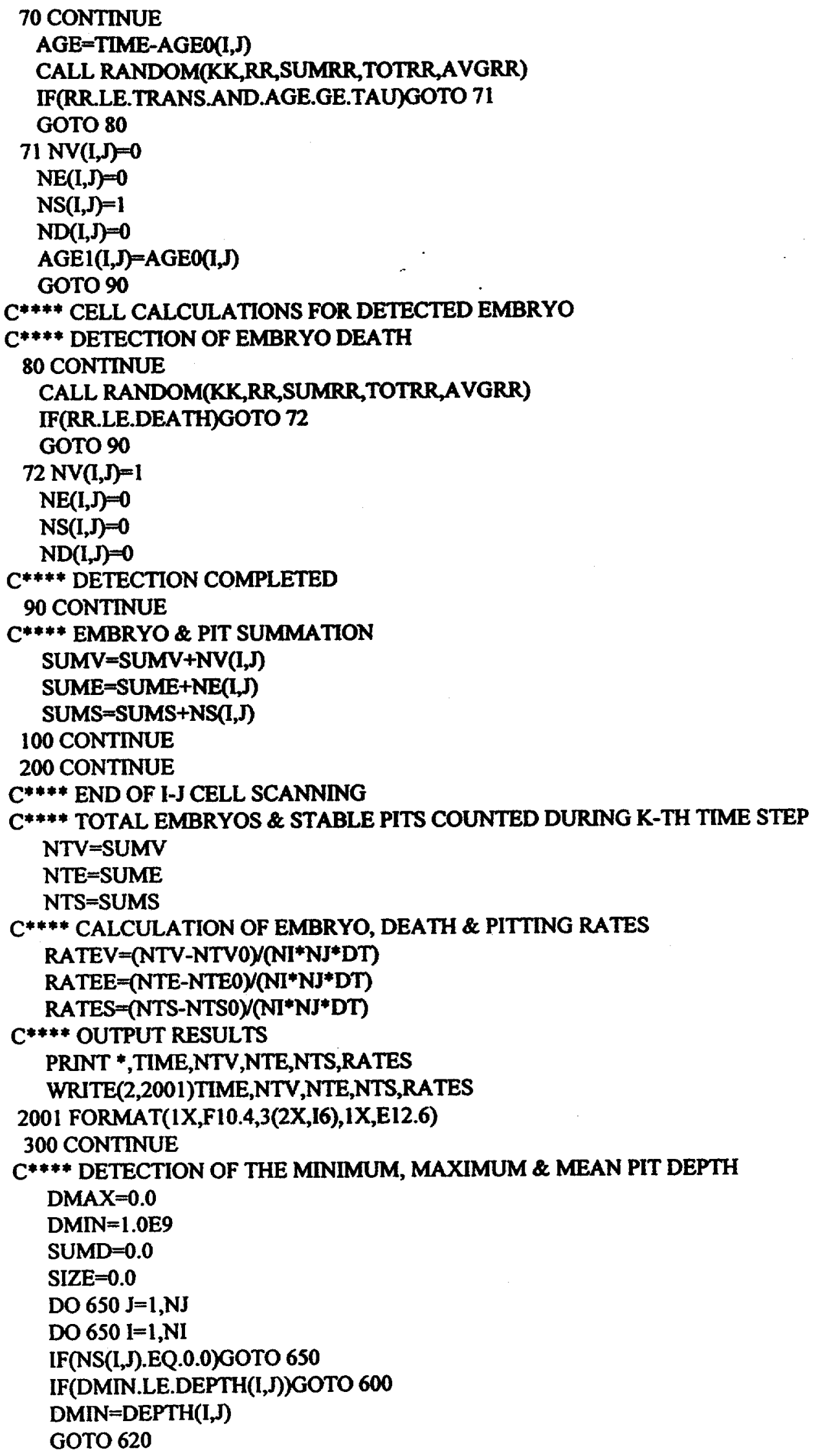




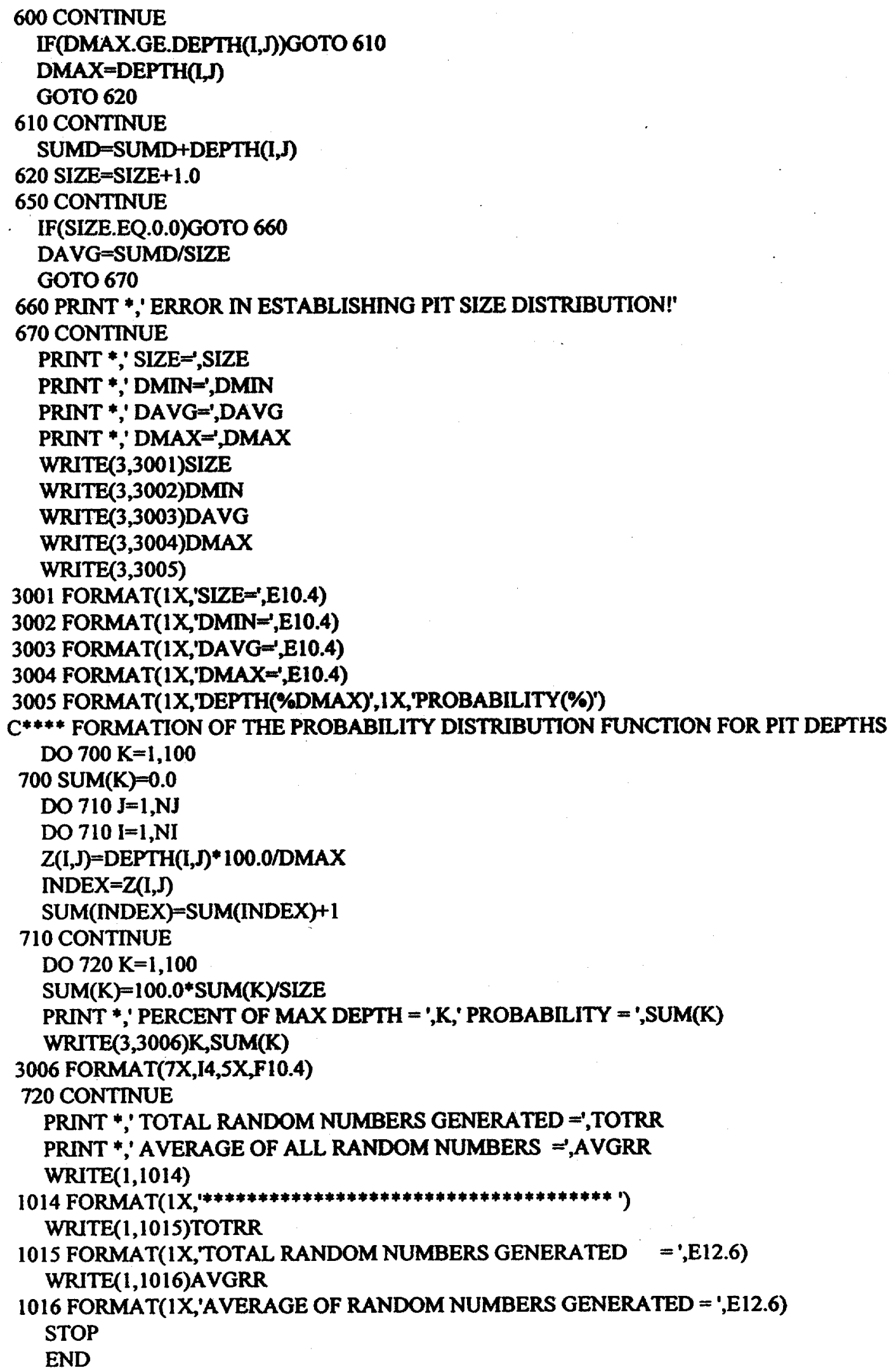




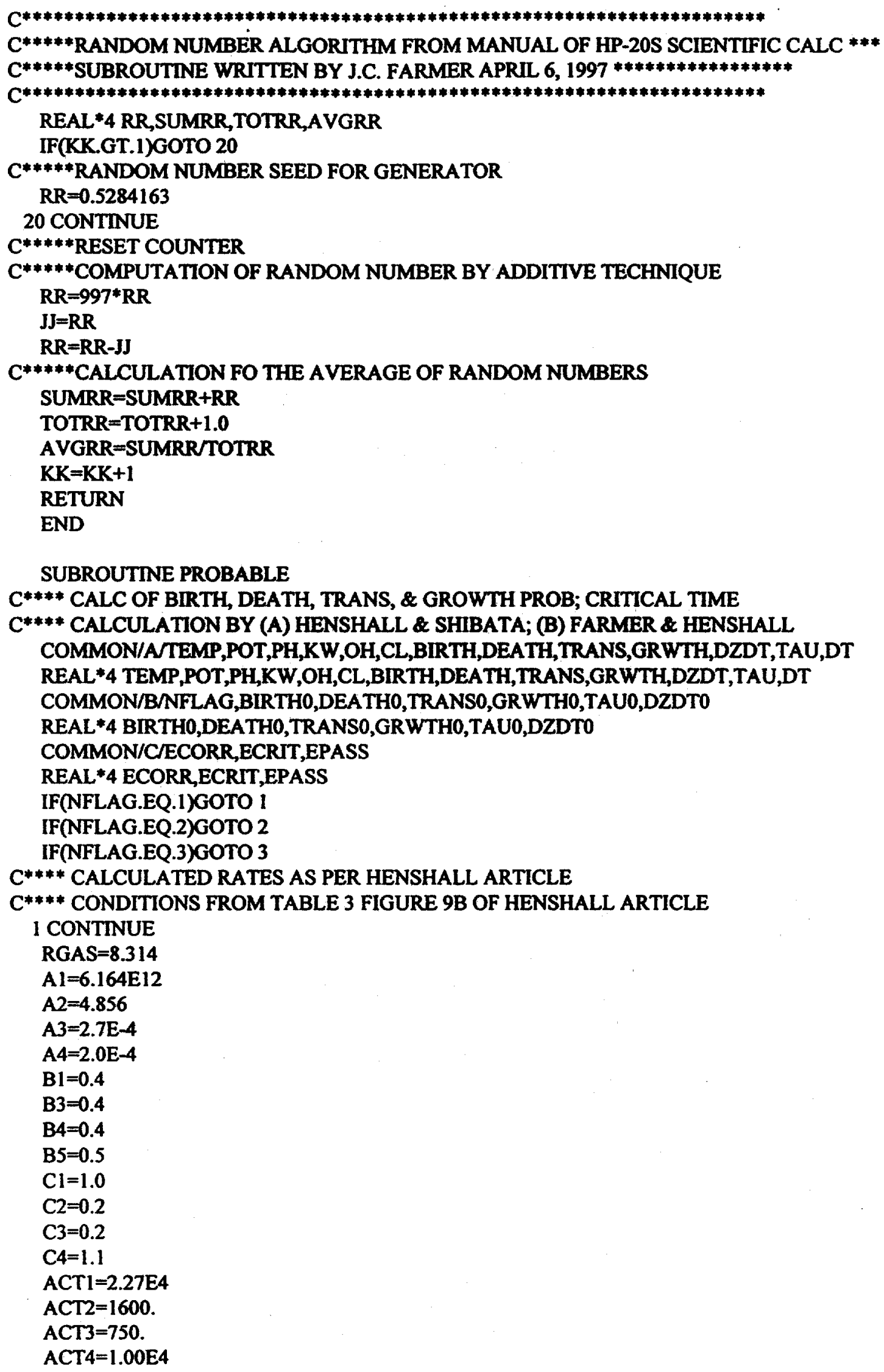




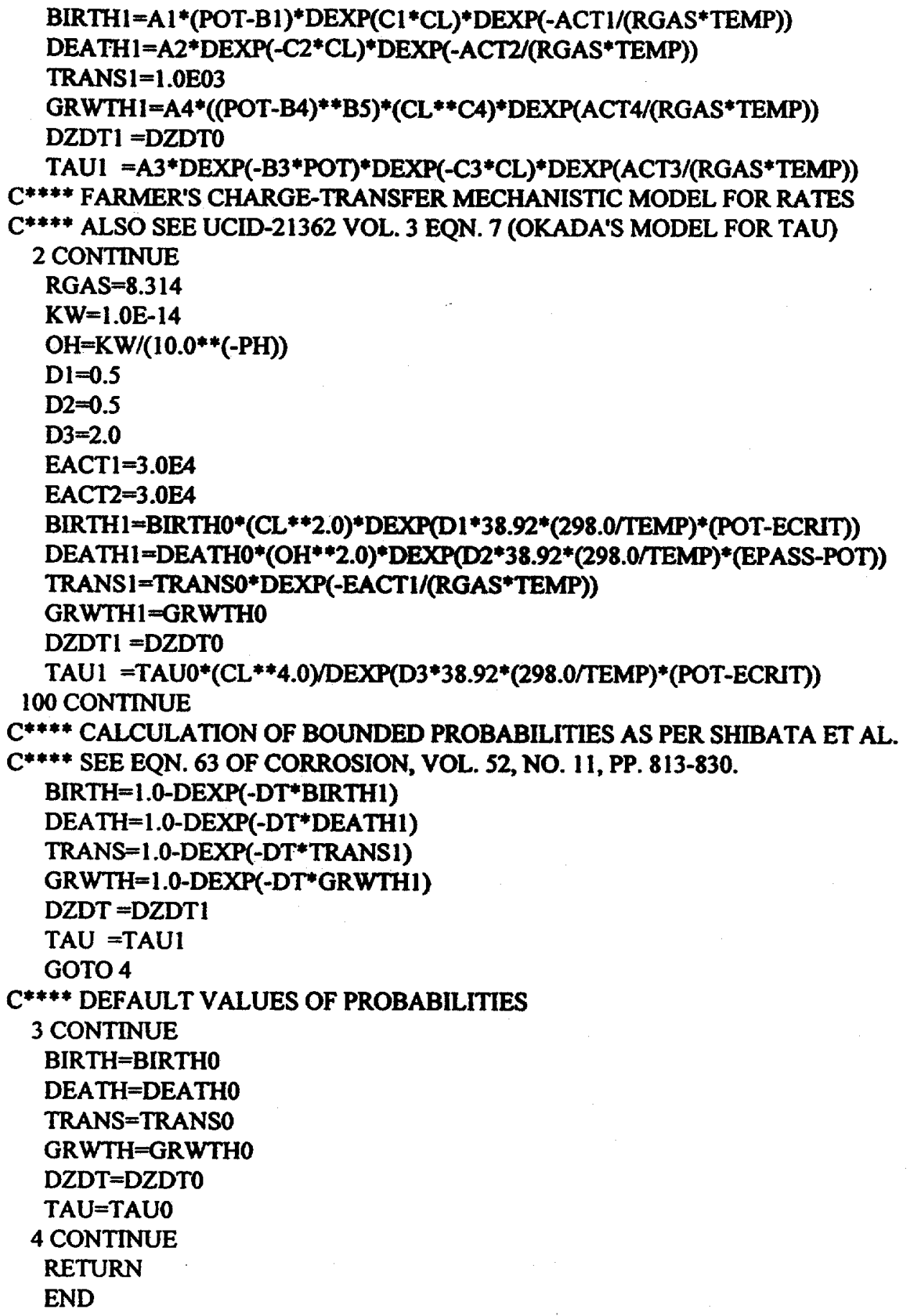




\section{Input Data for Source Code}

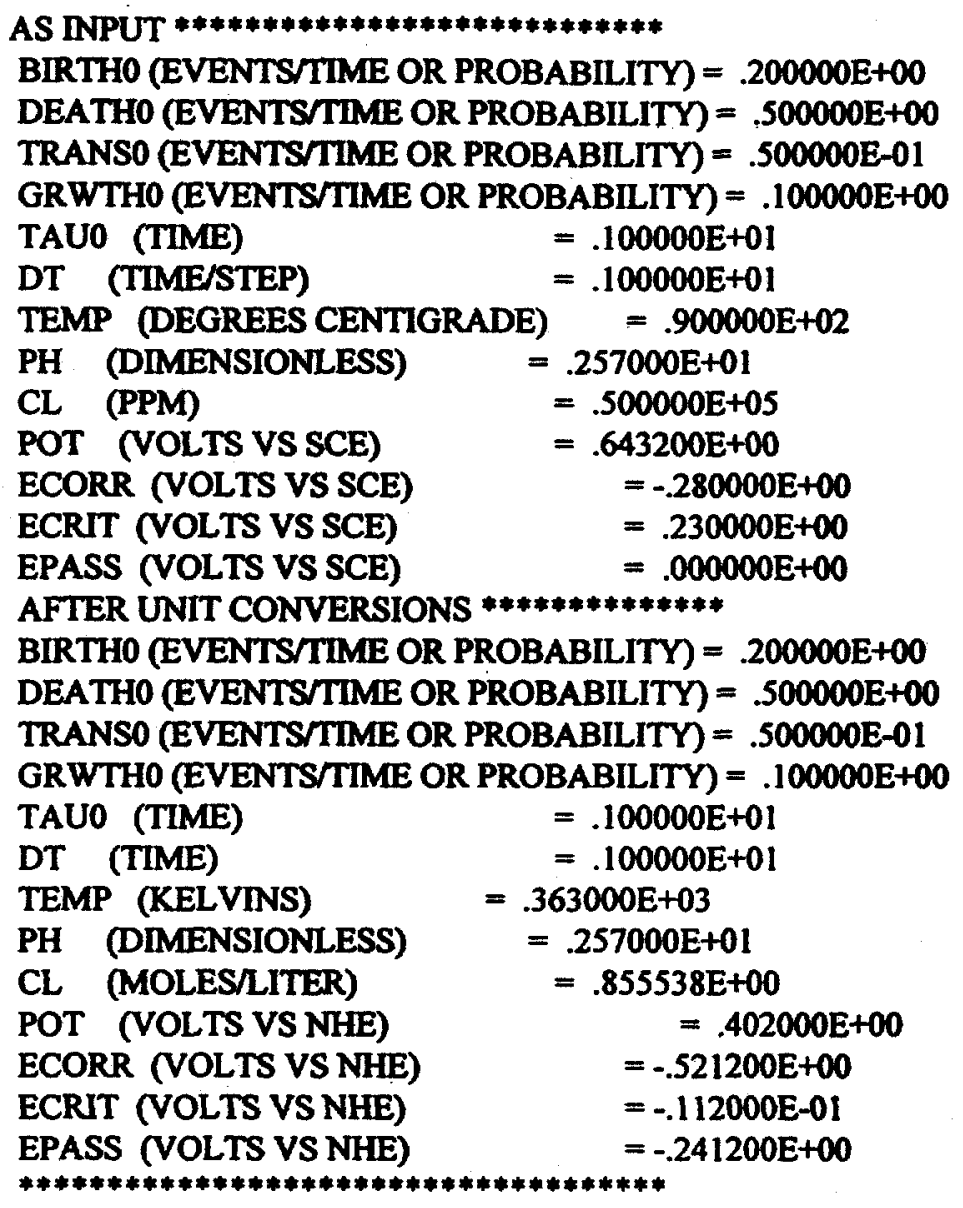

TOTAL RANDOM NUMBERS GENERATED $=.245023 E+07$ AVERAGE OF RANDOM NUMBERS GENERATED $=.500093 \mathrm{E}+00$ 


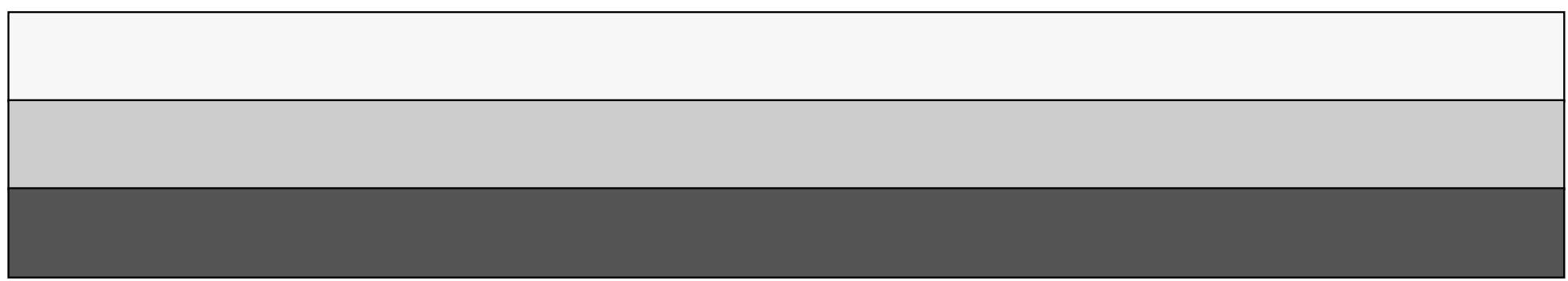

